\title{
Article \\ Polyphenylglyoxamide-Based Amphiphilic Small Molecular Peptidomimetics as Antibacterial Agents with Anti-Biofilm Activity
}

\author{
Tsz Tin Yu ${ }^{1}\left(\mathbb{D}\right.$, Rajesh Kuppusamy ${ }^{1,2}{ }^{\circledR}$, Muhammad Yasir ${ }^{2}{ }^{\circledR}$, Md. Musfizur Hassan ${ }^{1}$, Manjulatha Sara ${ }^{2}$,

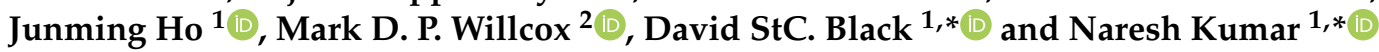 \\ 1 School of Chemistry, The University of New South Wales, Sydney, NSW 2052, Australia; \\ tsztin.yu@unsw.edu.au (T.T.Y.); r.kuppusamy@unsw.edu.au (R.K.); md.m.hassan@unsw.edu.au (M.M.H.); \\ junming.ho@unsw.edu.au (J.H.) \\ 2 School of Optometry and Vision Science, University of New South Wales, Sydney, NSW 2052, Australia; \\ m.yasir@unsw.edu.au (M.Y.); manjulatha.sara@unsw.edu.au (M.S.); m.willcox@unsw.edu.au (M.D.P.W.) \\ * Correspondence: d.black@unsw.edu.au (D.S.B.); n.kumar@unsw.edu.au (N.K.)
}

check for

updates

Citation: Yu, T.T.; Kuppusamy, R.; Yasir, M.; Hassan, M.M.; Sara, M.; Ho,

J.; Willcox, M.D.P.; Black, D.S.; Kumar,

N. Polyphenylglyoxamide- Based

Amphiphilic Small Molecular

Peptidomimetics as Antibacterial

Agents with Anti-Biofilm Activity. Int

J. Mol. Sci. 2021, 22, 7344. https://

doi.org/10.3390/ijms22147344

Academic Editor: Dong Ju Son

Received: 31 May 2021

Accepted: 4 July 2021

Published: 8 July 2021

Publisher's Note: MDPI stays neutral with regard to jurisdictional claims in published maps and institutional affiliations.

Copyright: (c) 2021 by the authors. Licensee MDPI, Basel, Switzerland. This article is an open access article distributed under the terms and conditions of the Creative Commons Attribution (CC BY) license (https:// creativecommons.org/licenses/by/ $4.0 /)$
Abstract: The rapid emergence of drug-resistant bacteria is a major global health concern. Antimicrobial peptides (AMPs) and peptidomimetics have arisen as a new class of antibacterial agents in recent years in an attempt to overcome antibiotic resistance. A library of phenylglyoxamide-based small molecular peptidomimetics was synthesised by incorporating an $\mathrm{N}$-alkylsulfonyl hydrophobic group with varying alkyl chain lengths and a hydrophilic cationic group into a glyoxamide core appended to phenyl ring systems. The quaternary ammonium iodide salts $16 \mathrm{~d}$ and $17 \mathrm{c}$ showed excellent minimum inhibitory concentration (MIC) of 4 and $8 \mu \mathrm{M}(2.9$ and $5.6 \mu \mathrm{g} / \mathrm{mL})$ against Staphylococcus aureus, respectively, while the guanidinium hydrochloride salt 34a showed an MIC of $16 \mu \mathrm{M}(8.5 \mu \mathrm{g} / \mathrm{mL})$ against Escherichia coli. Additionally, the quaternary ammonium iodide salt $17 \mathrm{c}$ inhibited $70 \%$ S. aureus biofilm formation at $16 \mu \mathrm{M}$. It also disrupted $44 \%$ of pre-established S. aureus biofilms at $32 \mu \mathrm{M}$ and $28 \%$ of pre-established E. coli biofilms $64 \mu \mathrm{M}$, respectively. A cytoplasmic membrane permeability study indicated that the synthesised peptidomimetics acted via disruption and depolarisation of membranes. Moreover, the quaternary ammonium iodide salts $16 \mathrm{~d}$ and $17 \mathrm{c}$ were non-toxic against human cells at their therapeutic dosages against $S$. aureus.

Keywords: antimicrobial peptide; peptidomimetics; terphenylglyoxamide; terphenyl; isatin; antibiofilm; membrane disruption

\section{Introduction}

Infections caused by multidrug-resistant bacteria pose a serious threat to humans and are a major health concern [1]. This multi-drug resistance arises from the selective survival pressure exerted by the mechanism of action of conventional antibiotics [2]. Bacteria resist antibiotics through various mechanisms, such as enzymatic degradation of antibiotics, reducing the permeability of the bacterial cell membrane, removal of antibiotics via efflux, and mutation or enzymatic alteration of drug binding sites [3-5].

Another survival strategy displayed by bacteria is the formation of biofilms. Biofilms are communities of bacteria encased in an extracellular polymeric matrix adhering to a surface [6-8]. Biofilm can form on both biotic surfaces, such as on the tooth and lung, as well as abiotic surfaces, such as catheters and shunts. Due to the protective barrier of the biofilm and the lower growth rate of bacteria inside biofilms, bacteria in biofilms are more resistant to antibiotics [6,8-10]. Bacteria in biofilms can be 10 to 1000 times more resistant to antibiotic treatment than in their planktonic form [10]. Biofilms are accountable for approximately $80 \%$ of chronic and recurrent bacterial infections $[8,11,12]$. As biofilms further complicate the treatment of bacterial infections, the ideal novel antibiotic should not only target planktonic bacteria, but also have the ability to disrupt bacterial biofilms. 
In response to the rapid emergence of multidrug-resistant bacteria and the formation of bacterial biofilms, attention has been drawn to the development of antimicrobial peptides (AMPs) as a novel class of antibiotics $[13,14]$. AMPs are a diverse group of natural bioactive peptides found in living organisms [15-17] and they play a significant role in the human defence system against microbial infection $[18,19]$. They act against bacteria by predominantly disrupting the bacterial cell membrane [18,20]. Examples of AMPs include pexiganan (MSI-78), which has reached phase III clinical trials for the topical treatment of infected diabetic foot ulcers, while cathelicidin (LL-37) is in phase IIb clinical trials for the treatment of chronic leg ulcers [13,21]. As AMPs disrupt bacterial cell membranes via non-receptor interactions, the emergence of antibacterial resistance against AMPs is less likely than for conventional antibiotics $[17,22,23]$. Other than disrupting bacterial cell membranes, some AMPs are known to kill bacteria by inhibiting DNA, RNA and protein synthesis of bacteria [18]. While AMPs are active against bacteria, their high manufacturing cost from solid-phase peptide synthesis and poor pharmacokinetics, such as low bioavailability and high susceptibility to proteolytic degradation, have limited their use as antibacterial agents $[18,21,24]$.

To address the limitations of AMPs, peptidomimetics have been developed [25,26]. These peptidomimetics include $\alpha$-peptides [27,28], $\beta$-peptides [29-31], peptoids [28,32-34], $\mathrm{N}$-acylated $\mathrm{N}$-aminoethylpeptides [35-37] and oligoacyllysines [38,39]. Alternatively, efforts have also been made to develop small molecular antimicrobial peptidomimetics, such as arylamide foldamers [40-42], phenyleneethynylenes [43], anthranilamides [44], binaphthyls [45] and sofalcones [46]. Like natural AMPs, peptidomimetics also possess an amphiphilic structure with polar and non-polar groups. The cationic groups first interact with anionic lipids on the bacterial cell membrane, followed by insertion into the bacterial cell membrane with the aid of hydrophobic groups. This leads to the disruption and formation of pores on the bacterial cell membrane, causing cell death [18,47-49].

In our previous studies, we reported phenylglyoxamide- and biphenylglyoxamidebased small molecular antimicrobial peptidomimetics 1 and $\mathbf{2}$ (Figure 1) with high antibacterial activity against Staphylococcus aureus, with minimum inhibitory concentration (MIC) values of 12 and $16 \mu \mathrm{M}$, respectively [50,51]. Moreover, peptidomimetic 2 also showed a good MIC value of $32 \mu \mathrm{M}$ against Escherichia coli. The hydrophobic octanesulfonyl group was found to be important for antibacterial activity, as potency was lost when the chain was shortened.<smiles>CCS(=O)(=O)Nc1ccc(Br)cc1C(=O)C(=O)NCCCNC(=N)N</smiles>

1<smiles>CCS(=O)(=O)Nc1ccc(-c2ccccc2)cc1C(=O)C(=O)NCCC[N+](C)(C)C</smiles>

2

Figure 1. Structures of phenylglyoxamide- and biphenylglyoxamide-based small molecular antimicrobial peptidomimetics $\mathbf{1}$ and $\mathbf{2}$.

Terphenyl derivatives possess antibacterial activities [52-55]; however, the effects of introducing a terphenyl moiety in place of the biphenyl moiety of the biphenylglyoxamide scaffold have not been explored. Additionally, lengthening the alkyl chain of the sulfonyl group has not been investigated either. In this study, we report the synthesis of new series of mono-, bi- and terphenylglyoxamide-based small molecular peptidomimetics with alkylsulfonyl groups of different alkyl chain lengths. The antibacterial activities of these synthesised peptidomimetics were evaluated against S. aureus, E. coli and Pseudomonas aeruginosa. The ability of the peptidomimetics to disrupt pre-established bacterial biofilms was also eval- 
uated. The possible mechanism of action of the peptidomimetics was investigated by a membrane depolarisation assay, while their in vitro toxicity against human cells was also assessed to determine their specificity.

\section{Results and Discussion}

\subsection{Synthesis of Polyphenylglyoxamide-Based Antimicrobial Peptidomimetics}

To incorporate the biphenyl or terphenyl group into the phenylglyoxamide backbone, 5-bromoisatin 3 was reacted with phenylboronic acid or 4-biphenylboronic acid with a catalytic amount of tetrakis(triphenylphosphine)palladium(0) via Suzuki-Miyaura crosscoupling reaction to give 5-phenylisatin 4 and 5-(biphenyl-4-yl)isatin 5 in good yields of $86 \%$ and $78 \%$, respectively (Scheme 1 ) $[51,56]$.

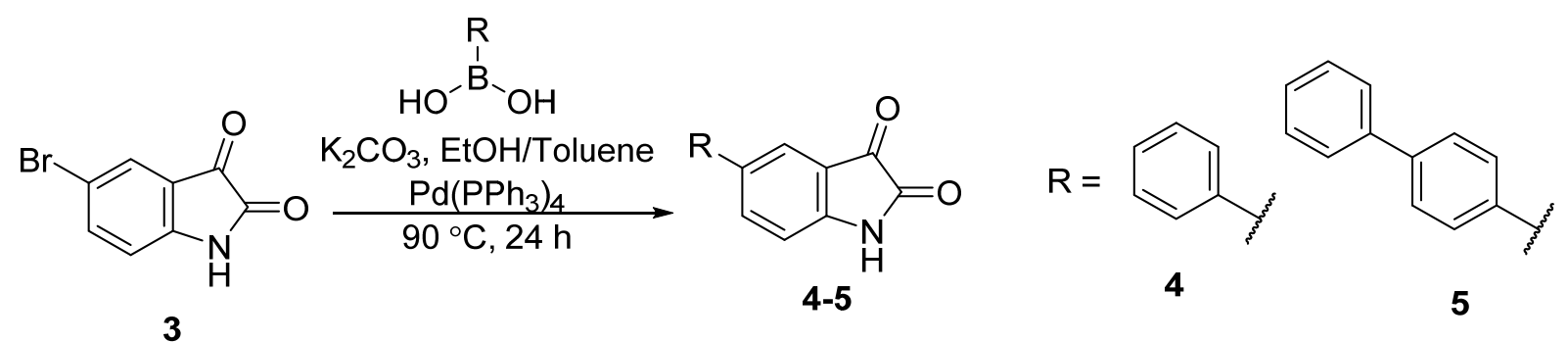

Scheme 1. Synthesis of 5-phenylisatin 4 and 5-(biphenyl-4-yl)isatin 5.

Alkylsulfonyl groups with different chain lengths were then installed into the isatin scaffold by following a previously reported procedure $[50,51]$ to provide the hydrophobic group for the target peptidomimetics. Isatins $\mathbf{6 a} \mathbf{a} \mathbf{6} \mathbf{d}$ were treated with triethylamine and various alkylsulfonyl chlorides in dichloromethane (DCM) at room temperature to afford $\mathrm{N}$ sulfonylisatins 7a-7d $(n=7), \mathbf{8 a}-\mathbf{8} \mathbf{d}(n=11)$ and $\mathbf{9 a}-\mathbf{9} \mathbf{c}(n=15)$ in $28-60 \%$ yield (Scheme 2$)$. However, the reaction between 5-(biphenyl-4-yl)isatin $6 \mathrm{~d}$ and 1-hexadecanesulfonyl chloride gave no product. It was initially suspected that the unsuccessful synthesis was due to the poor solubility of 5-(biphenyl-4-yl)isatin $\mathbf{6 d}$ and 1-hexadecanesulfonyl chloride in DCM; however, no reaction was observed, even when the sulfonylation reaction was then attempted in other solvents, such as tetrahydrofuran (THF), dimethylformamide (DMF) and toluene. Further attempts involved heating the reaction mixture at reflux in toluene and using sodium hydride or $\mathrm{N}, \mathrm{N}$-diisopropylethylamine (DIPEA) as the base, but none of the attempted conditions were successful in the synthesis of the desired product.

The synthesised $\mathrm{N}$-sulfonylisatins 7-9 were then ring-opened with 3-dimethylaminopropylamine in DCM to afford the corresponding glyoxamides 10-12 in excellent yields of $96-99 \%$, except glyoxamides 10d and 11d which gave moderate yields of $61 \%$ and $53 \%$, respectively. The lower yield of the latter compounds could be due to the low solubility of the starting material in DCM. The cationicity of the target molecule was then introduced by treating the glyoxamides 10-12 with $4 \mathrm{M} \mathrm{HCl}$ in dioxane to afford the corresponding tertiary ammonium chloride salts $\mathbf{1 3 - 1 5}$ in a moderate to good yield of $60-99 \%$. Alternatively, a different cationic group can be installed by treating the glyoxamides 10-12 with iodomethane to afford the corresponding quaternary ammonium iodide salts 13-15 in yields of $42-91 \%$.

To explore whether changing the position of the terminal phenyl ring in the terphenyl system has any effect on antibacterial activity, ammonium salts 22-23 bearing a metaterphenyl scaffold instead of a para-terphenyl scaffold were also synthesised following the above-mentioned synthetic route, with 3-biphenylboronic acid as the starting material in the initial Suzuki-Miyaura cross-coupling reaction (Scheme 3). 


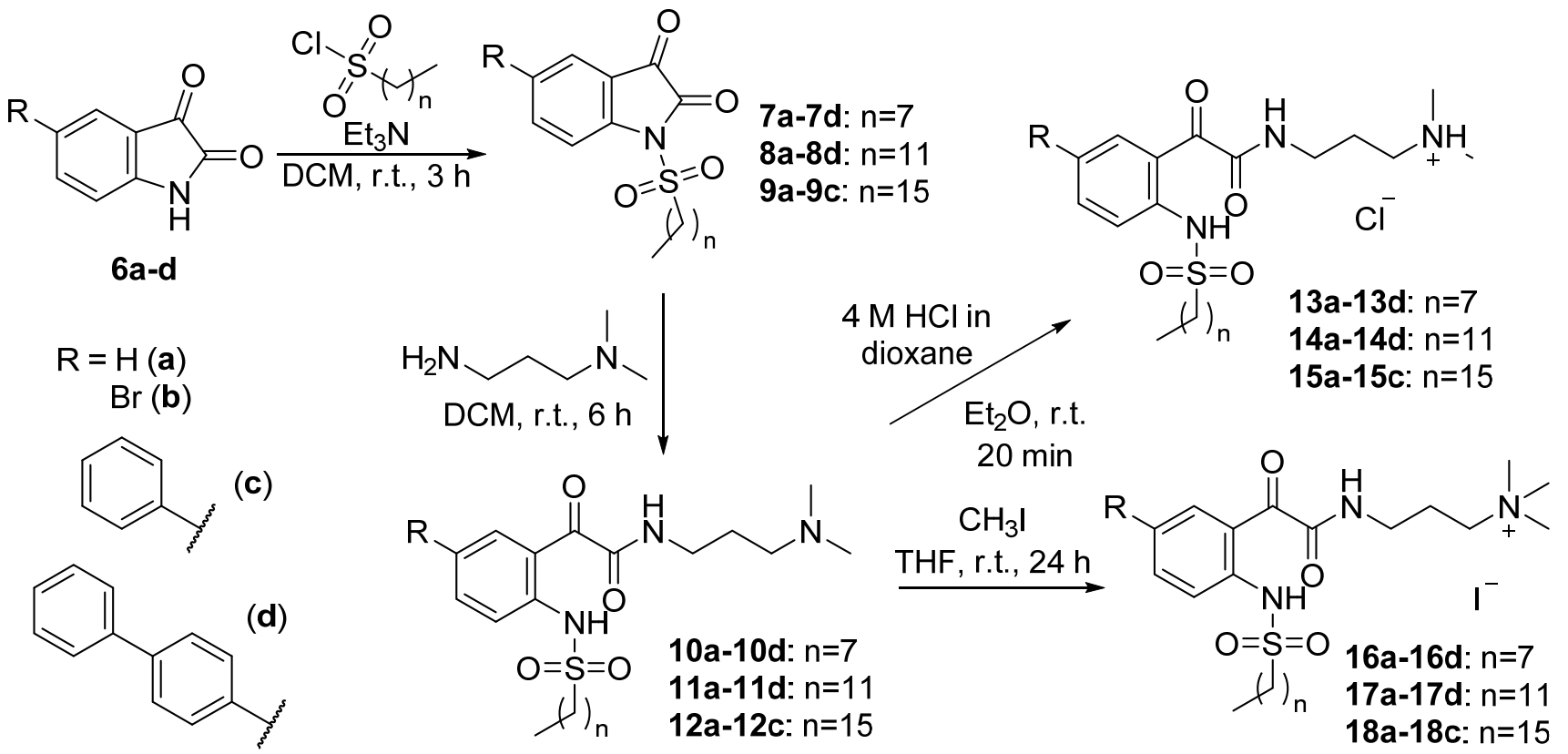

Scheme 2. Synthesis of glyoxamides 10-12, tertiary ammonium chloride salts $\mathbf{1 3 - 1 5}$ and quaternary ammonium iodide salts 16-18.

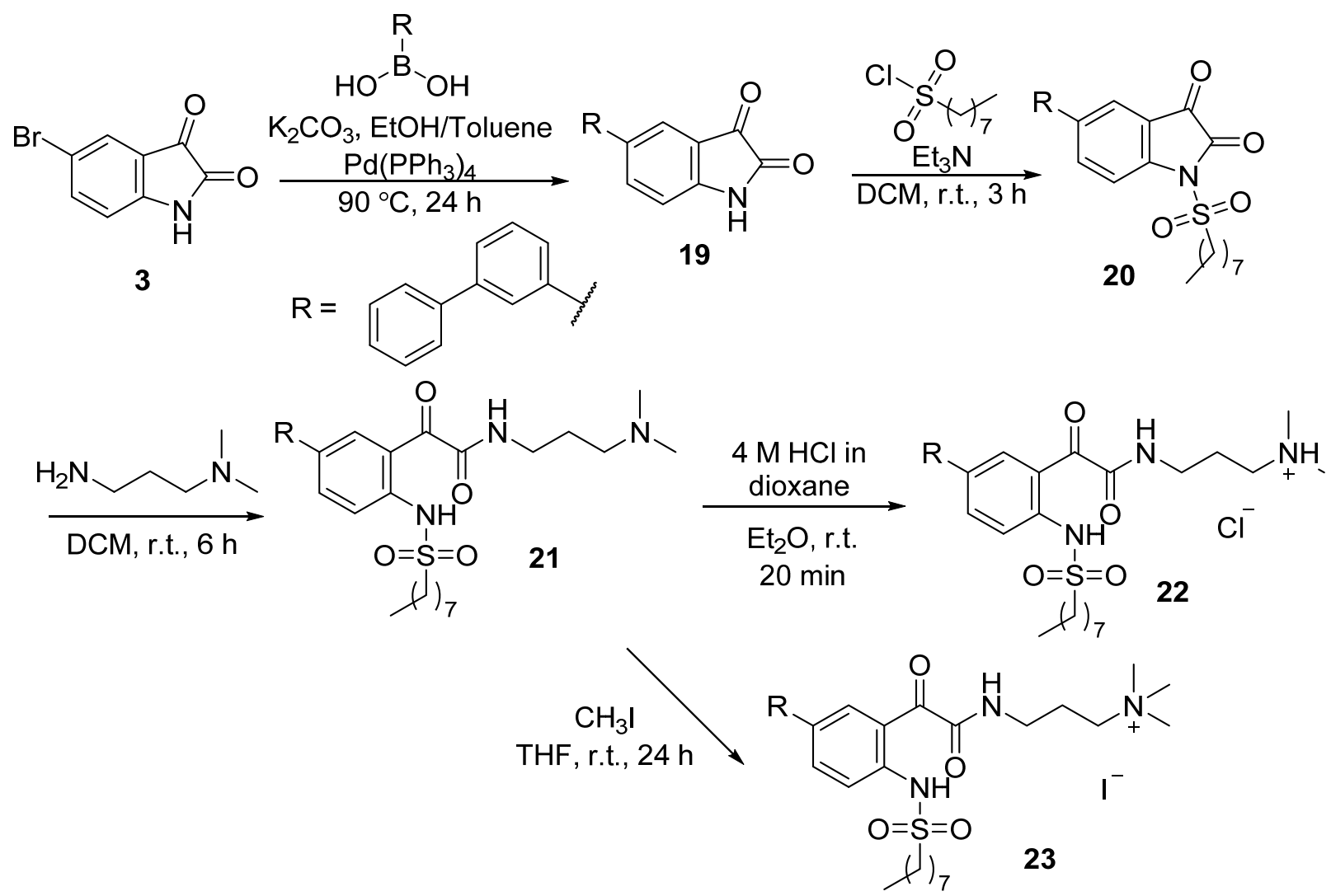

Scheme 3. Synthesis of glyoxamide 21, tertiary ammonium chloride salt 22 and quaternary ammonium iodide salt 23 bearing a meta-terphenyl system.

As previous studies have reported that the introduction of a guanidine as the cationic group could increase the potency of peptidomimetics against Gram-positive S. aureus [50,57], the guanidinium hydrochloride salts 33-35 were also synthesised (Scheme 4). To achieve 
this, $N$-sulfonylisatins 7-9 were ring-opened with $N$-Boc-1,3-propanediamine to afford the Boc-protected glyoxamides 24-26 in excellent yields of 88-98\%. The Boc-protecting group was then cleaved by treatment with $4 \mathrm{M} \mathrm{HCl}$ in dioxane to give the corresponding aminoglyoxamides $27-29$ in yields of $60-95 \%$. The guanidine moiety was then introduced to the molecule by reacting the aminoglyoxamides $27-29$ with $N, N^{\prime}$-di-Boc- $1 H$-pyrazole1-carboxamidine in the presence of triethylamine in acetonitrile (ACN) to give the Bocprotected guanidine glyoxamides 30-32 in yields of 51-87\%. Finally, the Boc-protecting group was cleaved with trifluoroacetic acid in DCM, followed by anion exchange reaction with $4 \mathrm{M} \mathrm{HCl}$ in dioxane to give the guanidinium hydrochloride salts 33-35 in $48-97 \%$ yield.<smiles>[R]c1ccc2c(c1)C(=O)C(=O)N2S(C)(=O)=O</smiles><smiles>CC(C)(C)NCCCN</smiles><smiles>[R]c1ccc(NS(=O)(=O)O[Na])c(C(=O)C(C)=O)c1</smiles>
8a-8c: $n=11$ 9a-9c: $n=15$<smiles>[R]c1ccc(NS(=O)(=O)[O-])c(C(=O)C(=O)NCCCN)c1</smiles><smiles>CC(C)(C)NC(=O)NC(=NC(=O)OCc1ccccc1)n1cccn1</smiles>

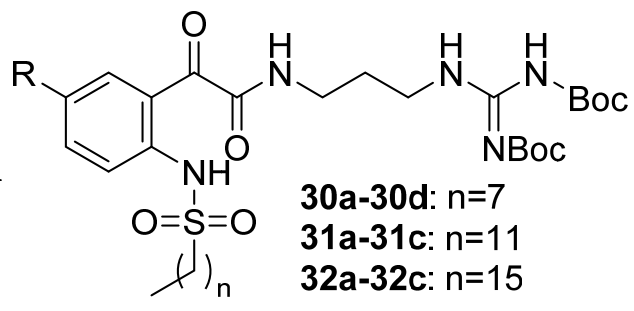

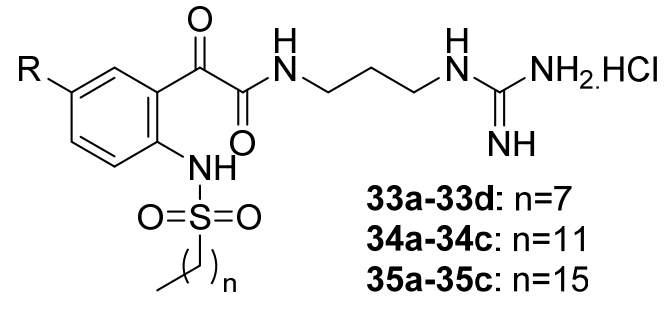<smiles>[R][Bi]Br</smiles>

Scheme 4. Synthesis of guanidinium hydrochloride salts 33-35.

\subsection{Antibacterial Activity}

The synthesised peptidomimetics were tested in the minimal inhibitory concentration (MIC) assay for the determination of their antibacterial activities against Gram-positive S. aureus (SA38). In addition, selected peptidomimetics (16d, 17b, 17c, 18a, 34a, 34b), which showed high antibacterial activity against Gram-positive $S$. aureus, were also tested for their antibacterial activities against Gram-negative E. coli (K12) and P. aeruginosa (PAO1). In general, the tested peptidomimetics possess lower antibacterial activity against Gramnegative bacteria than Gram-positive S. aureus, especially P. aeruginosa, for which none of the tested peptidomimetics in this study showed any antibacterial activity at the highest concentration tested $(250 \mu \mathrm{M})$. The MIC values of all tested peptidomimetics are shown in 
Table 1. There was no effect of the different growth media on MIC values, with the MIC of peptidomimetics $16 \mathrm{~d}$ and $17 \mathrm{c}$ being 4 and $8 \mu \mathrm{M}(2.9$ and $5.6 \mu \mathrm{g} / \mathrm{mL})$, respectively, in the trypticase soy broth (TSB), Mueller Hinton broth (MHB) or cationic adjusted MHB.

Table 1. Minimum inhibitory concentration (MIC) of peptidomimetics against S. aureus, E. coli and P. aeruginosa and the calculated AlogP values of peptidomimetics.

\begin{tabular}{|c|c|c|c|c|c|}
\hline & \multirow{2}{*}{ Compound } & \multirow{2}{*}{$A \log P$} & \multicolumn{3}{|c|}{$\mathrm{MIC}(\mu \mathrm{M} / \mu \mathrm{g} / \mathrm{mL})$} \\
\hline & & & S. aureus & E. coli & P. aeruginosa \\
\hline \multirow{12}{*}{$\begin{array}{l}\text { Glyoxamide } \\
\text { derivatives }\end{array}$} & $10 a$ & 2.61 & $250 / 106[50]$ & ND & ND \\
\hline & $10 \mathrm{~b}$ & 3.38 & $94 / 47$ [50] & ND & ND \\
\hline & 10c & 4.26 & $24 / 12[51]$ & ND & ND \\
\hline & $10 d$ & 5.91 & $8 / 4.6$ & ND & ND \\
\hline & $11 a$ & 4.39 & $32 / 15$ & ND & ND \\
\hline & $11 b$ & 5.16 & $32 / 18$ & ND & ND \\
\hline & 11c & 6.04 & $16 / 8.9$ & ND & ND \\
\hline & 11d & 7.69 & $250 / 158$ & ND & ND \\
\hline & $12 a$ & 6.17 & $63 / 34$ & ND & ND \\
\hline & $12 b$ & 6.94 & $250 / 154$ & ND & ND \\
\hline & $12 \mathrm{c}$ & 7.82 & $>250 />153$ & ND & ND \\
\hline & 21 & 5.91 & $16 / 9.2$ & ND & ND \\
\hline \multirow{12}{*}{$\begin{array}{c}\text { Tertiary } \\
\text { ammonium } \\
\text { chloride salts }\end{array}$} & $13 a$ & -0.89 & $\begin{array}{c}>250 />116 \\
{[50]}\end{array}$ & ND & ND \\
\hline & $13 b$ & -0.12 & $63 / 34$ [50] & ND & ND \\
\hline & $13 c$ & 0.76 & $16 / 8.6[51]$ & ND & ND \\
\hline & $13 d$ & 2.41 & $16 / 9.8$ & ND & ND \\
\hline & $14 a$ & 0.89 & $16 / 8.3$ & ND & ND \\
\hline & $14 b$ & 1.66 & $16 / 9.6$ & ND & ND \\
\hline & $14 \mathrm{c}$ & 2.54 & $16 / 9.5$ & ND & ND \\
\hline & $14 d$ & 4.18 & $125 / 84$ & ND & ND \\
\hline & $15 a$ & 2.67 & $63 / 36$ & ND & ND \\
\hline & $15 b$ & 3.44 & $250 / 163$ & ND & ND \\
\hline & $15 c$ & 4.32 & $>250 />163$ & ND & ND \\
\hline & 22 & 2.41 & $16 / 9.8$ & ND & ND \\
\hline \multirow{12}{*}{$\begin{array}{l}\text { Quaternary } \\
\text { ammonium } \\
\text { iodide salts }\end{array}$} & $16 a$ & -1.55 & $250 / 142$ [50] & ND & ND \\
\hline & $16 b$ & -0.78 & $63 / 41[50]$ & ND & ND \\
\hline & $2,16 \mathrm{c}$ & 0.10 & $16 / 10[51]$ & $32 / 21$ [51] & $125 / 80$ [51] \\
\hline & $16 d$ & 1.75 & $4 / 2.9$ & $>250 />180$ & $>250 />180$ \\
\hline & $17 a$ & 0.23 & $16 / 10$ & ND & ND \\
\hline & $17 \mathrm{~b}$ & 1.00 & $8 / 5.6$ & $32 / 22$ & $>250 />176$ \\
\hline & $17 \mathrm{c}$ & 1.88 & $8 / 5.6$ & $32 / 22$ & $>250 />175$ \\
\hline & $17 d$ & 3.52 & $63 / 48$ & ND & ND \\
\hline & $18 a$ & 2.01 & $8 / 5.4$ & $>250$ & $>250$ \\
\hline & $18 b$ & 2.78 & $125 / 95$ & ND & ND \\
\hline & $18 \mathrm{c}$ & 3.65 & $250 / 189$ & ND & ND \\
\hline & 23 & 1.75 & $8 / 5.8$ & ND & ND \\
\hline \multirow{10}{*}{$\begin{array}{l}\text { Guanidinium } \\
\text { hydrochloride } \\
\text { salts }\end{array}$} & $33 a$ & -1.46 & $47 / 22[50]$ & ND & ND \\
\hline & $1,33 b$ & -0.69 & $12 / 6.7[50]$ & ND & ND \\
\hline & $33 c$ & 0.19 & $8 / 4.4[51]$ & $63 / 35$ [51] & $63 / 35$ [51] \\
\hline & $33 d$ & 1.84 & $16 / 10$ & ND & ND \\
\hline & $34 a$ & 0.32 & $8 / 4.3$ & $16 / 8.5$ & $>250 />133$ \\
\hline & $34 b$ & 1.09 & $16 / 9.8$ & $>250 />153$ & $>250 />153$ \\
\hline & $34 c$ & 1.97 & $32 / 19$ & ND & ND \\
\hline & $35 a$ & 2.10 & $250 / 147$ & ND & ND \\
\hline & $35 b$ & 2.87 & $>250 />167$ & ND & ND \\
\hline & $35 c$ & 3.75 & $>250 />166$ & ND & ND \\
\hline
\end{tabular}


The incorporation of a biphenyl system in the glyoxamide scaffold enhanced the antibacterial activity of the peptidomimetics against both Gram-positive and Gram-negative bacteria [51]. To investigate the effect of lengthening the phenyl ring system on the antibacterial activity of the peptidomimetics, those bearing a meta- or para-terphenyl system were synthesised. Replacing the biphenyl system with a terphenyl system was generally beneficial for the antibacterial activity of the peptidomimetics against Gram-positive S. aureus. The previously reported quaternary ammonium iodide salt $16 \mathrm{c}$ bearing a biphenyl system and an octanesulfonyl group had an MIC value of $16 \mu \mathrm{M}(10 \mu \mathrm{g} / \mathrm{mL})$ [51]. When an additional phenyl ring was incorporated, the corresponding quaternary ammonium iodide salts $\mathbf{1 6 d}$ and 23 bearing a para-terphenyl or meta-terphenyl system, respectively, possessed MIC values of 4 and $8 \mu \mathrm{M}(2.9$ and $5.8 \mu \mathrm{g} / \mathrm{mL})$ against $S$. aureus, suggesting that the terphenyl system was preferred over biphenyl. In terms of the position of the terminal phenyl ring in the terphenyl system, quaternary ammonium iodide salt $16 \mathrm{~d}$ (MIC $=4 \mu \mathrm{M}$ or $2.9 \mu \mathrm{g} / \mathrm{mL}$ ) bearing a para-terphenyl system was slightly more potent than the corresponding quaternary ammonium iodide salt 23 (MIC $=8 \mu \mathrm{M}$ or $5.8 \mu \mathrm{g} / \mathrm{mL}$ ) bearing a meta-terphenyl system. Against Gram-negative E. coli and P. aeruginosa, while quaternary ammonium iodide salt 16c bearing a biphenyl system and an octanesulfonyl group possessed MIC values of 32 and $125 \mu \mathrm{M}(21$ and $80 \mu \mathrm{g} / \mathrm{mL})$ against E. coli and P. aeruginosa, respectively, the antibacterial activity of the peptidomimetics was completely lost upon converting the biphenyl system to terphenyl as exhibited by the corresponding quaternary ammonium iodide salt 16d (MIC $>250 \mu \mathrm{M}$ or $>180 \mu \mathrm{g} / \mathrm{mL}$ ). This suggested that the extra phenyl ring in the terphenyl system created steric hindrance, which may reduce the antibacterial activity of the peptidomimetics against Gram-negative bacteria.

As shortening the octanesulfonyl chain was previously reported to be detrimental to the antibacterial activity of the peptidomimetics $[50,51]$ and lengthening the octanesulfonyl chain was not previously studied, peptidomimetics with dodecanesulfonyl and hexadecanesulfonyl groups were synthesised to assess the effect of longer chain lengths on antibacterial activity. Interestingly, the effect of lengthening the alkylsulfonyl chain depended on the size of the phenyl ring system. For the monophenyl system, the previously reported unsubstituted parent (16a) and 5-bromosubstituted quaternary ammonium iodide salts (16b) bearing an octanesulfonyl chain had MICs of 250 and $63 \mu \mathrm{M}(142$ and $41 \mu \mathrm{g} / \mathrm{mL}$ ) against $S$. aureus, respectively. When the octanesulfonyl chain was lengthened to a dodecanesulfonyl chain, the MIC of the corresponding quaternary ammonium iodide salts $17 \mathrm{a}$ and $17 \mathrm{~b}$ decreased to 16 and $8 \mu \mathrm{M}(10$ and $5.6 \mu \mathrm{g} / \mathrm{mL})$ against $S$. aureus, respectively, indicating 16- and 8-fold increases in potency. A similar trend was also observed for quaternary ammonium iodide salts bearing a biphenyl system, although the increase in potency was only two-fold when comparing the quaternary ammonium iodide salt 16c $(\mathrm{MIC}=16 \mu \mathrm{M}$ or $10 \mu \mathrm{g} / \mathrm{mL}$ ) bearing an octanesulfonyl chain with the corresponding dodecanesulfonyl compound 17c (MIC $=8 \mu \mathrm{M}$ or $5.6 \mu \mathrm{g} / \mathrm{mL}$ ). However, against Gramnegative $E$. coli, lengthening the octanesulfonyl chain to dodecanesulfonyl chain gave no improvement in antibacterial activity, as both $16 \mathrm{c}$ and $17 \mathrm{c}$ shared the same MIC value of $32 \mu \mathrm{M}(10$ and $5.6 \mu \mathrm{g} / \mathrm{mL}$, respectively). Moreover, for the peptidomimetics bearing a terphenyl system, lengthening the octanesulfonyl chain to dodecanesulfonyl chain significantly decreased antibacterial activity against $S$. aureus, as the quaternary ammonium iodide salt 17d (MIC $=63 \mu \mathrm{M}$ or $48 \mu \mathrm{g} / \mathrm{mL}$ ) bearing a dodecanesulfonyl chain showed 16-fold lower potency than the corresponding octanesulfonyl compound 16d (MIC $=4 \mu \mathrm{M}$ or $2.9 \mu \mathrm{g} / \mathrm{mL}$ ). Further lengthening the alkylsulfonyl chain from dodecanesulfonyl to hexadecanesulfonyl was detrimental to the antibacterial activity of the peptidomimetics against S. aureus, as significant increases in MIC values were observed regardless of the phenyl ring system. One exception was the quaternary ammonium iodide salt 18a bearing an unsubstituted monophenyl system, where the lengthening of the alkylsulfonyl chain from dodecanesulfonyl (17a with MIC $=16 \mu \mathrm{M}$ or $10 \mu \mathrm{g} / \mathrm{mL}$ ) to hexadecanesulfonyl (18a with MIC $=8 \mu \mathrm{M}$ or $5.4 \mu \mathrm{g} / \mathrm{mL}$ ) showed a two-fold increase in antibacterial activity. 
In terms of cationic group modification, previous studies have identified that guanidinium hydrochloride salts bearing an octanesulfonyl chain possesses superior antibacterial activity against $S$. aureus compared to their corresponding tertiary ammonium chloride salts, quaternary ammonium iodide salts or uncharged glyoxamide compounds [50,51]. However, this was not necessarily true in this study when the octanesulfonyl chain was lengthened to dodecansulfonyl and hexadecanesulfonyl. In fact, guanidinium hydrochloride salts bearing a dodecanesulfonyl or hexadecanesulfonyl chain showed lower antibacterial activity against $S$. aureus than their corresponding quaternary ammonium iodide salts. The only exception was the monophenyl guanidinium hydrochloride salt 34a (MIC $=8 \mu \mathrm{M}$ or $4.3 \mu \mathrm{g} / \mathrm{mL}$ ) bearing a dodecanesulfonyl chain, which showed slightly higher potency against $S$. aureus than its corresponding quaternary ammonium iodide salt 17a (MIC $=16 \mu \mathrm{M}$ or $10 \mu \mathrm{g} / \mathrm{mL}$ ). Against Gram-negative E. coli, a similar trend was observed, where the 5-bromosubstituted quaternary ammonium iodide salt $\mathbf{1 7 b}$ with a dodecanesulfonyl chain showed good antibacterial activity (MIC $=32 \mu \mathrm{M}$ or $22 \mu \mathrm{g} / \mathrm{mL}$ ), while the corresponding guanidinium hydrochloride salt $34 \mathrm{~b}$ showed no antibacterial activity at the highest tested concentration (MIC $>250 \mu \mathrm{M}$ or $>153 \mu \mathrm{g} / \mathrm{mL}$ ).

Overall, the structure-activity relationship analysis for these peptidomimetics suggests that the optimal combination for Gram-positive antibacterial activity was a terphenyl system, an octanesulfonyl chain and a quaternary ammonium iodide cationic group. Compound $16 \mathrm{~d}$ with a combination of these was the most potent compound (MIC $=4 \mu \mathrm{M}$ or $2.9 \mu \mathrm{g} / \mathrm{mL}$ ) against $S$. aureus in this study. Interestingly, there appeared to be an inverse relationship between the size of the phenyl system and the length of the alkylsulfonyl chain in favour of high antibacterial activity. Specifically, peptidomimetics bearing a bulky terphenyl system preferred a shorter octanesulfonyl chain while peptidomimetics bearing a non-bulky monophenyl system preferred a longer hexadecanesulfonyl chain for high antibacterial activity. In terms of the terminal cationic group, compounds with the terphenyl system or a long dodecanesulfonyl chain favoured the quaternary ammonium iodide salts for antibacterial activity against $S$. aureus, while octanesulfonyl compounds preferred the guanidinium hydrochloride salts.

\subsection{Lipophilicity and Antibacterial Activity Correlation}

The apparent inverse relationship between the size of the phenyl system and the length of the alkylsulfonyl chain for strong antibacterial activity suggested that the lipophilicity of the peptidomimetics might be an important factor driving the potency of the compounds. Hence, the $\log \mathrm{P}$ values of all synthesised peptidomimetics were determined computationally.

While there are different computational methods and approaches used to estimate $\log P$ values, the AlogP method under the empirical fragment-based approaches was used in this study, as empirical fragment-based approaches are highly efficient and the AlogP method was previously demonstrated to be one of the best performing methods for estimating $\log \mathrm{P}$ (with mean absolute errors of $0.3 \log$ unit or less), compared to other physics-based implicit and atomistic methods [58,59]. The AlogP method was developed by Ghose and Crippen in 1986 and was trained on nearly 900 molecular structures [60-62]. In this study, the AlogP values of all peptidomimetics were calculated, using MarvinSketch (Table 1) [63]. The MIC against S. aureus vs. AlogP plots for the glyoxamide derivatives, ammonium chloride salts, quaternary ammonium iodide salts and guanidinium hydrochloride salts are exhibited in Figure 2.

The plots revealed that there is an optimum range of AlogP values for each series of peptidomimetics for high antibacterial activity. Peptidomimetics with AlogP value above or below the optimum range generally show lower antibacterial activity. For example, glyoxamide derivatives with AlogP values between 4.3 and 6.0 possessed high antibacterial activity with MIC values at or below $32 \mu \mathrm{M}$, while those outside of the optimum AlogP range exhibited MIC values at or above $63 \mu \mathrm{M}$. Similar trends were also observed for tertiary ammonium chloride salts, quaternary ammonium iodide salts and guanidinium hydrochloride salts, which exhibited optimal AlogP ranges of $0.8-2.5,0.1-2.0$ and $-0.7-1.8$, 
respectively. The elucidation of the optimal AlogP range for each series of peptidomimetics could be useful in the prediction of the antibacterial activity in the future development of glyoxamide-based antimicrobial peptidomimetics.

A

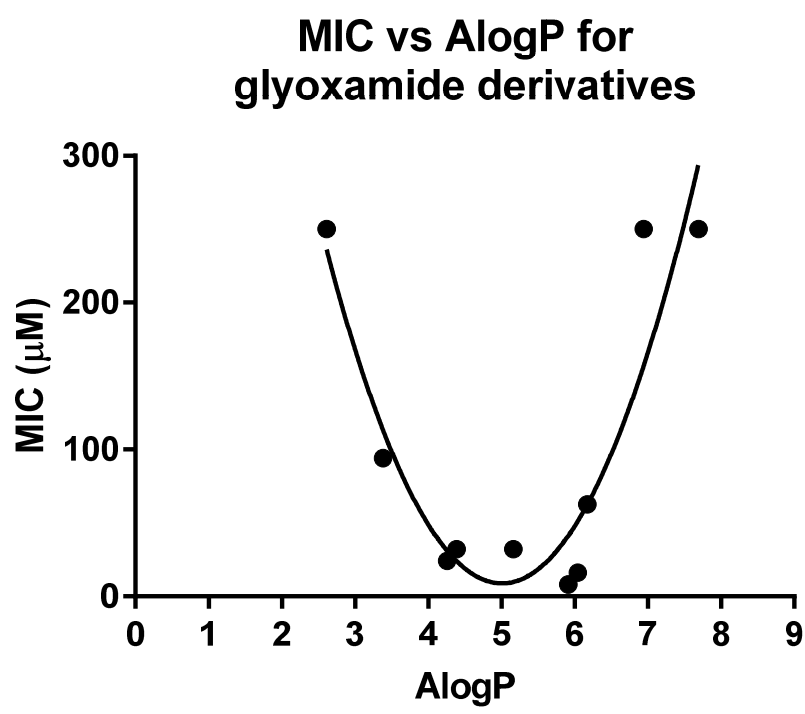

C
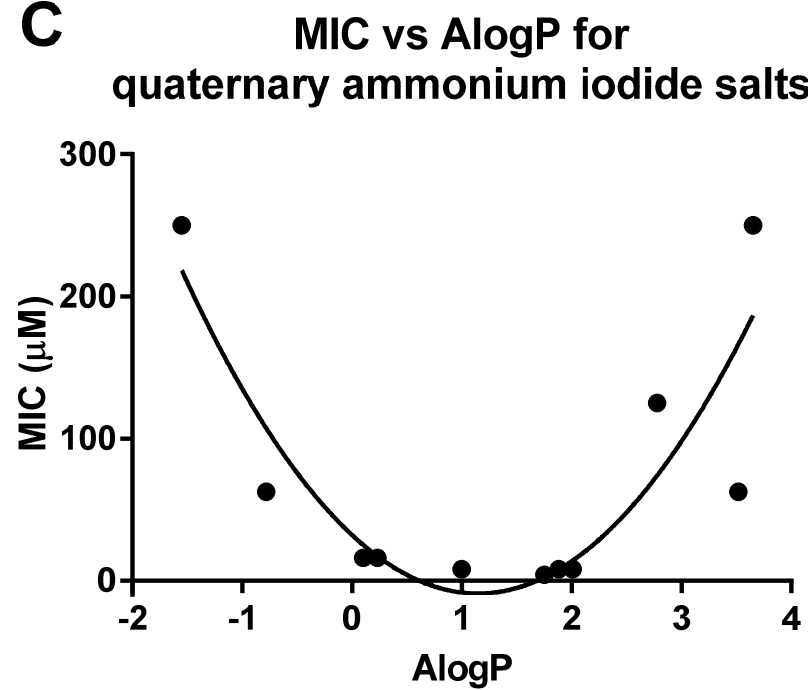

B
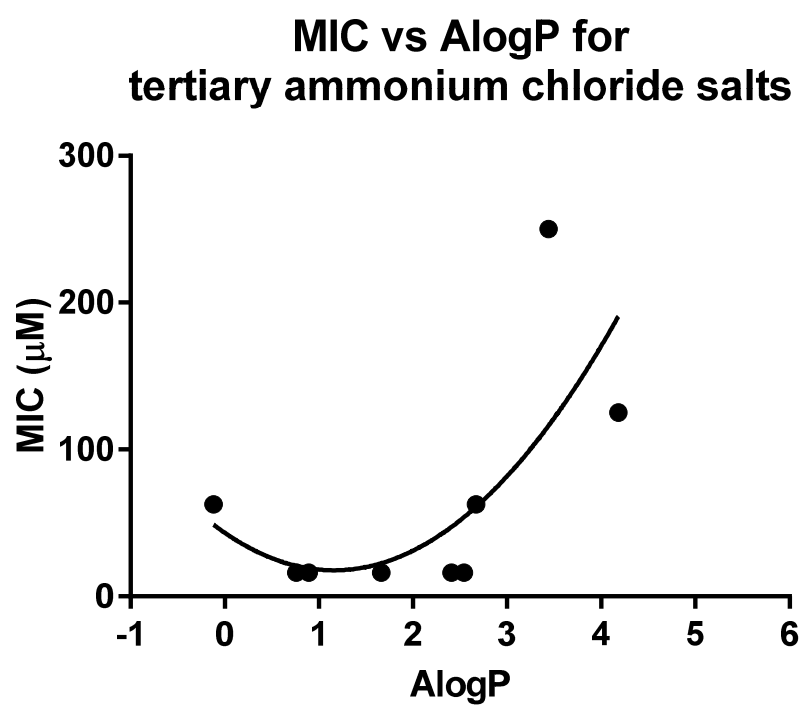

D
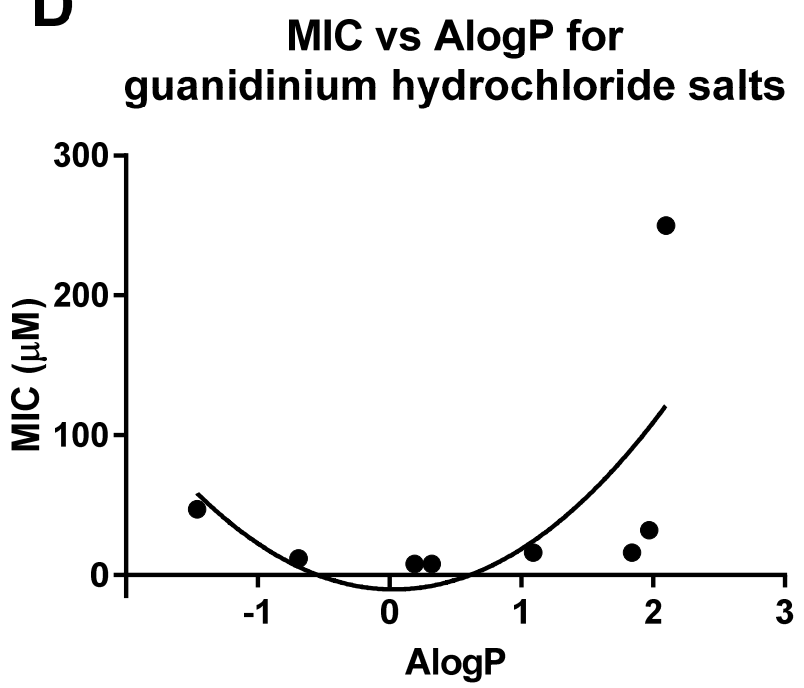

Figure 2. MIC vs. AlogP plot for (A) glyoxamide derivatives; (B) tertiary ammonium chloride salts; (C) quaternary ammonium iodide salts; and (D) guanidinium hydrochloride salts.

\subsection{Biofilm Disruption}

As bacterial biofilms are one of the major challenges in treating bacterial infection, the ability of the synthesised peptidomimetics to disrupt pre-established biofilms was investigated. In this study, selected potent peptidomimetics (16d, 17b, 17c, 18a, 34a, $34 b$ ) were tested against pre-established Gram-positive S. aureus biofilms at $1 \times, 2 \times$ and $4 \times$ MIC of the peptidomimetics, using the crystal violet assay (Figure 3). The ability of the tested peptidomimetics to disrupt pre-established biofilms generally increased with the concentration. 


\section{Biofilm disruption against $S$. aureus at 4x MIC of peptidomimetics}

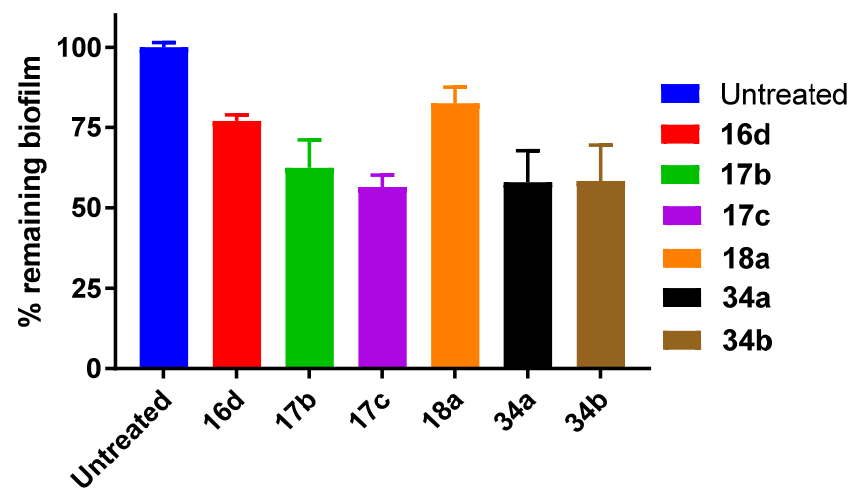

\section{Biofilm disruption against $S$. aureus at 2x MIC of peptidomimetics}

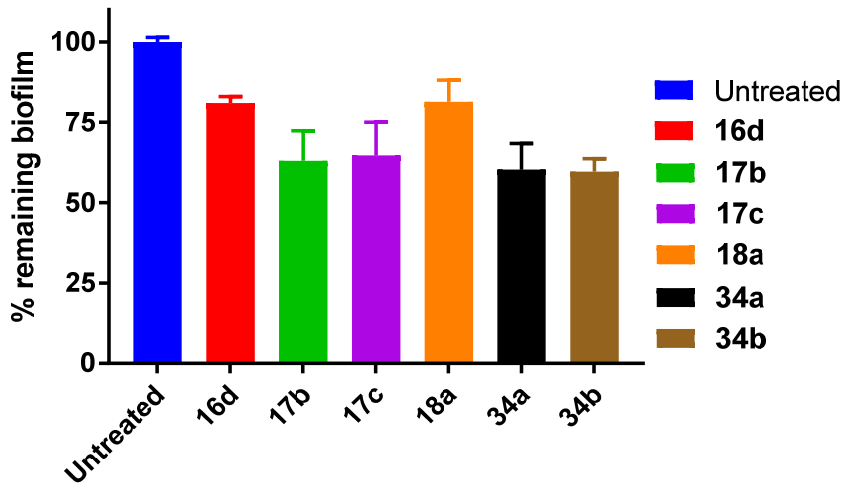

Biofilm disruption against $S$. aureus at 1x MIC of peptidomimetics

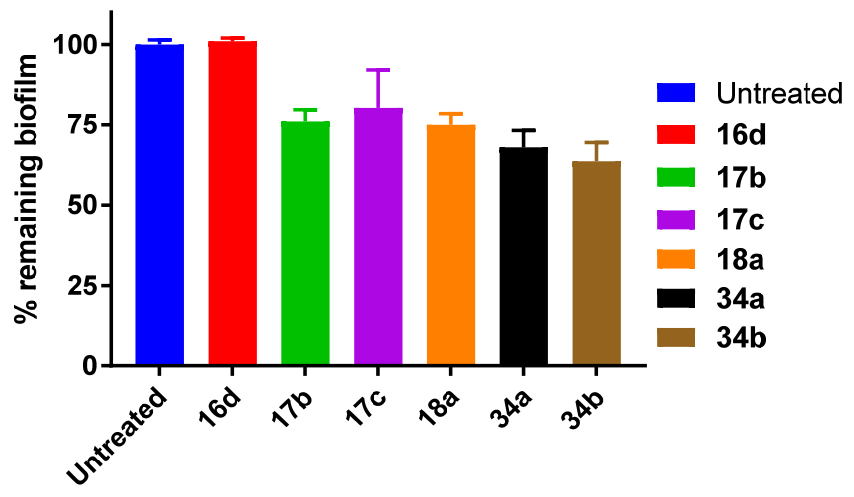

Figure 3. Percentage remaining $S$. aureus biofilms following $24 \mathrm{~h}$ treatment with peptidomimetics at $4 \times$ (top left), $2 \times$ (top right) and $1 \times$ (bottom) MIC. Error bars represent the standard error of at least triplicates $(n \geq 3)$.

In general, guanidinium hydrochloride salts $(34 \mathbf{a}, 34 \mathbf{b})$ were more potent $S$. aureus biofilm disruptors than quaternary ammonium iodide salts $(\mathbf{1 6 d}, \mathbf{1 7 b}, \mathbf{1 7 c}, \mathbf{1 8 a})$, as they were able to disrupt a higher amount of pre-established S. aureus biofilms at all tested concentrations. The only exception was quaternary ammonium iodide salt $\mathbf{1 7 c}$, which displayed a slightly higher biofilm disruption at $4 \times$ MIC. At lower concentration $(1 \times \mathrm{MIC})$, most peptidomimetics (17b, 17c, 18a, 34a, 34b) showed 20-36\% S. aureus biofilm disruption, except for quaternary ammonium iodide salt $16 \mathrm{~d}$, bearing a terphenyl scaffold and octanesulfonyl group, which showed no antibiofilm activity at $1 \times$ MIC. Amongst the active peptidomimetics, the guanidinium hydrochloride salt $\mathbf{3 4 b}$ bearing a dodecanesulfonyl group was the most potent compound, disrupting $36 \%$ of pre-established S. aureus biofilms at $1 \times$ MIC. It was also one of the most active compounds at the highest tested concentration $(4 \times \mathrm{MIC})$, possessing the same biofilm disruption ability as guanidinium hydrochloride salt $34 \mathbf{b}$, disrupting $42 \%$ of pre-established $S$. aureus biofilms, slightly lower than quaternary ammonium iodide salt $17 \mathrm{c}$, which managed to disrupt $44 \%$ of pre-established S. aureus biofilms. This was followed by quaternary ammonium iodide salt $\mathbf{1 7 b}$, which disrupted $38 \%$ of pre-established S. aureus biofilms at $4 \times$ MIC. These compounds possessed similar antibiofilm activity as LL-37, which disrupted about $40 \%$ pre-established S. aureus biofilms at $4 \times$ MIC [64].

The biofilm disruption activities of the synthesised peptidomimetics $\mathbf{1 7 b}, \mathbf{1 7 c}$, and $34 a$, which possessed good antibacterial activity against $E$. coli in the MIC assay, were also investigated at $1 \times$ and $2 \times$ MIC against pre-established E. coli biofilms. All tested compounds showed lower biofilm disruption ability against Gram-negative E. coli than against Gram-positive S. aureus. Of the three tested compounds, the quaternary ammonium 
iodide salts $17 \mathbf{b}$ and $17 \mathrm{c}$ were able to disrupt $31 \%$ and $28 \%$ of the pre-established E. coli biofilms at $2 \times$ MIC (Figure 4). Although the guanidinium hydrochloride salt 34a was the most potent compound at inhibiting E. coli growth in the MIC assay and was one of the best S. aureus biofilm disruptors, it was unable to disrupt any pre-established E. coli biofilms. This suggests that it can only target $E$. coli cells in their planktonic form, but not those that are embedded in the polymeric matrices of biofilms. The observed discrepancy in the antibiofilm activity of these peptidomimetics against Gram-positive S. aureus and Gramnegative E. coli could be due to the differences in the composition of their biofilms [65-67].

\section{Biofilm disruption of $17 b, 17 c$ and $34 a$ against $E$. coli}

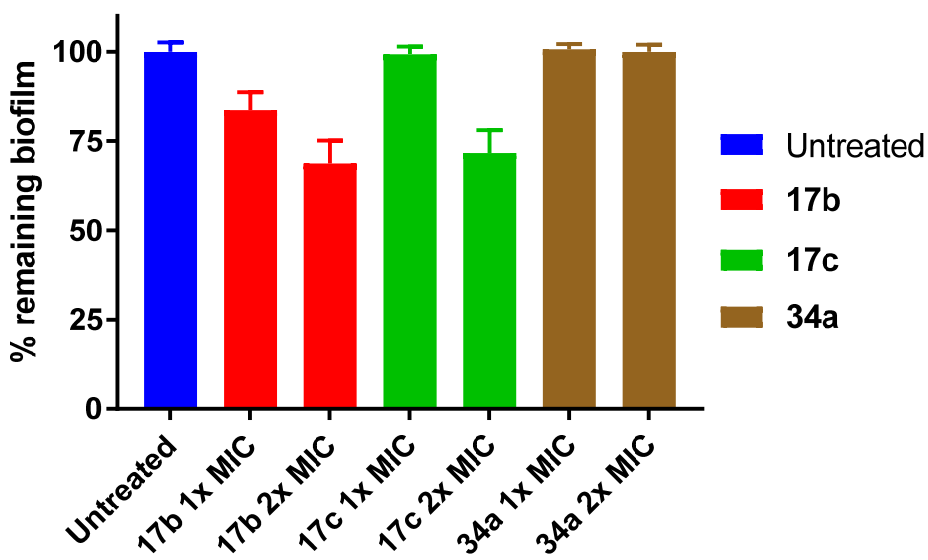

Figure 4. Percentage remaining E. coli biofilms following $24 \mathrm{~h}$ treatment with peptidomimetics $\mathbf{1 7 b}$, $17 \mathrm{c}$ and $34 \mathrm{a}$ at $1 \times$ and $2 \times$ MIC. Error bars represent the standard error of triplicates $(n=3)$.

\subsection{Biofilm Inhibition}

In addition to biofilm disruption assay, selected potent peptidomimetics $16 \mathrm{~d}$ and $17 \mathrm{c}$ were also tested for their ability to inhibit the formation of $S$. aureus biofilm at $0.5 \times, 1 \times, 2 \times$ and $4 \times$ MIC of the peptidomimetics (Figure 5). In this assay, S. aureus was incubated in the presence of different concentrations of the tested peptidomimetics under a static condition. After overnight incubation, planktonic bacteria were removed, and the remaining biofilms were quantified, using crystal violet staining.

\section{Biofilm inhibition of $16 \mathrm{~d}$ and $17 \mathrm{c}$ against $S$. aureus}

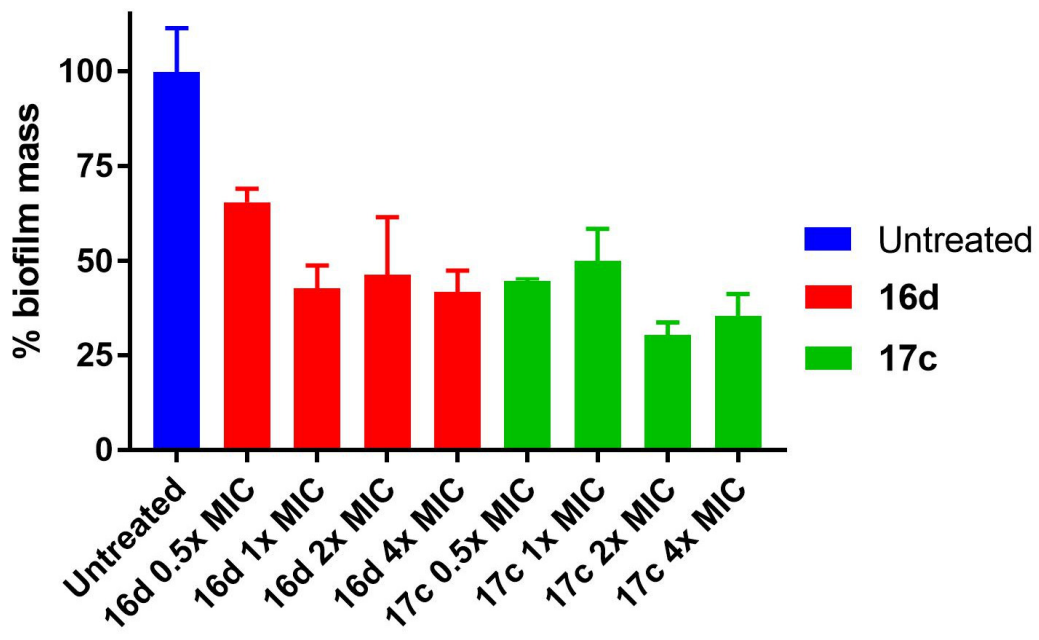

Figure 5. Inhibition of biofilm fomration of $S$. aureus by peptidomimetics $16 \mathrm{~d}$ and $17 \mathrm{c}$ at $0.5 \times, 1 \times$, $2 \times$ and $4 \times$ MIC. Error bars represent the standard error of triplicates $(n=3)$. 
Both peptidomimetics $16 \mathrm{~d}$ and $\mathbf{1 7} \mathrm{c}$ were effective in inhibiting S. aureus biofilm formation, as they were able to inhibit more than $50 \%$ of biofilm formation (except for peptidomimetics $\mathbf{1 6 d}$ at $0.5 \times$ of its MIC), with $\mathbf{1 7 c}$ showing a slightly higher inhibition than $\mathbf{1 6 d}$, except at $1 \times$ MIC. Of the two peptidomimetics, maximum inhibition of biofilm formation was observed for peptidomimetic $17 \mathrm{c}$ at $2 \times$ and $4 \times$ of its MIC, inhibiting $70 \%$ and $65 \%$ of biofilm formation, respectively. At sub-MIC $(0.5 \times$ MIC), $\mathbf{1 6 d}$ and $17 \mathrm{c}$ were able to inhibit $35 \%$ and $56 \%$ of biofilm formation, respectively.

\subsection{Cytoplasmic Membrane Permeability}

The disruption effect of selected potent peptidomimetics (16d, 17c, 34a) on bacterial cytoplasmic membrane was investigated in a membrane dye release assay, using the membrane potential-sensitive dye 3,3'-dipropylthiadicarbocyanine iodide (diSC3-5). This dye readily partitions into and aggregates in bacterial cell membranes, quenching its own fluorescence. However, structural damage to the bacterial cell membrane causes a loss in the membrane potential, which results in the leakage of dye from the bacterial cell membrane into the medium and an increase in fluorescence intensity. By detecting changes in fluorescence intensity, the integrity of the bacterial cytoplasmic membrane can be monitored.

It was hypothesised that the synthesised peptidomimetics possess similar mechanisms of action as natural AMPs, which act via the electrostatic interactions between the negatively charged bacterial cell membrane and the cationic group of the peptidomimetics. As this disrupts the bacterial membrane and/or forms pores on the membrane, causing an alteration of the membrane potential, an increase in fluorescence intensity was expected upon the treatment of bacterial cells with the test compounds.

Overall, all three tested compounds disrupted the cytoplasmic membranes of $S$. aureus, as an increase in fluorescence intensity was observed within $5 \mathrm{~min}$ after the deployment of the test compounds. Moreover, all test compounds disrupted cytoplasmic membranes in a concentration-dependent manner, as evidenced by a higher increase in fluorescence intensity at the higher concentration $(2 \times \mathrm{MIC})$ of the test compound than at the lower concentration $(1 \times$ MIC) (Figure 6$)$. Amongst the three compounds, guanidinium hydrochloride salt 34 a was the most active compound at $2 \times \mathrm{MIC}$, as it induced the highest increase in fluorescence intensity at $15 \mathrm{~min}$. However, at $1 \times$ MIC, there was no significant difference in the cytoplasmic membrane disruption ability between guanidinium hydrochloride salt $34 \mathbf{a}$ and the quaternary ammonium iodide salt $17 \mathrm{c}$. The least active compound was the quaternary ammonium iodide salt $\mathbf{1 6 d}$, as it showed the smallest increase in fluorescence intensity at $15 \mathrm{~min}$. However, it is worth mentioning that while increasing the bacterial cytoplasmic membrane permeability can be a mechanism of action of the tested compounds, these compounds can also exert their antibacterial action through other mechanisms, such as interacting with DNA, RNA or nucleotides [68-71]; these potential mechanisms of action of AMP will be investigated in future studies.

\subsection{Cytotoxicity}

The in vitro toxicity of selected potent peptidomimetics (10d, 13d, 16d, 17b, 17c, 18a, 22, 23, 33d, 34a, 34b) was assessed against MRC-5 normal human lung fibroblasts via the MTT assay. The $\mathrm{IC}_{50}$ values of the tested peptidomimetics were determined from a doseresponse curve. TY-01 was used as the positive control in this assay with the $\mathrm{IC}_{50}$ value to be $14.2 \mu \mathrm{M}(7.83 \mu \mathrm{g} / \mathrm{mL})$ [51]. The therapeutic indices for each tested peptidomimetic against Gram-positive S. aureus and Gram-negative E. coli were calculated by dividing the $\mathrm{IC}_{50}$ value against human cells by the corresponding MIC value (Table 2). An antibacterial agent, which can be utilised clinically, should possess a high therapeutic index, as this indicates a high selectivity for bacterial cells over human cells. 


\section{Cytoplasmic membrane depolarisation}

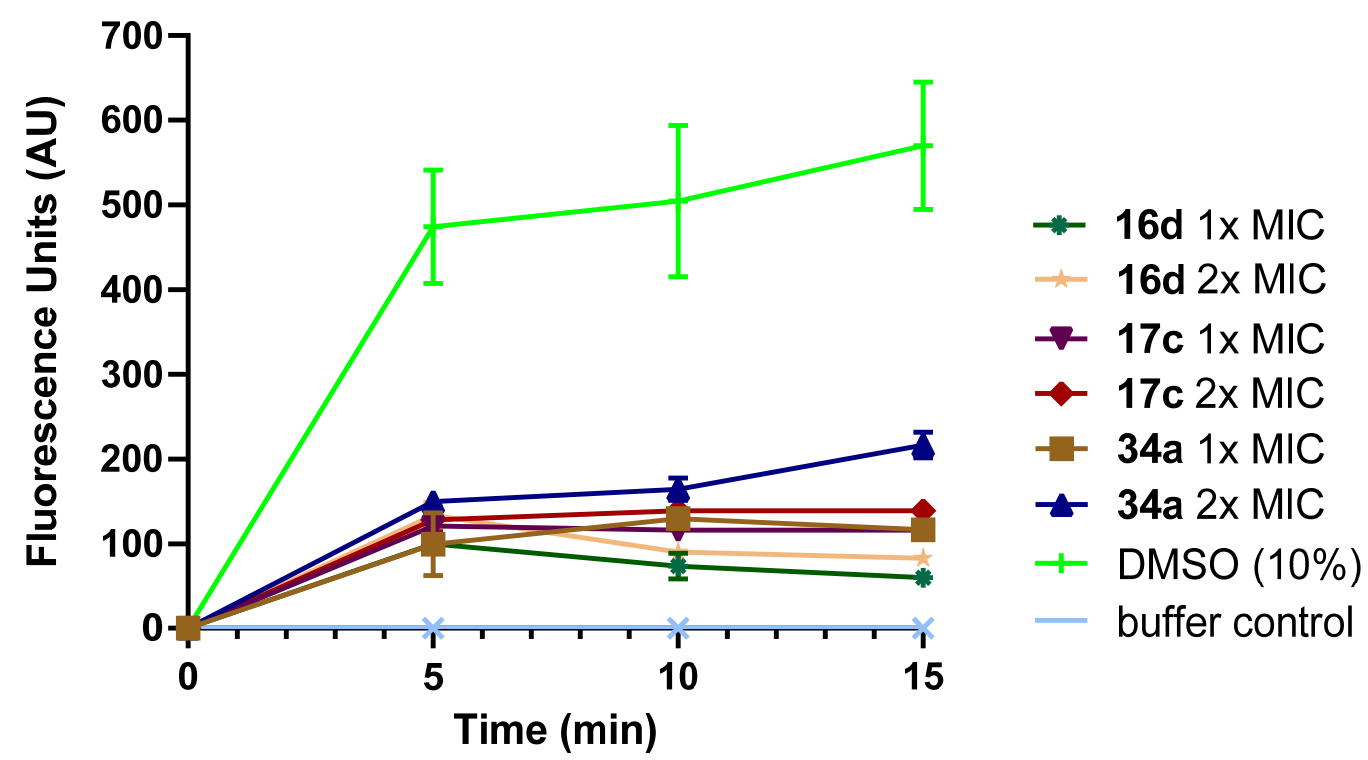

Figure 6. S. aureus cytoplasmic membrane depolarisation induced by peptidomimetics $16 \mathrm{~d}, \mathbf{1 7} \mathrm{c}$ and $34 \mathrm{a}$ at $1 \times \mathrm{MIC}$ and $2 \times$ MIC. As a positive control, 10\% DMSO was used. Error bars represent the standard error of triplicates $(n=3)$.

Table 2. $\mathrm{IC}_{50}$ value of peptidomimetics against MRC-5 normal human lung fibroblasts and their therapeutic indices with respect to $S$. aureus and E. coli.

\begin{tabular}{|c|c|c|c|c|}
\hline & \multirow{2}{*}{ Compound } & \multirow{2}{*}{$\begin{array}{c}\mathrm{IC}_{50} \\
(\mu \mathrm{M} / \mu \mathrm{g} / \mathrm{mL})\end{array}$} & \multicolumn{2}{|c|}{ Therapeutic Index } \\
\hline & & & S. aureus & E. coli \\
\hline Glyoxamide derivatives & 10d & $3.48 / 2.01$ & 0.44 & $\mathrm{~N} / \mathrm{A}$ \\
\hline \multirow{2}{*}{$\begin{array}{l}\text { Tertiary ammonium } \\
\text { chloride salts }\end{array}$} & 13d & $3.76 / 2.31$ & 0.24 & $\mathrm{~N} / \mathrm{A}$ \\
\hline & 22 & $3.46 / 2.13$ & 0.22 & N/A \\
\hline \multirow{5}{*}{$\begin{array}{l}\text { Quaternary ammonium } \\
\text { iodide salts }\end{array}$} & $16 d$ & $53.7 / 38.6$ & 15.4 & $\mathrm{~N} / \mathrm{A}$ \\
\hline & $17 b$ & $18.3 / 12.9$ & 2.29 & 0.57 \\
\hline & $17 \mathrm{c}$ & $57.5 / 40.2$ & 7.18 & 1.80 \\
\hline & $18 a$ & $52.4 / 35.6$ & 6.54 & $\mathrm{~N} / \mathrm{A}$ \\
\hline & 23 & $15.4 / 11.1$ & 1.93 & $\mathrm{~N} / \mathrm{A}$ \\
\hline \multirow{3}{*}{$\begin{array}{c}\text { Guanidinium } \\
\text { hydrochloride salts }\end{array}$} & $33 d$ & $16.9 / 10.6$ & 1.05 & $\mathrm{~N} / \mathrm{A}$ \\
\hline & $34 a$ & $27.2 / 14.5$ & 3.40 & 1.70 \\
\hline & $34 \mathrm{~b}$ & $21.1 / 14.8$ & 1.32 & $\mathrm{~N} / \mathrm{A}$ \\
\hline Positive control & TY-01 & $14.2 / 7.83$ & $\mathrm{~N} / \mathrm{A}$ & $\mathrm{N} / \mathrm{A}$ \\
\hline
\end{tabular}

Without the terminal cationic group, the neutral glyoxamide 10d showed high toxicity with an $\mathrm{IC}_{50}$ of $3.48 \mu \mathrm{M}(2.01 \mu \mathrm{g} / \mathrm{mL})$ against human cells and a therapeutic index of 0.44 against $S$. aureus, indicating that it is more effective at targeting human cells rather than bacterial cells. Converting the tertiary amine group of $\mathbf{1 0 d}$ into the tertiary ammonium chloride salt 13d did not improve toxicity, as there was no significant difference in the $\mathrm{IC}_{50}$ value $(\sim 4 \mu \mathrm{M}$ or $\sim 2 \mu \mathrm{g} / \mathrm{mL})$ between the two peptidomimetics. However, the corresponding quaternary ammonium iodide salt $\mathbf{1 6 d}$ showed a significant improvement in the toxicity, as the $\mathrm{IC}_{50}$ value against human cells rose to $53.7 \mu \mathrm{M}(38.6 \mu \mathrm{g} / \mathrm{mL})$, giving a therapeutic index of 15.4 against $S$. aureus. On the other hand, replacing the quaternary ammonium iodide group by a guanidinium hydrochloride group (33d) increased toxicity, as the $\mathrm{IC}_{50}$ value dropped to $16.9 \mu \mathrm{M}(10.6 \mu \mathrm{g} / \mathrm{mL})$, giving a therapeutic index of 1.05 against $S$. aureus. A similar trend was also observed for peptidomimetics bearing 
different phenyl systems and alkylsulfonyl chains, with quaternary ammonium iodide salts $(\mathbf{1 7 b}, \mathbf{1 7 c}, \mathbf{1 8 a})$ generally having higher therapeutic indices of 2.29-7.18 against $S$. aureus than guanidinium hydrochloride salts $(\mathbf{3 3 d}, \mathbf{3 4 a}, \mathbf{3 4} \mathbf{b})$ with therapeutic indices of 1.05-3.40. Against Gram-negative E. coli, the therapeutic indices of tested peptidomimetics $(\mathbf{1 7 b}, \mathbf{1 7 c}$, 34a) were between 0.57 and 1.80 . The lower therapeutic indices against $E$. coli compared to those of $S$. aureus were due to the higher MIC values of the peptidomimetics against $E$. coli.

In addition to assessing the cytotoxicity of the peptidomimetic on human lung fibroblasts, the potent peptidomimetics $\mathbf{1 6 d}$ and $\mathbf{1 7 c}$ were tested for their cytotoxicity against human red blood cells in a haemolysis assay. Both peptidomimetics gave relatively low haemolytic activities, with $\mathbf{1 6 d}$ and $\mathbf{1 7 c}$ showing only $11 \%$ and $16 \%$ haemolysis, respectively, at $32 \mu \mathrm{M}$. This concentration corresponded to $8 \times$ and $4 \times$ MIC of $\mathbf{1 6 d}$ and $17 \mathrm{c}$, respectively, against $S$. aureus.

Overall, the relatively low cytotoxicity (against lung fibroblast cells and erythrocytes) of peptidomimetics suggests that they are relatively non-toxic to human cells and, therefore, the corresponding high therapeutic indices indicate that the peptidomimetics $16 \mathrm{~d}, 17 \mathrm{c}$, 18a might be suitable antibiotics to develop further for the treatment of $S$. aureus infection. However, the relatively low therapeutic indices against $E$. coli suggest that these peptidomimetics might be unsafe to be used as antibacterial agents against $E$. coli, clinically.

\section{Materials and Methods}

\subsection{Synthesis of Analogues}

\subsubsection{General Information}

All commercially available reagents and solvents were purchased from standard suppliers (Sigma Aldrich, Alfa-Aesar, Combi-Blocks and Oakwook Chemicals) and used without further purification. All reactions were performed under anhydrous condition with an anhydrous solvent obtained using PureSolv MD Solvent Purification System unless otherwise specified. The progress of the reactions was monitored by thin layer chromatography plates precoated with Merck silica gel 60 F254 and visualised using short and/or long wavelength of ultraviolet light. Flash chromatography was carried out using Grace Davisil LC60A silica.

Melting points of the compounds were measured using an SRS MPA100 OptiMelt melting point apparatus and are reported without correction. ${ }^{1} \mathrm{H}$ and ${ }^{13} \mathrm{C}$ NMR spectra were acquired in the specified solvents on a Bruker Avance III HD 400 or Bruker Avance III 600 Cryo spectrometer. Chemical shifts $(\delta)$ are in parts per million (ppm) internally referenced to the solvent nuclei. Multiplicities are assigned as singlet (s), broad singlet (bs), doublet (d), triplet (t), quartet (q), multiplet (m) or a combination of these (e.g., dd, $\mathrm{dt}, \mathrm{td})$, and coupling constants $(J)$ are reported in Hertz (Hz). Infrared (IR) spectra were recorded using a Cary 630 FTIR spectrometer or Nicolet ${ }^{\mathrm{TM}}$ iS $^{\mathrm{TM}} 10$ FTIR spectrometer fitted with a diamond attenuated total reflectance (ATR) sample interface. High-resolution mass spectrometry (HRMS) was performed, using a Thermo LTQ Orbitrap XL instrument.

\subsubsection{Synthetic Procedures and Experimental Characterisation Data 5-Phenylindoline-2,3-dione (4)}

The synthesis of the titled compound followed the procedure previously described [51] with slight modification. A $2 \mathrm{M}$ potassium carbonate solution $(7.7 \mathrm{~mL}, 15.4 \mathrm{mmol})$ was degassed for $30 \mathrm{~min}$ and then added into a suspension of 5-bromoisatin (1.72 g, $7.59 \mathrm{mmol})$ and phenylboronic acid $(1.04 \mathrm{~g}, 8.35 \mathrm{mmol}$ ) in a degassed (for $30 \mathrm{~min}$ ) 1:1 ethanol/toluene solution $(30 \mathrm{~mL})$. The dark brown solution mixture was further degassed for $30 \mathrm{~min}$, followed by the addition of tetrakis(triphenylphosphine)palladium(0) $(92 \mathrm{mg}, 0.080 \mathrm{mmol}$ ). The resulting reaction mixture was heated at reflux under an atmosphere of nitrogen for $18 \mathrm{~h}$. The brownish-black reaction mixture was concentrated in vacuo. Glacial acetic acid $(30 \mathrm{~mL})$ was added to the dark brown solid, and the resulting reaction mixture was heated at reflux for $20 \mathrm{~min}$. The solution mixture was then allowed to cool to room temperature overnight. The red crystals formed was filtered and discarded. Water $(50 \mathrm{~mL})$ 
was then added to the filtrate. The organic layer was extracted thrice with dichloromethane $(3 \times 30 \mathrm{~mL})$, washed with brine $(50 \mathrm{~mL})$, dried over sodium sulphate and concentrated in vacuo to give a red solid, which was purified by flash column chromatography on silica, using methanol/dichloromethane as the eluent to give the product as a red solid (1.14 g, 67\%); mp 249.5-250.3 ${ }^{\circ} \mathrm{C} ;{ }^{1} \mathrm{H}$ NMR (400 MHz, DMSO-d $): \delta 11.12$ (bs, $\left.1 \mathrm{H}, \mathrm{NH}\right)$, $7.91(\mathrm{dd}, J=8.2,2.0 \mathrm{~Hz}, 1 \mathrm{H}, \mathrm{ArH}), 7.76(\mathrm{~d}, J=1.9 \mathrm{~Hz}, 1 \mathrm{H}, \mathrm{ArH}), 7.67-7.63$ (m, 2H, ArH), 7.48-7.43 (m. 2H, ArH), 7.39-7.33 (m, 1H, ArH), 7.01 (d, J = 8.2 Hz, 1H, ArH); MS (+ESI): $m / z 246.12,[\mathrm{M}+\mathrm{Na}]^{+}$.

\section{5-([1,1'-Biphenyl]-4-yl)indoline-2,3-dione (5)}

The synthesis of the titled compound followed the procedure previously described [56]. A $2 \mathrm{M}$ potassium carbonate solution $(9.2 \mathrm{~mL}, 18.4 \mathrm{mmol})$ was degassed for $30 \mathrm{~min}$, and then added into a suspension of 5-bromoisatin (2.06 $\mathrm{g}, 9.13 \mathrm{mmol})$ and 4-biphenylboronic acid $(1.89 \mathrm{~g}, 9.54 \mathrm{mmol})$ in a degassed (for $30 \mathrm{~min}) 1: 1$ ethanol/toluene solution $(40 \mathrm{~mL})$. The dark brown solution mixture was further degassed for $30 \mathrm{~min}$, followed by the addition of tetrakis(triphenylphosphine)palladium(0) $(109 \mathrm{mg}, 0.094 \mathrm{mmol})$. The resulting reaction mixture was heated at reflux under an atmosphere of nitrogen for $18 \mathrm{~h}$. The dark brown reaction mixture was concentrated in vacuo. Glacial acetic acid ( $30 \mathrm{~mL}$ ) was added to the dark brown solid, and the resulting reaction mixture was heated at reflux for $20 \mathrm{~min}$. The dark red precipitate was collected by vacuum filtration to give the crude product, which was redissolved in dimethylformamide and filtered. The filtrate was then poured into 1:1 ice-water mixture and the red precipitate formed was collected by vacuum filtration to give the product as a red solid $(2.28 \mathrm{~g}, 83 \%) ; \mathrm{mp} 239.9-240.8{ }^{\circ} \mathrm{C} ;{ }^{1} \mathrm{H}$ NMR $\left(400 \mathrm{MHz}, \mathrm{DMSO}-d_{6}\right)$ : $\delta 11.14(\mathrm{~s}, 1 \mathrm{H}, \mathrm{NH}), 7.98(\mathrm{dd}, J=8.2,2.1 \mathrm{~Hz}, 1 \mathrm{H}, \mathrm{ArH}), 7.84(\mathrm{~d}, J=2.0 \mathrm{~Hz}, 1 \mathrm{H}, \mathrm{ArH})$, 7.79-7.69 (m, 6H, ArH), 7.52-7.45 (m, 2H, ArH), 7.41-7.35 (m, 1H, ArH), 7.03 (d, J = 8.2 Hz, $1 \mathrm{H}, \mathrm{ArH}) ; \mathrm{HRMS}(+\mathrm{ESI})$ : Found $m / z 322.0839[\mathrm{M}+\mathrm{Na}]^{+}, \mathrm{C}_{20} \mathrm{H}_{13} \mathrm{NO}_{2} \mathrm{Na}$ required 322.0838 .

General synthetic procedure A for $N$-sulfonylisatins

Triethylamine (1.1 equivalents) was added slowly to a stirring solution of an appropriate isatin (1.0 equivalent) in dichloromethane $(15 \mathrm{~mL})$ at $0{ }^{\circ} \mathrm{C}$ in a nitrogen atmosphere. The reaction mixture was stirred at $0{ }^{\circ} \mathrm{C}$ for $20 \mathrm{~min}$, followed by the dropwise addition of an appropriate 1-alkylsulfonyl chloride (1.0 equivalent) in dichloromethane $(5 \mathrm{~mL})$ with stirring. The reaction mixture was then stirred at room temperature for $3 \mathrm{~h}$. After the completion of the reaction, the reaction mixture was concentrated in vacuo and washed with methanol to afford the product.

\section{5-([1,1'-Biphenyl]-4-yl)-1-(octylsulfonyl)indoline-2,3-dione (7d)}

The titled compound was synthesised from 5-([1,1'-biphenyl]-4-yl)indoline-2,3-dione 6d $(0.44 \mathrm{~g}, 1.46 \mathrm{mmol})$, triethylamine $(0.23 \mathrm{~mL}, 1.65 \mathrm{mmol})$ and 1-octanesulfonyl chloride $(0.30 \mathrm{~mL}, 1.53 \mathrm{mmol})$ following general synthetic procedure A. After washing the crude with methanol, the precipitate was collected by vacuum filtration, and the filtrate was discarded. The residue was then washed with dichloromethane $(5 \mathrm{~mL})$ and filtered. The filtrate was concentrated in vacuo to afford the product as an orange solid $(0.28 \mathrm{~g}, 40 \%)$; mp 173.5-173.9 ${ }^{\circ} \mathrm{C} ;{ }^{1} \mathrm{H}$ NMR $\left(400 \mathrm{MHz}, \mathrm{DMSO}-d_{6}\right): \delta 8.14(\mathrm{dd}, J=8.6,2.0 \mathrm{~Hz}, 1 \mathrm{H}, \mathrm{ArH})$, $8.05(\mathrm{~d}, J=2.0 \mathrm{~Hz}, 1 \mathrm{H}, \mathrm{ArH}), 7.87-7.70(\mathrm{~m}, 7 \mathrm{H}, \mathrm{ArH}), 7.50(\mathrm{t}, J=7.8 \mathrm{~Hz}, 2 \mathrm{H}, \mathrm{ArH}), 7.39$ $(\mathrm{t}, J=7.2 \mathrm{~Hz}, 1 \mathrm{H}, \mathrm{ArH}), 3.67-3.60\left(\mathrm{~m}, 2 \mathrm{H}, \mathrm{CH}_{2}\right), 1.87-1.76\left(\mathrm{~m}, 2 \mathrm{H}, \mathrm{CH}_{2}\right), 1.44-1.15(\mathrm{~m}$, $\left.10 \mathrm{H}, \mathrm{CH}_{2}\right), 0.84\left(\mathrm{t}, \mathrm{J}=7.1 \mathrm{~Hz}, 3 \mathrm{H}, \mathrm{CH}_{3}\right) ;{ }^{13} \mathrm{C} \mathrm{NMR}\left(100 \mathrm{MHz}, \mathrm{DMSO}-d_{6}\right): \delta 178.7(\mathrm{CO})$, 156.7 (CO), 146.2 (ArC), 139.7 (ArC), 139.4 (ArC), 136.9 (ArC), $136.4(\mathrm{ArC}), 135.7$ (ArCH), $129.1(\mathrm{ArCH}), 127.7(\mathrm{ArCH}), 127.4(\mathrm{ArCH}), 127.1(\mathrm{ArCH}), 126.6(\mathrm{ArCH}), 122.3(\mathrm{ArCH})$, 120.2 (ArC), $114.7(\mathrm{ArCH}), 53.7\left(\mathrm{CH}_{2}\right), 31.1\left(\mathrm{CH}_{2}\right), 28.4\left(\mathrm{CH}_{2}\right), 28.4\left(\mathrm{CH}_{2}\right), 27.3\left(\mathrm{CH}_{2}\right), 22.2$ $\left(\mathrm{CH}_{2}\right), 22.0\left(\mathrm{CH}_{2}\right), 13.9\left(\mathrm{CH}_{3}\right)$; IR (ATR): $v_{\max } 3854,3675,2987,2900,1765,1739,1613,1576$, 1559, 1473, 1434, 1405, 1393, 1373, 1309, 1290, 1254, 1240, 1174, 1140, 1075, 1066, 1057, 1027, 944, 892, 851, 836, 766, 729, 719, $692 \mathrm{~cm}^{-1}$; HRMS (+ESI): Found $m / z 498.1710[\mathrm{M}+\mathrm{Na}]^{+}$, $\mathrm{C}_{28} \mathrm{H}_{29} \mathrm{NO}_{4} \mathrm{SNa}$ required 498.1710 . 
1-(Dodecylsulfonyl)indoline-2,3-dione (8a)

The titled compound was synthesised from isatin $6 \mathrm{a}(0.23 \mathrm{~g}, 1.54 \mathrm{mmol})$, triethylamine $(0.24 \mathrm{~mL}, 1.72 \mathrm{mmol})$ and 1-dodecanesulfonyl chloride $(0.42 \mathrm{~g}, 1.56 \mathrm{mmol})$ following general synthetic procedure $\mathbf{A}$. The product was obtained as a yellow solid $(0.30 \mathrm{~g}, 51 \%)$; $\mathrm{mp} 128.1-129.6^{\circ} \mathrm{C}^{\prime}{ }^{1} \mathrm{H}$ NMR (400 MHz, DMSO- $\left.d_{6}\right): \delta 7.78-7.68(\mathrm{~m}, 3 \mathrm{H}, \mathrm{ArH}), 7.36-7.28$ (m, 1H, ArH), 3.64-3.56 (m, 2H, $\left.\mathrm{CH}_{2}\right), 1.83-1.72\left(\mathrm{~m}, 2 \mathrm{H}, \mathrm{CH}_{2}\right), 1.41-1.14\left(\mathrm{~m}, 18 \mathrm{H}, \mathrm{CH}_{2}\right)$, $0.85\left(\mathrm{t}, J=7.1 \mathrm{~Hz}, 3 \mathrm{H}, \mathrm{CH}_{3}\right) ;{ }^{13} \mathrm{C}$ NMR $\left(100 \mathrm{MHz}, \mathrm{DMSO}-d_{6}\right): \delta 178.8(\mathrm{CO}), 156.5(\mathrm{CO})$, $146.9(\mathrm{ArC}), 137.9(\mathrm{ArCH}), 125.1(\mathrm{ArCH}), 125.0(\mathrm{ArCH}), 119.4(\mathrm{ArC}), 114.1(\mathrm{ArCH}), 53.7$ $\left(\mathrm{CH}_{2}\right), 31.3\left(\mathrm{CH}_{2}\right), 29.0\left(\mathrm{CH}_{2}\right), 28.9\left(\mathrm{CH}_{2}\right), 28.7\left(\mathrm{CH}_{2}\right), 28.7\left(\mathrm{CH}_{2}\right), 28.4\left(\mathrm{CH}_{2}\right), 27.3\left(\mathrm{CH}_{2}\right)$, $22.1\left(\mathrm{CH}_{2}\right), 22.1\left(\mathrm{CH}_{2}\right), 14.0\left(\mathrm{CH}_{3}\right)$; IR (ATR): $v_{\max } 2996,2913.2847,1912,1733,1651,1593$, 1459, 1413, 1371, 1320, 1237, 1177, 1132, 1090, 1024, 933, 831, 784, $756 \mathrm{~cm}^{-1}$; HRMS (+ESI): Found $m / z 380.1891[\mathrm{M}+\mathrm{H}]^{+}, \mathrm{C}_{20} \mathrm{H}_{30} \mathrm{NO}_{4} \mathrm{~S}$ required 380.1890 .

5-Bromo-1-(dodecylsulfonyl)indoline-2,3-dione (8b)

The titled compound was synthesised from 5-bromoisatin $6 \mathbf{b}(0.35 \mathrm{~g}, 1.55 \mathrm{mmol})$, triethylamine $(0.24 \mathrm{~mL}, 1.72 \mathrm{mmol})$ and 1-dodecanesulfonyl chloride $(0.42 \mathrm{~g}, 1.58 \mathrm{mmol})$ following general synthetic procedure $\mathbf{A}$. The product was obtained as a yellow solid $(0.42 \mathrm{~g}, 60 \%) ; \mathrm{mp} 141.9^{\circ} \mathrm{C} ;{ }^{1} \mathrm{H}$ NMR $\left(400 \mathrm{MHz}, \mathrm{DMSO}-d_{6}\right): \delta 7.98-7.84(\mathrm{~m}, 2 \mathrm{H}, \mathrm{ArH}), 7.65$ $(\mathrm{d}, J=8.5 \mathrm{~Hz}, 1 \mathrm{H}, \mathrm{ArH}), 3.65-3.54\left(\mathrm{~m}, 2 \mathrm{H}, \mathrm{CH}_{2}\right), 1.85-1.68\left(\mathrm{~m}, 2 \mathrm{H}, \mathrm{CH}_{2}\right), 1.44-1.10(\mathrm{~m}$, $\left.18 \mathrm{H}, \mathrm{CH}_{2}\right), 0.92-0.78\left(\mathrm{~m}, 3 \mathrm{H}, \mathrm{CH}_{3}\right) ;{ }^{13} \mathrm{C}$ NMR $\left(100 \mathrm{MHz}, \mathrm{DMSO}-d_{6}\right): \delta 177.5(\mathrm{CO}), 156.0$ (CO), $145.7(\mathrm{ArC}), 139.6(\mathrm{ArCH}), 127.1(\mathrm{ArCH}), 121.4(\mathrm{ArC}), 117.2(\mathrm{ArC}), 116.1(\mathrm{ArCH}), 53.7$ $\left(\mathrm{CH}_{2}\right), 31.3\left(\mathrm{CH}_{2}\right), 29.0\left(\mathrm{CH}_{2}\right), 28.9\left(\mathrm{CH}_{2}\right), 28.7\left(\mathrm{CH}_{2}\right), 28.7\left(\mathrm{CH}_{2}\right), 28.4\left(\mathrm{CH}_{2}\right), 27.3\left(\mathrm{CH}_{2}\right)$, $22.0\left(\mathrm{CH}_{2}\right), 14.0\left(\mathrm{CH}_{3}\right)$; IR (ATR): $v_{\max } 3854,3675,3104,3066,2969,2913,2848,2360,1763$, 1742, 1717, 1596, 1578, 1461, 1427, 1413, 1393, 1372, 1290, 1270, 1234, 1191, 1177, 1140, 1116, 1095, 1077, 1065, 1057, 1027, 939, 898, 845, 786, 722, 707, $696 \mathrm{~cm}^{-1}$; HRMS (+ESI): Found $m / z 480.0816[\mathrm{M}+\mathrm{Na}]^{+}, \mathrm{C}_{20} \mathrm{H}_{28} \mathrm{BrNO}_{4} \mathrm{SNa}$ required 480.0815 .

\section{1-(Dodecylsulfonyl)-5-phenylindoline-2,3-dione (8c)}

The titled compound was synthesised from 5-phenylindoline-2,3-dione $6 \mathrm{c}(1.00 \mathrm{~g}$, $4.48 \mathrm{mmol})$, triethylamine $(0.70 \mathrm{~mL}, 5.02 \mathrm{mmol})$ and 1-dodecanesulfonyl chloride (1.21 g, $4.51 \mathrm{mmol}$ ) following general synthetic procedure $\mathbf{A}$. The product was obtained as a yellow solid (0.94 g, 46\%); mp 137.9-138.2 ${ }^{\circ} \mathrm{C} ;{ }^{1} \mathrm{H}$ NMR (400 MHz, DMSO- $\left.d_{6}\right): \delta 8.07(\mathrm{dd}$, $J=8.6,2.2 \mathrm{~Hz}, 1 \mathrm{H}, \mathrm{ArH}), 7.98(\mathrm{~d}, J=1.9 \mathrm{~Hz}, 1 \mathrm{H}, \mathrm{ArH}), 7.80(\mathrm{~d}, J=8.6 \mathrm{~Hz}, 1 \mathrm{H}, \mathrm{ArH})$, 7.75-7.70 (m, 2H, ArH), 7.52-7.46 (m. 2H, ArH), 7.43-7.38 (m, 1H, ArH), 3.67-3.58 (m, 2H, $\left.\mathrm{CH}_{2}\right), 1.86-1.74\left(\mathrm{~m}, 2 \mathrm{H}, \mathrm{CH}_{2}\right), 1.42-1.16\left(\mathrm{~m}, 18 \mathrm{H}, \mathrm{CH}_{2}\right), 0.84\left(\mathrm{t}, J=6.9 \mathrm{~Hz}, 3 \mathrm{H}, \mathrm{CH}_{3}\right) ;{ }^{13} \mathrm{C}$ NMR (100 MHz, DMSO- $\left.d_{6}\right): \delta 178.7$ (CO), 156.6 (CO), 146.1 (ArC), $138.0(\mathrm{ArC}), 137.0(\mathrm{ArC})$, 135.8 (ArCH), $129.1(\mathrm{ArCH}), 128.0(\mathrm{ArCH}), 126.5(\mathrm{ArCH}), 122.4(\mathrm{ArCH}), 120.1(\mathrm{ArC}), 114.6$ (ArCH), $53.7\left(\mathrm{CH}_{2}\right), 31.3\left(\mathrm{CH}_{2}\right), 29.0\left(\mathrm{CH}_{2}\right), 28.9\left(\mathrm{CH}_{2}\right), 28.7\left(\mathrm{CH}_{2}\right), 28.7\left(\mathrm{CH}_{2}\right), 28.4\left(\mathrm{CH}_{2}\right)$, $27.3\left(\mathrm{CH}_{2}\right), 22.2\left(\mathrm{CH}_{2}\right), 22.1\left(\mathrm{CH}_{2}\right), 13.9\left(\mathrm{CH}_{3}\right)$; IR (ATR): $v_{\max } 3675,2969,2914,2848,2360$, 1764, 1735, 1614, 1584, 1570, 1507, 1471, 1454, 1426, 1411, 1393, 1375, 1308, 1294, 1279, 1258, 1239, 1174, 1140, 1113, 1095, 1077, 1066, 1057, 1027, 944, 907, 852, 786, 763, 722, 704, 698, $650 \mathrm{~cm}^{-1}$; HRMS (+ESI): Found $m / z 478.2024[\mathrm{M}+\mathrm{Na}]^{+}, \mathrm{C}_{26} \mathrm{H}_{33} \mathrm{NO}_{4} \mathrm{SNa}$ required 478.2023.

\section{5-([1,1'-Biphenyl]-4-yl)-1-(dodecylsulfonyl)indoline-2,3-dione (8d)}

The titled compound was synthesised from 5-([1,1'-biphenyl]-4-yl)indoline-2,3-dione $6 \mathbf{d}(0.48 \mathrm{~g}, 1.59 \mathrm{mmol})$, triethylamine $(0.25 \mathrm{~mL}, 1.79 \mathrm{mmol})$ and 1-dodecanesulfonyl chloride $(0.43 \mathrm{~g}, 1.60 \mathrm{mmol})$ following general synthetic procedure A. After washing the crude with methanol, the precipitate was collected by vacuum filtration and the filtrate was discarded. The residue was then washed with dichloromethane $(5 \mathrm{~mL})$ and filtered. The filtrate was concentrated in vacuo to afford the product as an orange solid $(0.47 \mathrm{~g}, 56 \%) ; \mathrm{mp}$ 165.5-167.7 ${ }^{\circ} \mathrm{C} ;{ }^{1} \mathrm{H}$ NMR (600 MHz, DMSO- $\left.d_{6}\right): \delta 8.14(\mathrm{dd}, J=8.6,2.1 \mathrm{~Hz}, 1 \mathrm{H}, \mathrm{ArH}), 8.05$ $(\mathrm{d}, J=2.0 \mathrm{~Hz}, 1 \mathrm{H}, \mathrm{ArH}), 7.87-7.76(\mathrm{~m}, 5 \mathrm{H}, \mathrm{ArH}), 7.76-7.71(\mathrm{~m}, 2 \mathrm{H}, \mathrm{ArH}), 7.50(\mathrm{t}, J=7.8 \mathrm{~Hz}$, $2 \mathrm{H}, \mathrm{ArH}), 7.40(\mathrm{t}, J=7.5 \mathrm{~Hz}, 1 \mathrm{H}, \mathrm{ArH}), 3.66-3.61\left(\mathrm{~m}, 2 \mathrm{H}, \mathrm{CH}_{2}\right), 1.85-1.78\left(\mathrm{~m}, 2 \mathrm{H}, \mathrm{CH}_{2}\right)$, $1.41-1.34\left(\mathrm{~m}, 2 \mathrm{H}, \mathrm{CH}_{2}\right), 1.29-1.14\left(\mathrm{~m}, 16 \mathrm{H}, \mathrm{CH}_{2}\right), 0.83\left(\mathrm{t}, J=7.1 \mathrm{~Hz}, 3 \mathrm{H}, \mathrm{CH}_{3}\right) ;{ }^{13} \mathrm{C} \mathrm{NMR}$ 
(150 MHz, DMSO-d $d_{6}$ ): $\delta 178.7$ (CO), 156.6 (CO), 146.1 (ArC), 139.7 (ArC), 139.4 (ArC), 136.9 (ArC), $136.4(\mathrm{ArC}), 135.7(\mathrm{ArCH}), 129.0(\mathrm{ArCH}), 127.7(\mathrm{ArCH}), 127.3(\mathrm{ArCH}), 127.0(\mathrm{ArCH})$, 126.6 (ArCH), $122.3(\mathrm{ArCH}), 120.2(\mathrm{ArC}), 114.6(\mathrm{ArCH}), 53.7\left(\mathrm{CH}_{2}\right), 31.3\left(\mathrm{CH}_{2}\right), 29.0\left(\mathrm{CH}_{2}\right)$, $28.9\left(\mathrm{CH}_{2}\right), 28.7\left(\mathrm{CH}_{2}\right), 28.7\left(\mathrm{CH}_{2}\right), 28.4\left(\mathrm{CH}_{2}\right), 27.3\left(\mathrm{CH}_{2}\right), 22.2\left(\mathrm{CH}_{2}\right), 22.1\left(\mathrm{CH}_{2}\right), 13.9$ $\left(\mathrm{CH}_{3}\right)$; IR (ATR): $v_{\max } 3032,2914,2848,2679,2343,2107,1738,1613,1577,1471,1373,1289$, 1237, 1174, 1114, 1023, 943, 851, 765, 719, $693 \mathrm{~cm}^{-1}$; HRMS (+ESI): Found $\mathrm{m} / z 554.2336$ $[\mathrm{M}+\mathrm{Na}]^{+}, \mathrm{C}_{32} \mathrm{H}_{37} \mathrm{NO}_{4} \mathrm{SNa}$ required 554.2336.

1-(Hexadecylsulfonyl)indoline-2,3-dione (9a)

The titled compound was synthesised from isatin $6 \mathbf{a}(0.31 \mathrm{~g}, 2.07 \mathrm{mmol})$, triethylamine (0.32 mL, $2.30 \mathrm{mmol})$ and 1-hexadecanesulfonyl chloride $(0.68 \mathrm{~g}, 2.09 \mathrm{mmol})$ following general synthetic procedure A. The product was obtained as a yellow solid $(0.36 \mathrm{~g}, 40 \%)$; mp 122.0-123.9 ${ }^{\circ} \mathrm{C} ;{ }^{1} \mathrm{H}$ NMR $\left(400 \mathrm{MHz}, \mathrm{CDCl}_{3}\right): \delta 7.92(\mathrm{~d}, J=8.4 \mathrm{~Hz}, 1 \mathrm{H}, \mathrm{ArH}), 7.78$ $(\mathrm{dd}, J=7.6,0.9 \mathrm{~Hz}, 1 \mathrm{H}, \mathrm{ArH}), 7.74-7.68(\mathrm{~m}, 1 \mathrm{H}, \mathrm{ArH}), 7.32(\mathrm{td}, J=7.6,0.6 \mathrm{~Hz}, 1 \mathrm{H}, \mathrm{ArH})$, 3.62-3.55 (m, 2H, CH $), 1.94-1.83\left(\mathrm{~m}, 2 \mathrm{H}, \mathrm{CH}_{2}\right), 1.49-1.38\left(\mathrm{~m}, 2 \mathrm{H}, \mathrm{CH}_{2}\right), 1.34-1.18(\mathrm{~m}, 24 \mathrm{H}$, $\left.\mathrm{CH}_{2}\right), 0.87\left(\mathrm{t}, J=7.1 \mathrm{~Hz}, 3 \mathrm{H}, \mathrm{CH}_{3}\right) ;{ }^{13} \mathrm{C} \mathrm{NMR}\left(100 \mathrm{MHz} \mathrm{CDCl}_{3}\right): \delta 179.0(\mathrm{CO}), 156.7(\mathrm{CO})$, 148.1 (ArC), 139.6 (ArCH), $126.3(\mathrm{ArCH}), 126.1(\mathrm{ArCH}), 118.8(\mathrm{ArC}), 115.4(\mathrm{ArCH}), 54.9$ $\left(\mathrm{CH}_{2}\right), 32.1\left(\mathrm{CH}_{2}\right), 29.8\left(\mathrm{CH}_{2}\right), 29.8\left(\mathrm{CH}_{2}\right), 29.8\left(\mathrm{CH}_{2}\right), 29.7\left(\mathrm{CH}_{2}\right), 29.7\left(\mathrm{CH}_{2}\right), 29.5\left(\mathrm{CH}_{2}\right)$, $29.5\left(\mathrm{CH}_{2}\right), 29.3\left(\mathrm{CH}_{2}\right), 29.0\left(\mathrm{CH}_{2}\right), 28.1\left(\mathrm{CH}_{2}\right), 23.0\left(\mathrm{CH}_{2}\right), 22.8\left(\mathrm{CH}_{2}\right), 14.3\left(\mathrm{CH}_{3}\right)$; IR (ATR): $\nu_{\max } 2914,2846,2669,2343,1912,1733,1651,1596,1459,1413,1372,1320,1237,1177,1132$, 1090, 981, 934, 832, 786, 756, 723, $676 \mathrm{~cm}^{-1}$; HRMS (+ESI): Found $m / z 436.2515[\mathrm{M}+\mathrm{H}]^{+}$, $\mathrm{C}_{24} \mathrm{H}_{38} \mathrm{NO}_{4} \mathrm{~S}$ required 436.2516 .

5-Bromo-1-(hexadecylsulfonyl)indoline-2,3-dione (9b)

The titled compound was synthesised from 5-bromoisatin $6 \mathbf{b}(0.50 \mathrm{~g}, 2.19 \mathrm{mmol})$, triethylamine $(0.34 \mathrm{~mL}, 2.44 \mathrm{mmol})$ and 1-hexadecanesulfonyl chloride $(0.72 \mathrm{~g}, 2.20 \mathrm{mmol})$ following general synthetic procedure A. The product was obtained as a yellow solid $(0.65 \mathrm{~g}, 58 \%) ; \mathrm{mp} 142.4-144.0{ }^{\circ} \mathrm{C} ;{ }^{1} \mathrm{H}$ NMR (600 MHz, DMSO- $\left.d_{6}\right): \delta 7.92-7.89$ (m, 2H, ArH), 7.67-7.64 (m, 1H, ArH), 3.62-3.56 (m, 2H, CH $), 1.81-1.73\left(\mathrm{~m}, 2 \mathrm{H}, \mathrm{CH}_{2}\right), 1.39-1.31(\mathrm{~m}, 2 \mathrm{H}$, $\left.\mathrm{CH}_{2}\right), 1.30-1.16\left(\mathrm{~m}, 24 \mathrm{H}, \mathrm{CH}_{2}\right), 0.85\left(\mathrm{t}, J=7.2 \mathrm{~Hz}, 3 \mathrm{H}, \mathrm{CH}_{3}\right) ;{ }^{13} \mathrm{C} \mathrm{NMR}\left(150 \mathrm{MHz}, \mathrm{DMSO}-d_{6}\right)$ :

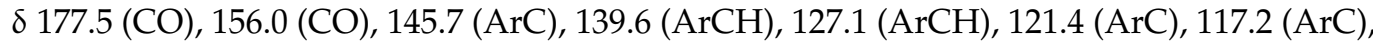
$116.2(\mathrm{ArCH}), 53.8\left(\mathrm{CH}_{2}\right), 31.3\left(\mathrm{CH}_{2}\right), 29.0\left(\mathrm{CH}_{2}\right), 29.0\left(\mathrm{CH}_{2}\right), 29.0\left(\mathrm{CH}_{2}\right), 29.0\left(\mathrm{CH}_{2}\right), 28.9$ $\left(\mathrm{CH}_{2}\right), 28.7\left(\mathrm{CH}_{2}\right), 28.7\left(\mathrm{CH}_{2}\right), 28.4\left(\mathrm{CH}_{2}\right), 27.3\left(\mathrm{CH}_{2}\right), 22.1\left(\mathrm{CH}_{2}\right), 14.0\left(\mathrm{CH}_{3}\right)$; IR $(\mathrm{ATR}): v_{\max }$ 3473, 3067, 2998, 2914, 2846, 2670, 2116, 1741, 1595, 1460, 1372, 1290, 1234, 1176, 1115, 1016 , $938,845,786,721 \mathrm{~cm}^{-1}$; HRMS (+ESI): Found $m / z 536.1433[\mathrm{M}+\mathrm{Na}]^{+}, \mathrm{C}_{24} \mathrm{H}_{36} \mathrm{BrNO}_{4} \mathrm{SNa}$ required 536.1441 .

\section{1-(Hexadecylsulfonyl)-5-phenylindoline-2,3-dione (9c)}

The titled compound was synthesised from 5-phenylindoline-2,3-dione $6 \mathrm{c}(0.81 \mathrm{~g}$, $3.61 \mathrm{mmol})$, triethylamine $(0.55 \mathrm{~mL}, 3.95 \mathrm{mmol})$ and 1-hexadecanesulfonyl chloride $(1.17 \mathrm{~g}$, $3.61 \mathrm{mmol}$ ) following general synthetic procedure $\mathbf{A}$. The product was obtained as a yellow solid (0.53 g, 28\%); mp 139.6-141.3 ${ }^{\circ} \mathrm{C} ;{ }^{1} \mathrm{H}$ NMR $\left(600 \mathrm{MHz}, \mathrm{CDCl}_{3}\right)$ : 8 8.00-7.96 (m, 2H, ArH), $7.92(\mathrm{dd}, J=8.7,1.9 \mathrm{~Hz}, 1 \mathrm{H}, \mathrm{ArH}), 7.57-7.54(\mathrm{~m}, 2 \mathrm{H}, \mathrm{ArH}), 7.50-7.46$ (m, 2H, ArH), 7.44-7.40 (m, 1H, ArH), 3.63-3.58 (m, 2H, $\left.\mathrm{CH}_{2}\right), 1.95-1.87$ (m, 2H, CH $), 1.50-1.42$ $\left(\mathrm{m}, 2 \mathrm{H}, \mathrm{CH}_{2}\right), 1.34-1.20\left(\mathrm{~m}, 24 \mathrm{H}, \mathrm{CH}_{2}\right), 0.88\left(\mathrm{t}, \mathrm{J}=7.2 \mathrm{~Hz}, 3 \mathrm{H}, \mathrm{CH}_{3}\right) ;{ }^{13} \mathrm{C} \mathrm{NMR}(150 \mathrm{MHz}$, $\left.\mathrm{CDCl}_{3}\right): \delta 179.2(\mathrm{CO}), 156.8(\mathrm{CO}), 147.1$ (ArC), 139.6 (ArC), $138.3(\mathrm{ArC}), 138.0(\mathrm{ArCH}), 129.4$ $(\mathrm{ArCH}), 128.6(\mathrm{ArCH}), 126.9(\mathrm{ArCH}), 124.4(\mathrm{ArCH}), 119.2(\mathrm{ArC}), 115.8(\mathrm{ArCH}), 55.0\left(\mathrm{CH}_{2}\right)$, $32.1\left(\mathrm{CH}_{2}\right), 29.8\left(\mathrm{CH}_{2}\right), 29.8\left(\mathrm{CH}_{2}\right), 29.8\left(\mathrm{CH}_{2}\right), 29.8\left(\mathrm{CH}_{2}\right), 29.7\left(\mathrm{CH}_{2}\right), 29.6\left(\mathrm{CH}_{2}\right), 29.5$ $\left(\mathrm{CH}_{2}\right), 29.3\left(\mathrm{CH}_{2}\right), 29.0\left(\mathrm{CH}_{2}\right), 28.2\left(\mathrm{CH}_{2}\right), 23.0\left(\mathrm{CH}_{2}\right), 22.8\left(\mathrm{CH}_{2}\right), 14.3\left(\mathrm{CH}_{3}\right)$; IR (ATR): $v_{\max }$ 3055, 2914, 2847, 2343, 1892, 1736, 1614, 1584, 1505, 1469, 1426, 1375, 1308, 1237, 1175, 1114, $1040,943,853,762,700 \mathrm{~cm}^{-1}$; HRMS (+ESI): Found $m / z 512.2812[\mathrm{M}+\mathrm{H}]^{+}, \mathrm{C}_{30} \mathrm{H}_{42} \mathrm{NO}_{4} \mathrm{~S}$ required 512.2829 .

General synthetic procedure B for glyoxamide derivatives 
3-Dimethylaminopropylamine (1.0 equivalent) was added to a stirring solution of $N$-sulfonylisatin (1.0 equivalent) in dichloromethane $(5 \mathrm{~mL})$ at $0{ }^{\circ} \mathrm{C}$. The resulting reaction mixture was stirred at room temperature for $6 \mathrm{~h}$. After the completion of the reaction, water was added to the reaction mixture, and the mixture was extracted into dichloromethane $(3 \times 25 \mathrm{~mL})$, washed with brine, dried over anhydrous sodium sulfate and concentrated in vacuo to afford the product.

N-(3-(Dimethylamino)propyl)-2-(4-(octylsulfonamido)-[1, $1^{\prime}: 4^{\prime}, 1^{\prime \prime}$-terphenyl]-3-yl)-2oxoacetamide (10d)

The titled compound was synthesised from 5-([1,1'-biphenyl]-4-yl)-1-(octylsulfonyl) indoline-2,3-dione $7 \mathbf{d}(0.10 \mathrm{~g}, 0.21 \mathrm{mmol})$ and 3-dimethylaminopropylamine (27 $\mu \mathrm{L}, 0.21 \mathrm{mmol})$ following general synthetic procedure B. The crude was purified by flash column chromatography on silica, using methanol/dichloromethane (1:9) as an eluent to afford the product as a yellow oil $(75 \mathrm{mg}, 61 \%) ;{ }^{1} \mathrm{H} \mathrm{NMR}\left(600 \mathrm{MHz}, \mathrm{CDCl}_{3}\right): \delta 8.57(\mathrm{~d}, \mathrm{~J}=2.1 \mathrm{~Hz}$, $1 \mathrm{H}, \mathrm{ArH}), 8.44(\mathrm{bs}, 1 \mathrm{H}, \mathrm{ArH}), 7.86(\mathrm{dd}, J=8.7,2.2 \mathrm{~Hz}, 1 \mathrm{H}, \mathrm{ArH}), 7.82(\mathrm{~d}, J=8.7 \mathrm{~Hz}, 1 \mathrm{H}$, ArH), 7.70-7.66 (m, 2H, ArH), 7.66-7.61 (m, 4H, ArH), 7.49-7.44 (m, 2H, ArH), 7.39-7.35 (m, 1H, ArH), 3.66-3.59 (m, 2H, $\left.\mathrm{CH}_{2}\right), 3.23-3.17\left(\mathrm{~m}, 2 \mathrm{H}, \mathrm{CH}_{2}\right), 3.12-3.04\left(\mathrm{~m}, 2 \mathrm{H}, \mathrm{CH}_{2}\right)$, $2.76\left(\mathrm{~s}, 6 \mathrm{H}, \mathrm{CH}_{3}\right), 2.19-2.11\left(\mathrm{~m}, 2 \mathrm{H}, \mathrm{CH}_{2}\right), 1.87-1.80\left(\mathrm{~m}, 2 \mathrm{H}, \mathrm{CH}_{2}\right), 1.43-1.35\left(\mathrm{~m}, 2 \mathrm{H}, \mathrm{CH}_{2}\right)$, 1.30-1.18 (m, 8H, CH $), 0.85\left(\mathrm{t}, J=7.2 \mathrm{~Hz}, 3 \mathrm{H}, \mathrm{CH}_{3}\right) ;{ }^{13} \mathrm{C} \mathrm{NMR}\left(150 \mathrm{MHz}, \mathrm{CDCl}_{3}\right): \delta 191.7$ (CO), 164.0 (CO), 140.8 (ArC), 140.5 (ArC), 137.9 (ArC), 135.7 (ArC), 134.7 (ArCH), 133.0 $(\mathrm{ArCH}), 129.0(\mathrm{ArCH}), 127.9(\mathrm{ArCH}), 127.7(\mathrm{ArCH}), 127.3(\mathrm{ArCH}), 127.2(\mathrm{ArCH}), 120.6$ (ArC), $119.3(\mathrm{ArCH}), 55.9\left(\mathrm{CH}_{2}\right), 52.9\left(\mathrm{CH}_{2}\right), 43.5\left(\mathrm{CH}_{3}\right), 36.9\left(\mathrm{CH}_{2}\right), 31.8\left(\mathrm{CH}_{2}\right), 29.1\left(\mathrm{CH}_{2}\right)$, $29.1\left(\mathrm{CH}_{2}\right), 28.3\left(\mathrm{CH}_{2}\right), 24.4\left(\mathrm{CH}_{2}\right), 23.5\left(\mathrm{CH}_{2}\right), 22.7\left(\mathrm{CH}_{2}\right), 14.2\left(\mathrm{CH}_{3}\right)$; IR (ATR): $v_{\max } 3674$, 3384, 2970, 2921, 1767, 1740, 1646, 1615, 1481, 1405, 1393, 1374, 1333, 1241, 1196, 1142, 1075, 1066, 1057, 1027, 915, 829, 765, 729, 696, $673 \mathrm{~cm}^{-1}$; HRMS (+ESI): Found $m / z 578.3074$ $[\mathrm{M}+\mathrm{H}]^{+}, \mathrm{C}_{33} \mathrm{H}_{44} \mathrm{~N}_{3} \mathrm{O}_{4} \mathrm{~S}$ required 578.3047.

N-(3-(Dimethylamino)propyl)-2-(2-(dodecylsulfonamido)phenyl)-2-oxoacetamide (11a)

The titled compound was synthesised from 1-(dodecylsulfonyl)indoline-2,3-dione $8 \mathbf{a}(0.11 \mathrm{~g}, 0.28 \mathrm{mmol})$ and 3-dimethylaminopropylamine $(36 \mu \mathrm{L}, 0.28 \mathrm{mmol})$ following general synthetic procedure B. The product was obtained as a yellow oil $(0.13 \mathrm{~g}, 98 \%) ;{ }^{1} \mathrm{H}$ NMR (400 MHz, CDCl 3 ): $\delta 8.76$ (bs, 1H, NH), 8.45 (dd, $J=8.1,1.6 \mathrm{~Hz}, 1 \mathrm{H}, \mathrm{ArH}), 7.77$ (dd, $J=8.5,0.9 \mathrm{~Hz}, 1 \mathrm{H}, \mathrm{ArH}), 7.62-7.56(\mathrm{~m}, 1 \mathrm{H}, \mathrm{ArH}), 7.18-7.11(\mathrm{~m}, 1 \mathrm{H}, \mathrm{ArH}), 3.55-3.46(\mathrm{~m}$, $\left.2 \mathrm{H}, \mathrm{CH}_{2}\right), 3.18-3.11\left(\mathrm{~m}, 2 \mathrm{H}, \mathrm{CH}_{2}\right), 2.49\left(\mathrm{t}, \mathrm{J}=6.2 \mathrm{~Hz}, 2 \mathrm{H}, \mathrm{CH}_{2}\right), 2.28\left(\mathrm{~s}, 6 \mathrm{H}, \mathrm{CH}_{3}\right), 1.85-1.71$ $\left(\mathrm{m}, 4 \mathrm{H}, \mathrm{CH}_{2}\right), 1.40-1.16\left(\mathrm{~m}, 18 \mathrm{H}, \mathrm{CH}_{2}\right), 0.87\left(\mathrm{t}, \mathrm{J}=7.1 \mathrm{~Hz}, 3 \mathrm{H}, \mathrm{CH}_{3}\right) ;{ }^{13} \mathrm{C} \mathrm{NMR}(100 \mathrm{MHz}$, $\left.\mathrm{CDCl}_{3}\right): \delta 192.1(\mathrm{CO}), 162.8(\mathrm{CO}), 142.0(\mathrm{ArC}), 136.5(\mathrm{ArCH}), 135.3(\mathrm{ArCH}), 122.6(\mathrm{ArCH})$, 119.0 (ArC), $117.9(\mathrm{ArCH}), 59.0\left(\mathrm{CH}_{2}\right), 52.6\left(\mathrm{CH}_{2}\right), 45.4\left(\mathrm{CH}_{3}\right), 40.1\left(\mathrm{CH}_{2}\right), 32.0\left(\mathrm{CH}_{2}\right), 29.7$ $\left(\mathrm{CH}_{2}\right), 29.7\left(\mathrm{CH}_{2}\right), 29.6\left(\mathrm{CH}_{2}\right), 29.5\left(\mathrm{CH}_{2}\right), 29.4\left(\mathrm{CH}_{2}\right), 29.1\left(\mathrm{CH}_{2}\right), 28.2\left(\mathrm{CH}_{2}\right), 25.3\left(\mathrm{CH}_{2}\right)$, $23.5\left(\mathrm{CH}_{2}\right), 22.8\left(\mathrm{CH}_{2}\right), 14.3\left(\mathrm{CH}_{3}\right)$; IR (ATR): $v_{\max } 3372,3068,2921,2852,2543,2341,2119$, $1635,1460,1336,1262,1144,1106,1041,941,754,719 \mathrm{~cm}^{-1}$; HRMS (+ESI): Found $\mathrm{m} / \mathrm{z}$ $482.3047[\mathrm{M}+\mathrm{H}]^{+}, \mathrm{C}_{25} \mathrm{H}_{44} \mathrm{~N}_{3} \mathrm{O}_{4} \mathrm{~S}$ required 482.3047 .

2-(5-Bromo-2-(dodecylsulfonamido)phenyl)-N-(3-(dimethylamino)propyl)-2oxoacetamide $(\mathbf{1 1 b})$

The titled compound was synthesised from 5-bromo-1-(dodecylsulfonyl)indoline2,3-dione $8 \mathrm{~b}$ (0.15 g, $0.33 \mathrm{mmol})$ and 3-dimethylaminopropylamine (41 $\mu \mathrm{L}, 0.33 \mathrm{mmol})$ following general synthetic procedure B. The product was obtained as a yellow oil $(0.18 \mathrm{~g}$, 99\%); ${ }^{1} \mathrm{H}$ NMR (400 MHz, $\left.\mathrm{CDCl}_{3}\right): \delta 8.95$ (bs, 1H, NH), 7.66-7.53 (m, 1H, ArH), 7.71-7.64 $(\mathrm{m}, 2 \mathrm{H}, \mathrm{ArH}), 3.51\left(\mathrm{t}, J=6.1 \mathrm{~Hz}, 2 \mathrm{H}, \mathrm{CH}_{2}\right), 3.16-3.08\left(\mathrm{~m}, 2 \mathrm{H}, \mathrm{CH}_{2}\right), 2.50(\mathrm{t}, J=6.1 \mathrm{~Hz}, 2 \mathrm{H}$, $\left.\mathrm{CH}_{2}\right), 2.29\left(\mathrm{~s}, 6 \mathrm{H}, \mathrm{CH}_{3}\right), 1.83-1.72\left(\mathrm{~m}, 4 \mathrm{H}, \mathrm{CH}_{2}\right), 1.41-1.17\left(\mathrm{~m}, 18 \mathrm{H}, \mathrm{CH}_{2}\right), 0.87(\mathrm{t}, J=7.0 \mathrm{~Hz}$, $\left.3 \mathrm{H}, \mathrm{CH}_{3}\right) ;{ }^{13} \mathrm{C} \mathrm{NMR}\left(100 \mathrm{MHz}, \mathrm{CDCl}_{3}\right)$ : $\delta 190.8$ (CO), $162.0(\mathrm{CO}), 140.9$ (ArC), $139.1(\mathrm{ArCH})$, $137.5(\mathrm{ArCH}), 120.7(\mathrm{ArC}), 119.9(\mathrm{ArCH}), 115.3(\mathrm{ArC}), 59.1\left(\mathrm{CH}_{2}\right), 52.8\left(\mathrm{CH}_{2}\right), 45.4\left(\mathrm{CH}_{3}\right)$, $40.3\left(\mathrm{CH}_{2}\right), 32.0\left(\mathrm{CH}_{2}\right), 29.7\left(\mathrm{CH}_{2}\right), 29.7\left(\mathrm{CH}_{2}\right), 29.6\left(\mathrm{CH}_{2}\right), 29.5\left(\mathrm{CH}_{2}\right), 29.4\left(\mathrm{CH}_{2}\right), 29.1$ $\left(\mathrm{CH}_{2}\right), 28.2\left(\mathrm{CH}_{2}\right), 25.1\left(\mathrm{CH}_{2}\right), 23.5\left(\mathrm{CH}_{2}\right), 22.8\left(\mathrm{CH}_{2}\right), 14.3\left(\mathrm{CH}_{3}\right)$; IR (ATR): $v_{\max } 3674,2970$, 
2921, 2361, 1653, 1464, 1405, 1393, 1334, 1259, 1270, 1148, 1075, 1066, 1027, 891, 800, 719, 653 $\mathrm{cm}^{-1}$; HRMS (+ESI): Found $m / z 560.2153[\mathrm{M}+\mathrm{H}]^{+}, \mathrm{C}_{25} \mathrm{H}_{43} \mathrm{BrN}_{3} \mathrm{O}_{4} \mathrm{~S}$ required 560.2152.

N-(3-(Dimethylamino)propyl)-2-(4-(dodecylsulfonamido)-[1,1'-biphenyl]-3-yl)-2oxoacetamide (11c)

The titled compound was synthesised from 1-(dodecylsulfonyl)-5-phenylindoline2,3-dione $8 \mathrm{c}(0.13 \mathrm{~g}, 0.28 \mathrm{mmol})$ and 3-dimethylaminopropylamine (35 $\mu \mathrm{L}, 0.28 \mathrm{mmol})$ following general synthetic procedure $B$. The product was obtained as a yellow oil $(0.16 \mathrm{~g}$, 99\%); ${ }^{1} \mathrm{H}$ NMR (400 MHz, $\mathrm{CDCl}_{3}$ ): $\delta 8.82$ (bs, 1H, NH), 8.76-8.71 (m, 1H, ArH), 7.88-7.79 (m, 2H, ArH), 7.61-7.54 (m, 2H, ArH), 7.47-7.41 (m, 2H, ArH), 7.39-7.33 (m, 1H, ArH), $3.53\left(\mathrm{t}, J=6.0 \mathrm{~Hz}, 2 \mathrm{H}, \mathrm{CH}_{2}\right), 3.22-3.14\left(\mathrm{~m}, 2 \mathrm{H}, \mathrm{CH}_{2}\right), 2.50\left(\mathrm{t}, J=6.1 \mathrm{~Hz}, 2 \mathrm{H}, \mathrm{CH}_{2}\right), 2.29$ (s, $\left.6 \mathrm{H}, \mathrm{CH}_{3}\right), 1.87-1.73\left(\mathrm{~m}, 4 \mathrm{H}, \mathrm{CH}_{2}\right), 1.44-1.16\left(\mathrm{~m}, 18 \mathrm{H}, \mathrm{CH}_{2}\right), 0.87\left(\mathrm{t}, J=7.1 \mathrm{~Hz}, 3 \mathrm{H}, \mathrm{CH}_{3}\right)$; ${ }^{13} \mathrm{C}$ NMR (100 MHz, $\left.\mathrm{CDCl}_{3}\right)$ : $\delta 192.0$ (CO), 162.7 (CO), 140.9 (ArC), 139.1 (ArC), 135.7 (ArC), $134.9(\mathrm{ArCH}), 133.7(\mathrm{ArCH}), 129.1(\mathrm{ArCH}), 127.9(\mathrm{ArCH}), 127.0(\mathrm{ArCH}), 119.6(\mathrm{ArC})$, $118.5(\mathrm{ArCH}), 58.9\left(\mathrm{CH}_{2}\right), 52.7\left(\mathrm{CH}_{2}\right), 45.4\left(\mathrm{CH}_{3}\right), 40.1\left(\mathrm{CH}_{2}\right), 32.0\left(\mathrm{CH}_{2}\right), 29.7\left(\mathrm{CH}_{2}\right), 29.7$ $\left(\mathrm{CH}_{2}\right), 29.6\left(\mathrm{CH}_{2}\right), 29.4\left(\mathrm{CH}_{2}\right), 29.4\left(\mathrm{CH}_{2}\right), 29.1\left(\mathrm{CH}_{2}\right), 28.2\left(\mathrm{CH}_{2}\right), 25.3\left(\mathrm{CH}_{2}\right), 23.5\left(\mathrm{CH}_{2}\right)$, $22.8\left(\mathrm{CH}_{2}\right), 14.2\left(\mathrm{CH}_{3}\right)$; IR (ATR): $v_{\max } 3675,3344,2970,2920,2853,2759,2362,1661,1632$, 1582, 1511, 1487, 1466, 1394, 1344, 1261, 1225, 1201, 1140, 1076, 1066, 1056, 928, 893, 857, $801,761,722,697,684 \mathrm{~cm}^{-1}$; HRMS (+ESI): Found $m / z 558.3361[\mathrm{M}+\mathrm{H}]^{+}, \mathrm{C}_{31} \mathrm{H}_{48} \mathrm{~N}_{3} \mathrm{O}_{4} \mathrm{~S}$ required 558.3360 .

N-(3-(Dimethylamino)propyl)-2-(4-(dodecylsulfonamido)-[1, $1^{\prime}: 4^{\prime}, 1^{\prime \prime}$-terphenyl]-3-yl)-2oxoacetamide (11d)

The titled compound was synthesised from 5-([1,1'-biphenyl]-4-yl)-1-(dodecylsulfonyl) indoline-2,3-dione $\mathbf{8 d}(0.17 \mathrm{~g}, 0.31 \mathrm{mmol})$ and 3-dimethylaminopropylamine $(40 \mu \mathrm{L}$, $0.31 \mathrm{mmol}$ ) following general synthetic procedure $\mathbf{B}$. The crude was purified by flash column chromatography on silica, using methanol/dichloromethane (1:9) as an eluent to afford the product as a yellow oil $(0.11 \mathrm{~g}, 53 \%) ;{ }^{1} \mathrm{H} \mathrm{NMR}\left(400 \mathrm{MHz}, \mathrm{CDCl}_{3}\right): \delta 8.64(\mathrm{~d}$, $J=1.9 \mathrm{~Hz}, 1 \mathrm{H}, \mathrm{ArH}), 8.53$ (bs, 1H, NH), 7.88-7.76 (m, 2H, ArH), 7.70-7.55 (m, 6H, ArH), 7.49-7.42 (m, 2H, ArH), 7.40-7.34 (m, 1H, ArH), 3.64-3.53 (m, 2H, CH2), 3.22-3.14 (m, 2H, $\left.\mathrm{CH}_{2}\right), 2.96-2.85\left(\mathrm{~m}, 2 \mathrm{H}, \mathrm{CH}_{2}\right), 2.62\left(\mathrm{~s}, 6 \mathrm{H}, \mathrm{CH}_{3}\right), 2.09-1.97\left(\mathrm{~m}, 2 \mathrm{H}, \mathrm{CH}_{2}\right), 1.87-1.77(\mathrm{~m}, 2 \mathrm{H}$, $\left.\mathrm{CH}_{2}\right), 1.43-1.15\left(\mathrm{~m}, 18 \mathrm{H}, \mathrm{CH}_{2}\right), 0.87\left(\mathrm{t}, J=7.1 \mathrm{~Hz}, 3 \mathrm{H}, \mathrm{CH}_{3}\right) ;{ }^{13} \mathrm{C} \mathrm{NMR}\left(100 \mathrm{MHz}, \mathrm{CDCl}_{3}\right): \delta$ 191.8 (CO), 163.6 (CO), 140.8 (ArC), 140.6 (ArC), 140.6 (ArC), 137.9 (ArC), 135.5 (ArC), 134.7 $(\mathrm{ArCH}), 133.1(\mathrm{ArCH}), 129.0(\mathrm{ArCH}), 127.8(\mathrm{ArCH}), 127.7(\mathrm{ArCH}), 127.3(\mathrm{ArCH}), 127.2$ $(\mathrm{ArCH}), 120.5(\mathrm{ArC}), 119.2(\mathrm{ArCH}), 58.3\left(\mathrm{CH}_{2}\right), 52.8\left(\mathrm{CH}_{2}\right), 44.1\left(\mathrm{CH}_{3}\right), 39.4\left(\mathrm{CH}_{2}\right), 32.0$ $\left(\mathrm{CH}_{2}\right), 29.7\left(\mathrm{CH}_{2}\right), 29.7\left(\mathrm{CH}_{2}\right), 29.6\left(\mathrm{CH}_{2}\right), 29.6\left(\mathrm{CH}_{2}\right), 29.5\left(\mathrm{CH}_{2}\right), 29.4\left(\mathrm{CH}_{2}\right), 29.1\left(\mathrm{CH}_{2}\right)$, $28.3\left(\mathrm{CH}_{2}\right), 24.7\left(\mathrm{CH}_{2}\right), 23.5\left(\mathrm{CH}_{2}\right), 22.8\left(\mathrm{CH}_{2}\right), 14.3\left(\mathrm{CH}_{3}\right)$; IR (ATR): $v_{\max } 3341,3190,3030$, 2921, 2851, 2527, 2342, 2111, 1911, 1610, 1481, 1390, 1333, 1276, 1196, 1141, 994, 919, 826, 764, $696 \mathrm{~cm}^{-1}$; HRMS (+ESI): Found $m / z 634.3673[\mathrm{M}+\mathrm{H}]^{+}, \mathrm{C}_{37} \mathrm{H}_{52} \mathrm{~N}_{3} \mathrm{O}_{4} \mathrm{~S}$ required 634.3673.

N-(3-(Dimethylamino)propyl)-2-(2-(hexadecylsulfonamido)phenyl)-2-oxoacetamide (12a)

The titled compound was synthesised from 1-(hexadecylsulfonyl)indoline-2,3-dione 9a $(0.13 \mathrm{~g}, 0.29 \mathrm{mmol})$ and 3-dimethylaminopropylamine $(36 \mu \mathrm{L}, 0.29 \mathrm{mmol})$ following general synthetic procedure $\mathbf{B}$. The product was obtained as a yellow sticky solid $(0.15 \mathrm{~g}$, $96 \%) ;{ }^{1} \mathrm{H}$ NMR $\left(400 \mathrm{MHz}, \mathrm{CDCl}_{3}\right): \delta 8.74(\mathrm{bs}, 1 \mathrm{H}, \mathrm{NH}), 8.45$ (dd, $\left.J=8.1,1.5 \mathrm{~Hz}, 1 \mathrm{H}, \mathrm{ArH}\right)$, $7.77(\mathrm{dd}, J=8.5,0.5 \mathrm{~Hz}, 1 \mathrm{H}, \mathrm{ArH}), 7.62-7.56(\mathrm{~m}, 1 \mathrm{H}, \mathrm{ArH}), 7.18-7.10(\mathrm{~m}, 1 \mathrm{H}, \mathrm{ArH}), 3.51$ $\left(\mathrm{t}, J=5.9 \mathrm{~Hz}, 2 \mathrm{H}, \mathrm{CH}_{2}\right), 3.17-3.11\left(\mathrm{~m}, 2 \mathrm{H}, \mathrm{CH}_{2}\right), 2.48\left(\mathrm{t}, J=6.2 \mathrm{~Hz}, 2 \mathrm{H}, \mathrm{CH}_{2}\right), 2.27(\mathrm{~s}, 6 \mathrm{H}$, $\left.\mathrm{CH}_{3}\right), 1.83-1.71\left(\mathrm{~m}, 4 \mathrm{H}, \mathrm{CH}_{2}\right), 1.40-1.16\left(\mathrm{~m}, 26 \mathrm{H}, \mathrm{CH}_{2}\right), 0.87\left(\mathrm{t}, J=7.0 \mathrm{~Hz}, 3 \mathrm{H}, \mathrm{CH}_{3}\right) ;{ }^{13} \mathrm{C}$ NMR (100 MHz, $\left.\mathrm{CDCl}_{3}\right)$ : $\delta 192.1$ (CO), $162.8(\mathrm{CO}), 142.0(\mathrm{ArC}), 136.5(\mathrm{ArCH}), 135.3(\mathrm{ArCH})$, 122.6 (ArCH), $119.0(\mathrm{ArC}), 117.9(\mathrm{ArCH}), 58.9\left(\mathrm{CH}_{2}\right), 52.6\left(\mathrm{CH}_{2}\right), 45.4\left(\mathrm{CH}_{3}\right), 40.0\left(\mathrm{CH}_{2}\right)$, $32.0\left(\mathrm{CH}_{2}\right), 29.8\left(\mathrm{CH}_{2}\right), 29.8\left(\mathrm{CH}_{2}\right), 29.7\left(\mathrm{CH}_{2}\right), 29.6\left(\mathrm{CH}_{2}\right), 29.5\left(\mathrm{CH}_{2}\right), 29.4\left(\mathrm{CH}_{2}\right), 29.1$ $\left(\mathrm{CH}_{2}\right), 28.2\left(\mathrm{CH}_{2}\right), 25.3\left(\mathrm{CH}_{2}\right), 23.5\left(\mathrm{CH}_{2}\right), 22.8\left(\mathrm{CH}_{2}\right), 14.3\left(\mathrm{CH}_{3}\right)$; IR (ATR): $v_{\max } 3351$, $3229,3057,2920,2851,2781,2533,2119,1633,1527,1463,1401,1337,1262,1232,1147,1100$, 
$1042,984,918,755,673 \mathrm{~cm}^{-1}$; HRMS (+ESI): Found $m / z 538.3672[\mathrm{M}+\mathrm{H}]^{+}, \mathrm{C}_{29} \mathrm{H}_{52} \mathrm{~N}_{3} \mathrm{O}_{4} \mathrm{~S}$ required 538.3673 .

2-(5-Bromo-2-(hexadecylsulfonamido)phenyl)-N-(3-(dimethylamino)propyl)-2oxoacetamide $(\mathbf{1 2 b})$

The titled compound was synthesised from 5-bromo-1-(hexadecylsulfonyl)indoline2,3-dione $9 \mathrm{~b}(0.15 \mathrm{~g}, 0.30 \mathrm{mmol})$ and 3-dimethylaminopropylamine (38 $\mu \mathrm{L}, 0.30 \mathrm{mmol})$ following general synthetic procedure $\mathbf{B}$. The product was obtained as a yellow oil $(0.18 \mathrm{~g}$, 98\%); ${ }^{1} \mathrm{H}$ NMR (400 MHz, $\mathrm{CDCl}_{3}$ ): $\delta 8.94$ (bs, 1H, NH), 7.64-7.63 (m, 1H, ArH), 7.69-7.66 $(\mathrm{m}, 2 \mathrm{H}, \mathrm{ArH}), 3.52\left(\mathrm{t}, J=6.2 \mathrm{~Hz}, 2 \mathrm{H}, \mathrm{CH}_{2}\right), 3.16-3.08\left(\mathrm{~m}, 2 \mathrm{H}, \mathrm{CH}_{2}\right), 2.52(\mathrm{t}, J=6.1 \mathrm{~Hz}, 2 \mathrm{H}$, $\left.\mathrm{CH}_{2}\right), 2.30\left(\mathrm{~s}, 6 \mathrm{H}, \mathrm{CH}_{3}\right), 1.82-1.71\left(\mathrm{~m}, 4 \mathrm{H}, \mathrm{CH}_{2}\right), 1.42-1.17\left(\mathrm{~m}, 26 \mathrm{H}, \mathrm{CH}_{2}\right), 0.87(\mathrm{t}, \mathrm{J}=7.0 \mathrm{~Hz}$, $\left.3 \mathrm{H}, \mathrm{CH}_{3}\right) ;{ }^{13} \mathrm{C} \mathrm{NMR}\left(100 \mathrm{MHz}, \mathrm{CDCl}_{3}\right): \delta 190.8$ (CO), 162.1 (CO), 140.8 (ArC), $139.1(\mathrm{ArCH})$, 137.4 (ArCH), $120.8(\mathrm{ArC}), 119.9(\mathrm{ArCH}), 115.3(\mathrm{ArC}), 58.9\left(\mathrm{CH}_{2}\right), 52.8\left(\mathrm{CH}_{2}\right), 45.3\left(\mathrm{CH}_{3}\right)$, $40.2\left(\mathrm{CH}_{2}\right), 32.1\left(\mathrm{CH}_{2}\right), 29.8\left(\mathrm{CH}_{2}\right), 29.8\left(\mathrm{CH}_{2}\right), 29.8\left(\mathrm{CH}_{2}\right), 29.8\left(\mathrm{CH}_{2}\right), 29.8\left(\mathrm{CH}_{2}\right), 29.7$ $\left(\mathrm{CH}_{2}\right), 29.6\left(\mathrm{CH}_{2}\right), 29.5\left(\mathrm{CH}_{2}\right), 29.4\left(\mathrm{CH}_{2}\right), 29.1\left(\mathrm{CH}_{2}\right), 28.2\left(\mathrm{CH}_{2}\right), 25.1\left(\mathrm{CH}_{2}\right), 23.5\left(\mathrm{CH}_{2}\right)$, $22.8\left(\mathrm{CH}_{2}\right), 14.3\left(\mathrm{CH}_{3}\right)$; IR (ATR): $v_{\max } 2922,2852,2361,1682,1575,1465,1334,1285,1148$, $1100,972,868,823,720 \mathrm{~cm}^{-1}$; HRMS (+ESI): Found $m / z 616.2779[\mathrm{M}+\mathrm{H}]^{+}, \mathrm{C}_{29} \mathrm{H}_{51} \mathrm{BrN}_{3} \mathrm{O}_{4} \mathrm{~S}$ required 616.2778 .

N-(3-(Dimethylamino)propyl)-2-(4-(hexadecylsulfonamido)-[1,1'-biphenyl]-3-yl)-2oxoacetamide $(\mathbf{1 2 c})$

The titled compound was synthesised from 1-(hexadecylsulfonyl)-5-phenylindoline2,3-dione 9c (0.11 g, $0.21 \mathrm{mmol})$ and 3-dimethylaminopropylamine (26 $\mu \mathrm{L}, 0.21 \mathrm{mmol})$ following general synthetic procedure $\mathbf{B}$. The product was obtained as a yellow solid (0.12 g, 96\%); mp 76.7-79.4 ${ }^{\circ} \mathrm{C} ;{ }^{1} \mathrm{H}$ NMR (400 MHz, $\left.\mathrm{CDCl}_{3}\right): \delta 8.74(\mathrm{bs}, 1 \mathrm{H}, \mathrm{NH}), 8.71(\mathrm{~d}$, $J=1.7 \mathrm{~Hz}, 1 \mathrm{H}, \mathrm{ArH}), 7.87-7.79$ (m, 2H, ArH), 7.60-7.55 (m, 2H, ArH), 7.48-7.41 (m, 2H, $\mathrm{ArH}), 7.39-7.33(\mathrm{~m}, 1 \mathrm{H}, \mathrm{ArH}), 3.54\left(\mathrm{t}, J=5.6 \mathrm{~Hz}, 2 \mathrm{H}, \mathrm{CH}_{2}\right), 3.21-3.14\left(\mathrm{~m}, 2 \mathrm{H}, \mathrm{CH}_{2}\right), 2.59$ (t, $\left.J=6.1 \mathrm{~Hz}, 2 \mathrm{H}, \mathrm{CH}_{2}\right), 2.36\left(\mathrm{~s}, 6 \mathrm{H}, \mathrm{CH}_{3}\right), 1.89-1.75\left(\mathrm{~m}, 4 \mathrm{H}, \mathrm{CH}_{2}\right), 1.42-1.17\left(\mathrm{~m}, 26 \mathrm{H}, \mathrm{CH}_{2}\right)$, $0.87\left(\mathrm{t}, J=7.0 \mathrm{~Hz}, 3 \mathrm{H}, \mathrm{CH}_{3}\right) ;{ }^{13} \mathrm{C} \mathrm{NMR}\left(100 \mathrm{MHz}, \mathrm{CDCl}_{3}\right): \delta 191.9(\mathrm{CO}), 162.9(\mathrm{CO}), 140.9$ (ArC), $139.1(\mathrm{ArC}), 135.8(\mathrm{ArC}), 134.9(\mathrm{ArCH}), 133.6(\mathrm{ArCH}), 129.1(\mathrm{ArCH}), 127.9(\mathrm{ArCH})$, 127.0 (ArCH), $119.7(\mathrm{ArC}), 118.6(\mathrm{ArCH}), 58.4\left(\mathrm{CH}_{2}\right), 52.7\left(\mathrm{CH}_{2}\right), 45.1\left(\mathrm{CH}_{3}\right), 39.6\left(\mathrm{CH}_{2}\right)$, $32.1\left(\mathrm{CH}_{2}\right), 29.8\left(\mathrm{CH}_{2}\right), 29.8\left(\mathrm{CH}_{2}\right), 29.8\left(\mathrm{CH}_{2}\right), 29.8\left(\mathrm{CH}_{2}\right), 29.7\left(\mathrm{CH}_{2}\right), 29.6\left(\mathrm{CH}_{2}\right), 29.5$ $\left(\mathrm{CH}_{2}\right), 29.4\left(\mathrm{CH}_{2}\right), 29.1\left(\mathrm{CH}_{2}\right), 28.3\left(\mathrm{CH}_{2}\right), 25.2\left(\mathrm{CH}_{2}\right), 23.5\left(\mathrm{CH}_{2}\right), 22.8\left(\mathrm{CH}_{2}\right), 14.3\left(\mathrm{CH}_{3}\right)$; IR (ATR): $v_{\max } 3346,3181,2918,2850,2758,2342,1631,1581,1511,1486,1395,1344,1264$, 1200, 1138, 1098, 1034, 925, 892, 855, 822, 761, $684 \mathrm{~cm}^{-1}$; HRMS (+ESI): Found $\mathrm{m} / z 614.3986$ $[\mathrm{M}+\mathrm{H}]^{+}, \mathrm{C}_{35} \mathrm{H}_{56} \mathrm{~N}_{3} \mathrm{O}_{4} \mathrm{~S}$ required 614.3986 .

General synthetic procedure $\mathrm{C}$ for tertiary ammonium chloride salts

$4 \mathrm{M} \mathrm{HCl}$ in dioxane (5.0 equivalents) was added to a stirring solution of glyoxamide derivative (1.0 equivalent) in diethyl ether $(5 \mathrm{~mL})$. The resulting reaction mixture was stirred at room temperature for $20 \mathrm{~min}$. After the completion of the reaction, the reaction solvent was removed under reduced pressure, and the residue was washed three times with diethyl ether and freeze-dried to afford the product.

N,N-Dimethyl-3-(2-(4-(octylsulfonamido)-[1,1' $: 4^{\prime}, 1^{\prime \prime}$-terphenyl]-3-yl)-2oxoacetamido)propan-1-aminium chloride (13d)

The titled compound was synthesised from N-(3-(dimethylamino)propyl)-2-(4(octylsulfonamido)-[1, $1^{\prime}: 4^{\prime}, 1^{\prime \prime}$-terphenyl]-3-yl)-2-oxoacetamide 10d (24 mg, $\left.0.042 \mathrm{mmol}\right)$ and $4 \mathrm{M} \mathrm{HCl}$ /dioxane $(58 \mu \mathrm{L}, 0.23 \mathrm{mmol})$ following general synthetic procedure $\mathrm{C}$. The product was obtained as a yellow sticky solid $(22 \mathrm{mg}, 88 \%) ;{ }^{1} \mathrm{H}$ NMR $\left(600 \mathrm{MHz}, \mathrm{DMSO}-d_{6}\right)$ : $\delta 10.28$ (bs, 2H, NH), $9.04(\mathrm{t}, J=6.0 \mathrm{~Hz}, 1 \mathrm{H}, \mathrm{NH}), 8.09-8.03(\mathrm{~m}, 2 \mathrm{H}, \mathrm{ArH}), 7.83-7.79(\mathrm{~m}, 2 \mathrm{H}$, ArH), 7.78-7.75 (m, 2H, ArH), 7.75-7.71 (m, 2H, ArH), 7.66-7.61 (m, 1H, ArH), 7.52-7.47 (m, 2H, ArH), 7.42-7.37 (m, 1H, ArH), 3.26-3.21 (m, 2H, $\left.\mathrm{CH}_{2}\right), 3.13-3.08\left(\mathrm{~m}, 2 \mathrm{H}, \mathrm{CH}_{2}\right), 2.74$ (s, $\left.6 \mathrm{H}, \mathrm{CH}_{3}\right), 3.12-3.04\left(\mathrm{~m}, 2 \mathrm{H}, \mathrm{CH}_{2}\right), 1.99-1.91\left(\mathrm{~m}, 2 \mathrm{H}, \mathrm{CH}_{2}\right), 1.72-1.64\left(\mathrm{~m}, 2 \mathrm{H}, \mathrm{CH}_{2}\right), 1.37-1.30$ $\left(\mathrm{m}, 2 \mathrm{H}, \mathrm{CH}_{2}\right), 1.27-1.15\left(\mathrm{~m}, 8 \mathrm{H}, \mathrm{CH}_{2}\right), 0.83\left(\mathrm{t}, \mathrm{J}=7.2 \mathrm{~Hz}, 3 \mathrm{H}, \mathrm{CH}_{3}\right) ;{ }^{13} \mathrm{C} \mathrm{NMR}(150 \mathrm{MHz}$, 
DMSO- $\left.d_{6}\right): \delta 192.1(\mathrm{CO}), 163.7$ (CO), 139.6 (ArC), $139.4(\mathrm{ArC}), 138.0(\mathrm{ArC}), 137.2(\mathrm{ArC})$, $135.3(\mathrm{ArC}), 132.7(\mathrm{ArCH}), 130.1(\mathrm{ArCH}), 129.0(\mathrm{ArCH}), 127.7(\mathrm{ArCH}), 127.4(\mathrm{ArCH}), 127.0$ $(\mathrm{ArCH}), 126.6(\mathrm{ArCH}), 125.8(\mathrm{ArC}), 122.4(\mathrm{ArCH}), 54.5\left(\mathrm{CH}_{2}\right), 51.4\left(\mathrm{CH}_{2}\right), 42.1\left(\mathrm{CH}_{3}\right), 36.0$ $\left(\mathrm{CH}_{2}\right), 31.1\left(\mathrm{CH}_{2}\right), 28.4\left(\mathrm{CH}_{2}\right), 28.3\left(\mathrm{CH}_{2}\right), 28.3\left(\mathrm{CH}_{2}\right), 23.9\left(\mathrm{CH}_{2}\right), 22.9\left(\mathrm{CH}_{2}\right), 22.0\left(\mathrm{CH}_{2}\right)$, $13.9\left(\mathrm{CH}_{3}\right)$; IR (ATR): $v_{\max } 3366,3030,2925,2854,2697,2360,1647,1527,1481,1395,1332$, 1272, 1196, 1142, 1076, 1006, 975, 917, 828, 764, 728, 696, $673 \mathrm{~cm}^{-1}$; HRMS (+ESI): Found $m / z 578.3049[\mathrm{M}+\mathrm{H}]^{+}, \mathrm{C}_{33} \mathrm{H}_{44} \mathrm{~N}_{3} \mathrm{O}_{4} \mathrm{~S}$ required 578.3047.

3-(2-(2-(Dodecylsulfonamido)phenyl)-2-oxoacetamido)- $N, N$-dimethylpropan-1-aminium chloride (14a)

The titled compound was synthesised from N-(3-(dimethylamino)propyl)-2-(2(dodecylsulfonamido) phenyl)-2-oxoacetamide 11a (30 mg, $0.062 \mathrm{mmol}$ ) and $4 \mathrm{M} \mathrm{HCl} /$ dioxane $(0.10 \mathrm{~mL}, 0.40 \mathrm{mmol})$ following general synthetic procedure $\mathrm{C}$. The product was obtained as a pale yellow sticky solid $(25 \mathrm{mg}, 76 \%) ;{ }^{1} \mathrm{H}$ NMR $\left(600 \mathrm{MHz}, \mathrm{DMSO}-d_{6}\right): \delta 10.23$ (bs, 2H, NH), 8.99 (t, J = 5.9 Hz, 1H, NH), 7.78 (dd, J = 7.8, 1.5 Hz, 1H, ArH), 7.72-7.68 (m, $1 \mathrm{H}, \mathrm{ArH}), 7.53(\mathrm{~d}, J=8.2 \mathrm{~Hz}, 1 \mathrm{H}, \mathrm{ArH}), 7.33-7.30(\mathrm{~m}, 1 \mathrm{H}, \mathrm{ArH}), 3.30(\mathrm{q}, J=6.5 \mathrm{~Hz}, 2 \mathrm{H}$, $\left.\mathrm{CH}_{2}\right), 3.23-3.19\left(\mathrm{~m}, 2 \mathrm{H}, \mathrm{CH}_{2}\right), 3.11-3.06\left(\mathrm{~m}, 2 \mathrm{H}, \mathrm{CH}_{2}\right), 2.74\left(\mathrm{~s}, 6 \mathrm{H}, \mathrm{CH}_{3}\right), 1.96-1.89(\mathrm{~m}, 2 \mathrm{H}$, $\left.\mathrm{CH}_{2}\right), 1.68-1.60\left(\mathrm{~m}, 2 \mathrm{H}, \mathrm{CH}_{2}\right), 1.35-1.15\left(\mathrm{~m}, 18 \mathrm{H}, \mathrm{CH}_{2}\right), 0.85\left(\mathrm{t}, J=7.1 \mathrm{~Hz}, 3 \mathrm{H}, \mathrm{CH}_{3}\right) ;{ }^{13} \mathrm{C}$ NMR (150 MHz, DMSO-d $\left.d_{6}\right)$ : $\delta 192.9$ (CO), 164.2 (CO), 139.1 (ArC), 135.3 (ArCH), 132.9 $(\mathrm{ArCH}), 124.1(\mathrm{ArCH}), 124.0(\mathrm{ArC}), 121.0(\mathrm{ArCH}), 54.5\left(\mathrm{CH}_{2}\right), 51.3\left(\mathrm{CH}_{2}\right), 42.1\left(\mathrm{CH}_{3}\right), 35.9$ $\left(\mathrm{CH}_{2}\right), 31.3\left(\mathrm{CH}_{2}\right), 29.0\left(\mathrm{CH}_{2}\right), 28.9\left(\mathrm{CH}_{2}\right), 28.7\left(\mathrm{CH}_{2}\right), 28.7\left(\mathrm{CH}_{2}\right), 28.4\left(\mathrm{CH}_{2}\right), 27.2\left(\mathrm{CH}_{2}\right)$, $23.9\left(\mathrm{CH}_{2}\right), 22.9\left(\mathrm{CH}_{2}\right), 22.1\left(\mathrm{CH}_{2}\right), 14.0\left(\mathrm{CH}_{3}\right)$; IR (ATR): $v_{\max } 3380,3260,3082,2917,2851$, 2689, 2093, 1663, 1527, 1456, 1420, 1328, 1263, 1217, 1143, 1065, 989, 925, 869, 798, $774 \mathrm{~cm}^{-1}$; HRMS (+ESI): Found $m / z 482.3046[\mathrm{M}+\mathrm{H}]^{+}, \mathrm{C}_{25} \mathrm{H}_{44} \mathrm{~N}_{3} \mathrm{O}_{4} \mathrm{~S}$ required 482.3047.

3-(2-(5-Bromo-2-(dodecylsulfonamido)phenyl)-2-oxoacetamido)- $N, N$-dimethylpropan-1aminium chloride $(\mathbf{1 4 b})$

The titled compound was synthesised from 2-(5-bromo-2-(dodecylsulfonamido)phenyl)$\mathrm{N}$-(3-(dimethylamino)propyl)-2-oxoacetamide $\mathbf{1 1 b}(30 \mathrm{mg}, 0.054 \mathrm{mmol})$ and $4 \mathrm{M} \mathrm{HCl} /$ dioxane $(0.10 \mathrm{~mL}, 0.40 \mathrm{mmol})$ following general synthetic procedure $\mathrm{C}$. The product was obtained as a yellow sticky solid $(22 \mathrm{mg}, 67 \%) ;{ }^{1} \mathrm{H}$ NMR $\left(600 \mathrm{MHz}, \mathrm{DMSO}-d_{6}\right): \delta 10.10$ (bs, 2H, NH), $8.96(\mathrm{t}, J=6.0 \mathrm{~Hz}, 1 \mathrm{H}, \mathrm{NH}), 7.88-7.83(\mathrm{~m}, 2 \mathrm{H}, \mathrm{ArH}), 7.43(\mathrm{~d}, J=8.6 \mathrm{~Hz}, 1 \mathrm{H}$, $\mathrm{ArH}), 3.29$ (q, $\left.J=6.4 \mathrm{~Hz}, 2 \mathrm{H}, \mathrm{CH}_{2}\right), 3.17-3.05\left(\mathrm{~m}, 4 \mathrm{H}, \mathrm{CH}_{2}\right), 2.74\left(\mathrm{~s}, 6 \mathrm{H}, \mathrm{CH}_{3}\right), 1.94-1.88(\mathrm{~m}$, $\left.2 \mathrm{H}, \mathrm{CH}_{2}\right), 1.66-1.59\left(\mathrm{~m}, 2 \mathrm{H}, \mathrm{CH}_{2}\right), 1.34-1.16\left(\mathrm{~m}, 18 \mathrm{H}, \mathrm{CH}_{2}\right), 0.85\left(\mathrm{t}, J=7.1 \mathrm{~Hz}, 3 \mathrm{H}, \mathrm{CH}_{3}\right)$; ${ }^{13} \mathrm{C}$ NMR (150 MHz, DMSO- $\left.d_{6}\right): \delta 190.0$ (CO), 162.9 (CO), 137.2 (ArC), 136.8 (ArCH), 133.9 $(\mathrm{ArCH}), 129.1$ (ArC), $124.9(\mathrm{ArCH}), 116.7(\mathrm{ArC}), 54.5\left(\mathrm{CH}_{2}\right), 51.3\left(\mathrm{CH}_{2}\right), 42.1\left(\mathrm{CH}_{3}\right), 36.0$ $\left(\mathrm{CH}_{2}\right), 31.3\left(\mathrm{CH}_{2}\right), 29.0\left(\mathrm{CH}_{2}\right), 28.9\left(\mathrm{CH}_{2}\right), 28.7\left(\mathrm{CH}_{2}\right), 28.7\left(\mathrm{CH}_{2}\right), 28.4\left(\mathrm{CH}_{2}\right), 27.3\left(\mathrm{CH}_{2}\right)$, $23.8\left(\mathrm{CH}_{2}\right), 22.8\left(\mathrm{CH}_{2}\right), 22.1\left(\mathrm{CH}_{2}\right), 14.0\left(\mathrm{CH}_{3}\right)$; IR (ATR): $v_{\max } 3382,2921,2851,2698,2361$, $1648,1529,1478,1389,1331,1198,1147,1073,975,916,824,719,655 \mathrm{~cm}^{-1}$; HRMS (+ESI): Found $m / z 560.2150[\mathrm{M}+\mathrm{H}]^{+}, \mathrm{C}_{25} \mathrm{H}_{43} \mathrm{BrN}_{3} \mathrm{O}_{4} \mathrm{~S}$ required 560.2152.

3-(2-(4-(Dodecylsulfonamido)-[1,1'-biphenyl]-3-yl)-2-oxoacetamido)-N,Ndimethylpropan-1-aminium chloride (14c)

The titled compound was synthesised from N-(3-(dimethylamino)propyl)-2-(4(dodecylsulfonamido)-[1,1'-biphenyl]-3-yl)-2-oxoacetamide 11c (30 mg, $0.054 \mathrm{mmol}$ ) and $4 \mathrm{M} \mathrm{HCl}$ /dioxane $(0.10 \mathrm{~mL}, 0.40 \mathrm{mmol})$ following general synthetic procedure $\mathrm{C}$. The product was obtained as a yellow sticky solid $(19 \mathrm{mg}, 60 \%) ;{ }^{1} \mathrm{H}$ NMR $\left(600 \mathrm{MHz}, \mathrm{DMSO}-d_{6}\right)$ : $\delta 10.19$ (bs, 2H, NH), $9.02(\mathrm{t}, J=6.1 \mathrm{~Hz}, 1 \mathrm{H}, \mathrm{NH}), 8.02-7.97(\mathrm{~m}, 2 \mathrm{H}, \mathrm{ArH}), 7.68-7.63(\mathrm{~m}, 2 \mathrm{H}$, ArH), 7.63-7.59 (m, 1H, ArH), 7.53-7.47 (m, 2H, ArH), 7.43-7.38 (m, 1H, ArH), 3.35-3.29 (m, 2H, $\left.\mathrm{CH}_{2}\right), 3.24-3.18\left(\mathrm{~m}, 2 \mathrm{H}, \mathrm{CH}_{2}\right), 3.13-3.07\left(\mathrm{~m}, 2 \mathrm{H}, \mathrm{CH}_{2}\right), 2.74\left(\mathrm{~s}, 6 \mathrm{H}, \mathrm{CH}_{3}\right), 1.97-1.89$ $\left(\mathrm{m}, 2 \mathrm{H}, \mathrm{CH}_{2}\right), 1.71-1.62\left(\mathrm{~m}, 2 \mathrm{H}, \mathrm{CH}_{2}\right), 1.37-1.14\left(\mathrm{~m}, 18 \mathrm{H}, \mathrm{CH}_{2}\right), 0.84\left(\mathrm{t}, J=7.2 \mathrm{~Hz}, 3 \mathrm{H}, \mathrm{CH}_{3}\right)$; ${ }^{13} \mathrm{C}$ NMR (150 MHz, DMSO-d 6 ): $\delta 192.1$ (CO), 163.7 (CO), 138.2 (ArC), 137.9 (ArC), 136.0 (ArC), $132.9(\mathrm{ArCH}), 130.2(\mathrm{ArCH}), 129.2(\mathrm{ArCH}), 127.9(\mathrm{ArCH}), 126.5(\mathrm{ArCH}), 125.8(\mathrm{ArC})$, $122.4(\mathrm{ArCH}), 54.5\left(\mathrm{CH}_{2}\right), 51.3\left(\mathrm{CH}_{2}\right), 42.1\left(\mathrm{CH}_{3}\right), 36.0\left(\mathrm{CH}_{2}\right), 31.3\left(\mathrm{CH}_{2}\right), 29.0\left(\mathrm{CH}_{2}\right), 28.9$ $\left(\mathrm{CH}_{2}\right), 28.7\left(\mathrm{CH}_{2}\right), 28.7\left(\mathrm{CH}_{2}\right), 28.3\left(\mathrm{CH}_{2}\right), 27.3\left(\mathrm{CH}_{2}\right), 23.9\left(\mathrm{CH}_{2}\right), 22.9\left(\mathrm{CH}_{2}\right), 22.1\left(\mathrm{CH}_{2}\right)$, 
$14.0\left(\mathrm{CH}_{3}\right)$; IR (ATR): $v_{\max } 3341,2921,2852,2696,2360,1661,1631,1582,1512,1487,1467$, 1396, 1345, 1268, 1201, 1139, 1075, 1003, 973, 925, 889, 853, 826, 761, 721, $683 \mathrm{~cm}^{-1}$; HRMS (+ESI): Found $m / z 558.3363[\mathrm{M}+\mathrm{H}]^{+}, \mathrm{C}_{31} \mathrm{H}_{48} \mathrm{~N}_{3} \mathrm{O}_{4} \mathrm{~S}$ required 558.3360.

3-(2-(4-(Dodecylsulfonamido)-[1,1':4',1"-terphenyl]-3-yl)-2-oxoacetamido)- $N, N$ dimethylpropan-1-aminium chloride $(\mathbf{1 4 d})$

The titled compound was synthesised from N-(3-(dimethylamino)propyl)-2-(4(dodecylsulfonamido)-[1,1' $: 4^{\prime}, 1^{\prime \prime}$-terphenyl]-3-yl)-2-oxoacetamide 11d (37 mg, $\left.0.058 \mathrm{mmol}\right)$ and $4 \mathrm{M} \mathrm{HCl}$ /dioxane $(0.10 \mathrm{~mL}, 0.40 \mathrm{mmol})$ following general synthetic procedure $\mathrm{C}$. The product was obtained as a white sticky solid $(19 \mathrm{mg}, 48 \%) ;{ }^{1} \mathrm{H}$ NMR $\left(600 \mathrm{MHz}, \mathrm{DMSO}-d_{6}\right)$ : $\delta 10.19$ (bs, 2H, ArH), $9.03(\mathrm{t}, J=5.9 \mathrm{~Hz}, 1 \mathrm{H}, \mathrm{NH}), 8.09-8.03(\mathrm{~m}, 2 \mathrm{H}, \mathrm{ArH}), 7.83-7.79(\mathrm{~m}, 2 \mathrm{H}$, ArH), 7.78-7.75 (m, 2H, ArH), 7.75-7.70 (m, 2H, ArH), 7.65-7.61 (m, 1H, ArH), 7.52-7.47 (m, 2H, ArH), 7.42-7.37 (m, 1H, ArH), 3.36-3.30 (m, 2H, $\left.\mathrm{CH}_{2}\right), 3.25-3.21\left(\mathrm{~m}, 2 \mathrm{H}, \mathrm{CH}_{2}\right)$, 3.13-3.07 (m, 2H, CH $), 2.74\left(\mathrm{~s}, 6 \mathrm{H}, \mathrm{CH}_{3}\right), 1.98-1.90\left(\mathrm{~m}, 2 \mathrm{H}, \mathrm{CH}_{2}\right), 1.71-1.63\left(\mathrm{~m}, 2 \mathrm{H}, \mathrm{CH}_{2}\right)$, 1.37-1.30 (m, 2H, CH 2$), 1.27-1.15\left(\mathrm{~m}, 16 \mathrm{H}, \mathrm{CH}_{2}\right), 0.82\left(\mathrm{t}, \mathrm{J}=7.2 \mathrm{~Hz}, 3 \mathrm{H}, \mathrm{CH}_{3}\right)$; ${ }^{13} \mathrm{C} \mathrm{NMR}$ (150 MHz, DMSO-d $)$ ): $\delta 192.1$ (CO), 163.7 (CO), 139.6 (ArC), 139.4 (ArC), 138.0 (ArC), 137.2 (ArC), $135.4(\mathrm{ArC}), 132.7(\mathrm{ArCH}), 130.1(\mathrm{ArCH}), 129.0(\mathrm{ArCH}), 127.7(\mathrm{ArCH}), 127.4(\mathrm{ArCH})$, $127.0(\mathrm{ArCH}), 126.6(\mathrm{ArCH}), 125.8(\mathrm{ArC}), 122.4(\mathrm{ArCH}), 54.5\left(\mathrm{CH}_{2}\right), 51.3\left(\mathrm{CH}_{2}\right), 42.1\left(\mathrm{CH}_{3}\right)$, $36.0\left(\mathrm{CH}_{2}\right), 31.3\left(\mathrm{CH}_{2}\right), 29.0\left(\mathrm{CH}_{2}\right), 28.9\left(\mathrm{CH}_{2}\right), 28.7\left(\mathrm{CH}_{2}\right), 28.7\left(\mathrm{CH}_{2}\right), 28.4\left(\mathrm{CH}_{2}\right), 27.3$ $\left(\mathrm{CH}_{2}\right), 24.0\left(\mathrm{CH}_{2}\right), 22.9\left(\mathrm{CH}_{2}\right), 22.1\left(\mathrm{CH}_{2}\right), 14.0\left(\mathrm{CH}_{3}\right)$; IR (ATR): $v_{\max } 3353,3261,3030,2920$, 2850, 2689, 2477, 2113, 1920, 1650, 1525, 1481, 1400, 1333, 1272, 1195, 1144, 1073, 1005, 974, 917, 826, 764, 719, $695 \mathrm{~cm}^{-1}$; HRMS (+ESI): Found $m / z 634.3672[\mathrm{M}+\mathrm{H}]^{+}, \mathrm{C}_{37} \mathrm{H}_{52} \mathrm{~N}_{3} \mathrm{O}_{4} \mathrm{~S}$ required 634.3673 .

3-(2-(2-(Hexadecylsulfonamido)phenyl)-2-oxoacetamido)-N,N-dimethylpropan-1aminium chloride (15a)

The titled compound was synthesised from N-(3-(dimethylamino)propyl)-2-(2(hexadecylsulfonamido) phenyl)-2-oxoacetamide 12 a $(30 \mathrm{mg}, 0.056 \mathrm{mmol})$ and $4 \mathrm{M} \mathrm{HCl} /$ dioxane $(0.10 \mathrm{~mL}, 0.40 \mathrm{mmol})$ following general synthetic procedure $\mathrm{C}$. The product was obtained as a white sticky solid (32 mg, 99\%); ${ }^{1} \mathrm{H}$ NMR (600 MHz, DMSO- $\left.d_{6}\right): \delta 10.20$ (bs, 2H, NH), $8.99(\mathrm{t}, J=5.9 \mathrm{~Hz}, 1 \mathrm{H}, \mathrm{NH}), 7.77(\mathrm{dd}, J=7.9,1.5 \mathrm{~Hz}, 1 \mathrm{H}, \mathrm{ArH}), 7.72-7.67(\mathrm{~m}, 1 \mathrm{H}$, ArH), $7.53(\mathrm{dd}, J=8.3,0.7 \mathrm{~Hz}, 1 \mathrm{H}, \mathrm{ArH}), 7.33-7.30(\mathrm{~m}, 1 \mathrm{H}, \mathrm{ArH}), 3.30$ (q, J = 6.4 Hz, 2H, $\left.\mathrm{CH}_{2}\right), 3.23-3.18\left(\mathrm{~m}, 2 \mathrm{H}, \mathrm{CH}_{2}\right), 3.10-3.05\left(\mathrm{~m}, 2 \mathrm{H}, \mathrm{CH}_{2}\right), 2.74\left(\mathrm{~s}, 6 \mathrm{H}, \mathrm{CH}_{3}\right), 1.96-1.88(\mathrm{~m}, 2 \mathrm{H}$, $\left.\mathrm{CH}_{2}\right), 1.68-1.60\left(\mathrm{~m}, 2 \mathrm{H}, \mathrm{CH}_{2}\right), 1.35-1.14\left(\mathrm{~m}, 26 \mathrm{H}, \mathrm{CH}_{2}\right), 0.85\left(\mathrm{t}, \mathrm{J}=7.1 \mathrm{~Hz}, 3 \mathrm{H}, \mathrm{CH}_{3}\right) ;{ }^{13} \mathrm{C}$ NMR (150 MHz, DMSO-d d : $\delta 192.9$ (CO), 164.2 (CO), 139.1 (ArC), 135.3 (ArCH), 132.9 $(\mathrm{ArCH}), 124.1(\mathrm{ArCH}), 124.0(\mathrm{ArC}), 121.0(\mathrm{ArCH}), 54.5\left(\mathrm{CH}_{2}\right), 51.3\left(\mathrm{CH}_{2}\right), 42.2\left(\mathrm{CH}_{3}\right), 35.9$ $\left(\mathrm{CH}_{2}\right), 31.3\left(\mathrm{CH}_{2}\right), 29.1\left(\mathrm{CH}_{2}\right), 29.1\left(\mathrm{CH}_{2}\right), 29.0\left(\mathrm{CH}_{2}\right), 29.0\left(\mathrm{CH}_{2}\right), 28.9\left(\mathrm{CH}_{2}\right), 28.7\left(\mathrm{CH}_{2}\right)$, $28.7\left(\mathrm{CH}_{2}\right), 28.4\left(\mathrm{CH}_{2}\right), 27.3\left(\mathrm{CH}_{2}\right), 23.9\left(\mathrm{CH}_{2}\right), 22.9\left(\mathrm{CH}_{2}\right), 22.1\left(\mathrm{CH}_{2}\right), 14.0\left(\mathrm{CH}_{3}\right)$; IR (ATR): $v_{\max } 3312,3297,3033,2916,2848,2692,2479,2108,1649,1573,1534,1491,1465,1399,1333$, $1211,1147,1067,973,922,819,757,721,673 \mathrm{~cm}^{-1}$; HRMS (+ESI): Found $\mathrm{m} / z 538.3672$ $[\mathrm{M}+\mathrm{H}]^{+}, \mathrm{C}_{29} \mathrm{H}_{52} \mathrm{~N}_{3} \mathrm{O}_{4} \mathrm{~S}$ required 538.3673 .

3-(2-(5-Bromo-2-(hexadecylsulfonamido)phenyl)-2-oxoacetamido)- $N, N$-dimethylpropan1-aminium chloride (15b)

The titled compound was synthesised from 2-(5-bromo-2-(hexadecylsulfonamido) phenyl)-N-(3-(dimethylamino)propyl)-2-oxoacetamide 12b (32 mg, $0.052 \mathrm{mmol}$ ) and $4 \mathrm{M}$ $\mathrm{HCl}$ /dioxane $(0.10 \mathrm{~mL}, 0.40 \mathrm{mmol})$ following general synthetic procedure $\mathrm{C}$. The product was obtained as a pale yellow sticky solid $(26 \mathrm{mg}, 77 \%) ;{ }^{1} \mathrm{H}$ NMR $\left(600 \mathrm{MHz}, \mathrm{DMSO}-d_{6}\right): \delta$ 10.28 (bs, 1H, NH), 10.11 (bs, 1H, NH), 8.97 (t, $J=6.2 \mathrm{~Hz}, 1 \mathrm{H}, \mathrm{NH}), 7.89-7.82(\mathrm{~m}, 2 \mathrm{H}, \mathrm{ArH})$, $7.44(\mathrm{~d}, J=8.8 \mathrm{~Hz}, 1 \mathrm{H}, \mathrm{ArH}), 3.29\left(\mathrm{q}, J=6.5 \mathrm{~Hz}, 2 \mathrm{H}, \mathrm{CH}_{2}\right), 3.16-3.06\left(\mathrm{~m}, 4 \mathrm{H}, \mathrm{CH}_{2}\right), 2.74$ (s, $\left.6 \mathrm{H}, \mathrm{CH}_{3}\right), 1.95-1.87\left(\mathrm{~m}, 2 \mathrm{H}, \mathrm{CH}_{2}\right), 1.68-1.58\left(\mathrm{~m}, 2 \mathrm{H}, \mathrm{CH}_{2}\right), 1.35-1.15\left(\mathrm{~m}, 26 \mathrm{H}, \mathrm{CH}_{2}\right), 0.85(\mathrm{t}$, $\left.J=7.1 \mathrm{~Hz}, 3 \mathrm{H}, \mathrm{CH}_{3}\right) ;{ }^{13} \mathrm{C}$ NMR (150 MHz, DMSO-d 6 ): $\delta 190.0$ (CO), 162.9 (CO), $137.3(\operatorname{ArC})$, $136.8(\mathrm{ArCH}), 133.9(\mathrm{ArCH}), 129.0(\mathrm{ArC}), 124.9(\mathrm{ArCH}), 116.7(\mathrm{ArC}), 54.5\left(\mathrm{CH}_{2}\right), 51.3\left(\mathrm{CH}_{2}\right)$, $42.1\left(\mathrm{CH}_{3}\right), 36.0\left(\mathrm{CH}_{2}\right), 31.3\left(\mathrm{CH}_{2}\right), 29.0\left(\mathrm{CH}_{2}\right), 29.0\left(\mathrm{CH}_{2}\right), 29.0\left(\mathrm{CH}_{2}\right), 29.0\left(\mathrm{CH}_{2}\right), 28.9$ 
$\left(\mathrm{CH}_{2}\right), 28.7\left(\mathrm{CH}_{2}\right), 28.7\left(\mathrm{CH}_{2}\right), 28.4\left(\mathrm{CH}_{2}\right), 27.3\left(\mathrm{CH}_{2}\right), 23.8\left(\mathrm{CH}_{2}\right), 22.8\left(\mathrm{CH}_{2}\right), 22.1\left(\mathrm{CH}_{2}\right)$, $14.0\left(\mathrm{CH}_{3}\right)$; IR (ATR): $v_{\max } 3378,3251,3067,2916,2848,2710,2104,1741,1644,1595,1526$, 1461, 1372, 1337, 1289, 1234, 1193, 1142, 975, 936, 843, 786, $720 \mathrm{~cm}^{-1}$; HRMS (+ESI): Found $m / z 616.2778[\mathrm{M}+\mathrm{H}]^{+}, \mathrm{C}_{29} \mathrm{H}_{51} \mathrm{BrN}_{3} \mathrm{O}_{4} \mathrm{~S}$ required 616.2778.

3-(2-(4-(Hexadecylsulfonamido)-[1,1'-biphenyl]-3-yl)-2-oxoacetamido)- $N, N$ dimethylpropan-1-aminium chloride (15c)

The titled compound was synthesised from $\mathrm{N}$-(3-(dimethylamino)propyl)-2-(4(hexadecylsulfonamido)-[1,1'-biphenyl]-3-yl)-2-oxoacetamide 12c (31 mg, $0.051 \mathrm{mmol})$ and $4 \mathrm{M} \mathrm{HCl}$ /dioxane $(0.10 \mathrm{~mL}, 0.40 \mathrm{mmol})$ following general synthetic procedure $\mathrm{C}$. The product was obtained as a yellow sticky solid $(26 \mathrm{mg}, 79 \%) ;{ }^{1} \mathrm{H}$ NMR $\left(600 \mathrm{MHz}, \mathrm{DMSO}-d_{6}\right)$ : $\delta 10.18(\mathrm{bs}, 2 \mathrm{H}, \mathrm{NH}), 9.01(\mathrm{t}, J=5.9 \mathrm{~Hz}, 1 \mathrm{H}, \mathrm{NH}), 8.01-7.98(\mathrm{~m}, 2 \mathrm{H}, \mathrm{ArH}), 7.67-7.63(\mathrm{~m}, 2 \mathrm{H}$, ArH), 7.62-7.59 (m, 1H, ArH), 7.52-7.48 (m, 2H, ArH), 7.42-7.39 (m, 1H, ArH), 3.35-3.29 $\left(\mathrm{m}, 2 \mathrm{H}, \mathrm{CH}_{2}\right), 3.24-3.19\left(\mathrm{~m}, 2 \mathrm{H}, \mathrm{CH}_{2}\right), 3.11-3.06\left(\mathrm{~m}, 2 \mathrm{H}, \mathrm{CH}_{2}\right), 2.73\left(\mathrm{~s}, 6 \mathrm{H}, \mathrm{CH}_{3}\right), 1.97-1.88$ $\left(\mathrm{m}, 2 \mathrm{H}, \mathrm{CH}_{2}\right), 1.71-1.63\left(\mathrm{~m}, 2 \mathrm{H}, \mathrm{CH}_{2}\right), 1.37-1.14\left(\mathrm{~m}, 26 \mathrm{H}, \mathrm{CH}_{2}\right), 0.85\left(\mathrm{t}, J=7.0 \mathrm{~Hz}, 3 \mathrm{H}, \mathrm{CH}_{3}\right)$; ${ }^{13} \mathrm{C}$ NMR $\left(150 \mathrm{MHz}\right.$, DMSO- $\left.d_{6}\right): \delta 192.1$ (CO), 163.7 (CO), 138.2 (ArC), 137.9 (ArC), 135.9 $(\mathrm{ArC}), 132.9(\mathrm{ArCH}), 130.2(\mathrm{ArCH}), 129.2(\mathrm{ArCH}), 127.9(\mathrm{ArCH}), 126.5(\mathrm{ArCH}), 125.8(\mathrm{ArC})$, $122.3(\mathrm{ArCH}), 54.5\left(\mathrm{CH}_{2}\right), 51.3\left(\mathrm{CH}_{2}\right), 42.1\left(\mathrm{CH}_{3}\right), 36.0\left(\mathrm{CH}_{2}\right), 31.3\left(\mathrm{CH}_{2}\right), 29.0\left(\mathrm{CH}_{2}\right), 29.0$ $\left(\mathrm{CH}_{2}\right), 29.0\left(\mathrm{CH}_{2}\right), 29.0\left(\mathrm{CH}_{2}\right), 28.9\left(\mathrm{CH}_{2}\right), 28.7\left(\mathrm{CH}_{2}\right), 28.7\left(\mathrm{CH}_{2}\right), 28.4\left(\mathrm{CH}_{2}\right), 27.3\left(\mathrm{CH}_{2}\right)$, $24.0\left(\mathrm{CH}_{2}\right), 22.9\left(\mathrm{CH}_{2}\right), 22.1\left(\mathrm{CH}_{2}\right), 13.9\left(\mathrm{CH}_{3}\right)$; IR (ATR): $v_{\max } 3345,3186,2918,2850,2643$, 2477, 2110, 1631, 1581, 1511, 1486, 1396, 1345, 1268, 1201, 1139, 1088, 973, 926, 826, 761, 685 $\mathrm{cm}^{-1}$; HRMS (+ESI): Found $m / z 614.3986[\mathrm{M}+\mathrm{H}]^{+}, \mathrm{C}_{35} \mathrm{H}_{56} \mathrm{~N}_{3} \mathrm{O}_{4} \mathrm{~S}$ required 614.3986.

\section{General synthetic procedure $D$ for quaternary ammonium iodide salts}

Iodomethane (2.5 equivalents) was added to a stirring solution of glyoxamide derivative (1.0 equivalent) in tetrahydrofuran $(3 \mathrm{~mL})$. The resulting reaction mixture was stirred at room temperature for $24 \mathrm{~h}$. After the completion of the reaction, the reaction solvent was removed under reduced pressure, and the residue was washed three times with diethyl ether and freeze-dried to afford the product.

N,N,N-Trimethyl-3-(2-(4-(octylsulfonamido)-[1,1':4', $1^{\prime \prime}$-terphenyl]-3-yl)-2oxoacetamido)propan-1-aminium iodide (16d)

The titled compound was synthesised from $\mathrm{N}$-(3-(dimethylamino)propyl)-2-(4(octylsulfonamido)-[1, $1^{\prime}: 4^{\prime}, 1^{\prime \prime}$-terphenyl]-3-yl)-2-oxoacetamide $10 \mathrm{~d}(21 \mathrm{mg}, 0.036 \mathrm{mmol}$ ) and iodomethane $(6.0 \mu \mathrm{L}, 0.096 \mathrm{mmol})$ following general synthetic procedure $\mathbf{D}$. The product was obtained as a yellow sticky solid $(24 \mathrm{mg}, 91 \%) ;{ }^{1} \mathrm{H} \mathrm{NMR}\left(600 \mathrm{MHz}, \mathrm{DMSO}-d_{6}\right)$ : $\delta 10.11$ (bs, 1H, ArH), 8.98 (bs, 1H, NH), 8.05 (d, J = 1.7 Hz, 2H, ArH), 7.82-7.75 (m, 4H, ArH), 7.75-7.71 (m, 2H, ArH), 7.62-7.57 (m, 1H, ArH), 7.52-7.47 (m, 2H, ArH), 7.42-7.37 (m, $1 \mathrm{H}, \mathrm{ArH}), 3.41-3.29\left(\mathrm{~m}, 4 \mathrm{H}, \mathrm{CH}_{2}\right), 3.19\left(\mathrm{t}, J=7.8 \mathrm{~Hz}, 2 \mathrm{H}, \mathrm{CH}_{2}\right), 3.08\left(\mathrm{~s}, 9 \mathrm{H}, \mathrm{CH}_{3}\right), 2.04-1.96$ $\left(\mathrm{m}, 2 \mathrm{H}, \mathrm{CH}_{2}\right), 1.72-1.64\left(\mathrm{~m}, 2 \mathrm{H}, \mathrm{CH}_{2}\right), 1.38-1.29\left(\mathrm{~m}, 2 \mathrm{H}, \mathrm{CH}_{2}\right), 1.27-1.15\left(\mathrm{~m}, 8 \mathrm{H}, \mathrm{CH}_{2}\right)$, $0.83\left(\mathrm{t}, J=7.2 \mathrm{~Hz}, 3 \mathrm{H}, \mathrm{CH}_{3}\right) ;{ }^{13} \mathrm{C}$ NMR $\left(150 \mathrm{MHz}, \mathrm{DMSO}-d_{6}\right): \delta 191.9(\mathrm{CO}), 163.7(\mathrm{CO})$, 139.6 ( $\mathrm{ArC}), 139.4(\mathrm{ArC}), 137.6(\mathrm{ArC}), 137.2(\mathrm{ArC}), 135.6(\mathrm{ArC}), 132.5(\mathrm{ArCH}), 129.9(\mathrm{ArCH})$, 129.0 (ArCH), 127.7 (ArCH), 127.4 (ArCH), $127.0(\mathrm{ArCH}), 126.9(\mathrm{ArC}), 126.6(\mathrm{ArCH}), 122.9$ (ArCH), $63.5\left(\mathrm{CH}_{2}\right), 52.3\left(\mathrm{CH}_{3}\right), 51.2\left(\mathrm{CH}_{2}\right), 35.9\left(\mathrm{CH}_{2}\right), 31.1\left(\mathrm{CH}_{2}\right), 28.4\left(\mathrm{CH}_{2}\right), 28.3\left(\mathrm{CH}_{2}\right)$, 27.3 $\left(\mathrm{CH}_{2}\right), 22.9\left(\mathrm{CH}_{2}\right), 22.6\left(\mathrm{CH}_{2}\right), 22.0\left(\mathrm{CH}_{2}\right), 13.9\left(\mathrm{CH}_{3}\right)$; IR (ATR): $v_{\max } 3382,2924,2854$, 2360, 1979, 1670, 1527, 1481, 1396, 1332, 1259, 1195, 1141, 1075, 1006, 914, 883, 829, 765, 729, $697,673 \mathrm{~cm}^{-1}$; HRMS (+ESI): Found $m / z 592.3206[\mathrm{M}]^{+}, \mathrm{C}_{34} \mathrm{H}_{46} \mathrm{~N}_{3} \mathrm{O}_{4} \mathrm{~S}$ required 592.3204 .

3-(2-(2-(Dodecylsulfonamido)phenyl)-2-oxoacetamido)- $N, N, N$-trimethylpropan-1aminium iodide (17a)

The titled compound was synthesised from N-(3-(dimethylamino)propyl)-2-(2(dodecylsulfonamido) phenyl)-2-oxoacetamide $11 \mathrm{a}(30 \mathrm{mg}, 0.062 \mathrm{mmol}$ ) and iodomethane $(10.0 \mu \mathrm{L}, 0.16 \mathrm{mmol})$ following general synthetic procedure $\mathbf{D}$. The product was obtained as a yellow sticky solid $(25 \mathrm{mg}, 64 \%) ;{ }^{1} \mathrm{H}$ NMR $\left(600 \mathrm{MHz}\right.$, DMSO- $\left.d_{6}\right): \delta 10.14$ (bs, $\left.1 \mathrm{H}, \mathrm{NH}\right)$, $8.95(\mathrm{t}, J=5.9 \mathrm{~Hz}, 1 \mathrm{H}, \mathrm{NH}), 7.77(\mathrm{dd}, J=7.9,1.6 \mathrm{~Hz}, 1 \mathrm{H}, \mathrm{ArH}), 7.73-7.68(\mathrm{~m}, 1 \mathrm{H}, \mathrm{ArH}), 7.50$ 
(dd, $J=8.3,0.7 \mathrm{~Hz}, 1 \mathrm{H}, \mathrm{ArH}), 7.35-7.31(\mathrm{~m}, 1 \mathrm{H}, \mathrm{ArH}), 3.37-3.27\left(\mathrm{~m}, 4 \mathrm{H}, \mathrm{CH}_{2}\right), 3.20-3.15(\mathrm{~m}$, $\left.2 \mathrm{H}, \mathrm{CH}_{2}\right), 3.07\left(\mathrm{~s}, 9 \mathrm{H}, \mathrm{CH}_{3}\right), 2.02-1.93\left(\mathrm{~m}, 2 \mathrm{H}, \mathrm{CH}_{2}\right), 1.68-1.60\left(\mathrm{~m}, 2 \mathrm{H}, \mathrm{CH}_{2}\right), 1.36-1.14(\mathrm{~m}$, $\left.18 \mathrm{H}, \mathrm{CH}_{2}\right), 0.85\left(\mathrm{t}, J=7.2 \mathrm{~Hz}, 3 \mathrm{H}, \mathrm{CH}_{3}\right) ;{ }^{13} \mathrm{C}$ NMR $\left(150 \mathrm{MHz}, \mathrm{DMSO}-d_{6}\right): \delta 192.5(\mathrm{CO}), 164.1$ (CO), $138.7(\mathrm{ArC}), 135.1(\mathrm{ArCH}), 132.6(\mathrm{ArCH}), 125.1(\mathrm{ArC}), 124.4(\mathrm{ArCH}), 121.6(\mathrm{ArCH})$, 63.4 $\left(\mathrm{CH}_{2}\right), 52.3\left(\mathrm{CH}_{3}\right), 51.2\left(\mathrm{CH}_{2}\right), 35.8\left(\mathrm{CH}_{2}\right), 31.3\left(\mathrm{CH}_{2}\right), 29.0\left(\mathrm{CH}_{2}\right), 28.9\left(\mathrm{CH}_{2}\right), 28.7$ $\left(\mathrm{CH}_{2}\right), 28.7\left(\mathrm{CH}_{2}\right), 28.4\left(\mathrm{CH}_{2}\right), 27.3\left(\mathrm{CH}_{2}\right), 22.9\left(\mathrm{CH}_{2}\right), 22.6\left(\mathrm{CH}_{2}\right), 22.1\left(\mathrm{CH}_{2}\right), 14.0\left(\mathrm{CH}_{3}\right) ; \mathrm{IR}$ (ATR): $v_{\max } 3510,3448,3258,3175,3038,2918,2851,1666,1602,1524,1453,1327,1261,1214$, $1141,1107,984,913,883,772 \mathrm{~cm}^{-1}$; HRMS (+ESI): Found $m / z 496.3203[\mathrm{M}]^{+}, \mathrm{C}_{26} \mathrm{H}_{46} \mathrm{~N}_{3} \mathrm{O}_{4} \mathrm{~S}$ required 496.3204 .

3-(2-(5-Bromo-2-(dodecylsulfonamido)phenyl)-2-oxoacetamido)- $\mathrm{N}, \mathrm{N}, \mathrm{N}$-trimethylpropan1-aminium iodide (17b)

The titled compound was synthesised from 2-(5-bromo-2-(dodecylsulfonamido)phenyl)$\mathrm{N}$-(3-(dimethylamino)propyl)-2-oxoacetamide $\mathbf{1 1 b}$ (34 $\mathrm{mg}, 0.061 \mathrm{mmol}$ ) and iodomethane $(10.0 \mu \mathrm{L}, 0.16 \mathrm{mmol})$ following general synthetic procedure $\mathbf{D}$. The product was obtained as a yellow sticky solid (34 mg, 80\%); ${ }^{1} \mathrm{H}$ NMR $\left(600 \mathrm{MHz}, \mathrm{DMSO}-d_{6}\right): \delta 10.00(\mathrm{~s}, 1 \mathrm{H}, \mathrm{NH})$, $8.95(\mathrm{t}, J=6.0 \mathrm{~Hz}, 1 \mathrm{H}, \mathrm{NH}), 7.90-7.82(\mathrm{~m}, 2 \mathrm{H}, \mathrm{ArH}), 7.42-7.38(\mathrm{~m}, 1 \mathrm{H}, \mathrm{ArH}), 3.40-3.27(\mathrm{~m}$, $\left.4 \mathrm{H}, \mathrm{CH}_{2}\right), 3.13-3.03\left(\mathrm{~m}, 2 \mathrm{H}, \mathrm{CH}_{2}\right), 3.06\left(\mathrm{~s}, 9 \mathrm{H}, \mathrm{CH}_{3}\right), 2.02-1.93\left(\mathrm{~m}, 2 \mathrm{H}, \mathrm{CH}_{2}\right), 1.68-1.58$ $\left(\mathrm{m}, 2 \mathrm{H}, \mathrm{CH}_{2}\right), 1.37-1.14\left(\mathrm{~m}, 18 \mathrm{H}, \mathrm{CH}_{2}\right), 0.85\left(\mathrm{t}, J=7.1 \mathrm{~Hz}, 3 \mathrm{H}, \mathrm{CH}_{3}\right) ;{ }^{13} \mathrm{C} \mathrm{NMR}(150 \mathrm{MHz}$, DMSO- $\left.d_{6}\right)$ : $\delta 189.8(\mathrm{CO}), 162.8(\mathrm{CO}), 136.9(\mathrm{ArC}), 136.7(\mathrm{ArCH}), 133.9(\mathrm{ArCH}), 129.9(\mathrm{ArC})$, 125.4 (ArCH), $117.1(\mathrm{ArC}), 63.5\left(\mathrm{CH}_{2}\right), 52.3\left(\mathrm{CH}_{3}\right), 51.2\left(\mathrm{CH}_{2}\right), 35.9\left(\mathrm{CH}_{2}\right), 31.3\left(\mathrm{CH}_{2}\right)$, $29.0\left(\mathrm{CH}_{2}\right), 28.9\left(\mathrm{CH}_{2}\right), 28.7\left(\mathrm{CH}_{2}\right), 28.7\left(\mathrm{CH}_{2}\right), 28.4\left(\mathrm{CH}_{2}\right), 27.3\left(\mathrm{CH}_{2}\right), 22.8\left(\mathrm{CH}_{2}\right), 22.5$ $\left(\mathrm{CH}_{2}\right), 22.1\left(\mathrm{CH}_{2}\right), 14.0\left(\mathrm{CH}_{3}\right)$; IR (ATR): $v_{\max } 3808,3650,3289,2920,2850,2360,1979$, 1677, 1649, 1561, 1541, 1480, 1391, 1340, 1291, 1274, 1260, 1228, 1203, 1152, 1077, 967, 922, $871,829,721,698,655 \mathrm{~cm}^{-1}$; HRMS (+ESI): Found $m / z 574.2318[\mathrm{M}]^{+}, \mathrm{C}_{26} \mathrm{H}_{45} \mathrm{BrN}_{3} \mathrm{O}_{4} \mathrm{~S}$ required 574.2309.

3-(2-(4-(Dodecylsulfonamido)-[1,1'-biphenyl]-3-yl)-2-oxoacetamido)- $N, N, N$ trimethylpropan-1-aminium iodide (17c)

The titled compound was synthesised from $\mathrm{N}$-(3-(dimethylamino)propyl)-2-(4(dodecylsulfonamido)-[1,1'-biphenyl]-3-yl)-2-oxoacetamide 11c (34 mg, $0.061 \mathrm{mmol}$ ) and iodomethane $(10.0 \mu \mathrm{L}, 0.16 \mathrm{mmol})$ following general synthetic procedure $\mathrm{D}$. The product was obtained as a yellow sticky solid $(36 \mathrm{mg}, 85 \%) ;{ }^{1} \mathrm{H}$ NMR $\left(600 \mathrm{MHz}, \mathrm{DMSO}-d_{6}\right): \delta$ $10.10(\mathrm{bs}, 1 \mathrm{H}, \mathrm{NH}), 8.98(\mathrm{t}, J=6.0 \mathrm{~Hz}, 1 \mathrm{H}, \mathrm{NH}), 8.04-7.94(\mathrm{~m}, 2 \mathrm{H}, \mathrm{ArH}), 7.68-7.64(\mathrm{~m}, 2 \mathrm{H}$, ArH), 7.60-7.56 (m, 1H, ArH), 7.52-7.46 (m, 2H, ArH), 7.43-7.38 (m, 1H, ArH), 3.41-3.28 $\left(\mathrm{m}, 4 \mathrm{H}, \mathrm{CH}_{2}\right), 3.23-3.14\left(\mathrm{~m}, 2 \mathrm{H}, \mathrm{CH}_{2}\right), 3.07\left(\mathrm{~s}, 9 \mathrm{H}, \mathrm{CH}_{3}\right), 2.04-1.93\left(\mathrm{~m}, 2 \mathrm{H}, \mathrm{CH}_{2}\right), 1.71-1.61$ $\left(\mathrm{m}, 2 \mathrm{H}, \mathrm{CH}_{2}\right), 1.39-1.14\left(\mathrm{~m}, 18 \mathrm{H}, \mathrm{CH}_{2}\right), 0.84\left(\mathrm{t}, J=7.2 \mathrm{~Hz}, 3 \mathrm{H}, \mathrm{CH}_{3}\right) ;{ }^{13} \mathrm{C} \mathrm{NMR}(150 \mathrm{MHz}$, DMSO- $\left.d_{6}\right)$ : $\delta 191.8$ (CO), 163.7 (CO), $138.3(\mathrm{ArC}), 137.5(\mathrm{ArC}), 136.3(\mathrm{ArC}), 132.7(\mathrm{ArCH})$, 130.1 (ArCH), $129.2(\mathrm{ArCH}), 127.9(\mathrm{ArCH}), 126.8(\mathrm{ArC}), 126.5(\mathrm{ArCH}), 122.9(\mathrm{ArCH}), 63.5$ $\left(\mathrm{CH}_{2}\right), 52.3\left(\mathrm{CH}_{3}\right), 51.2\left(\mathrm{CH}_{2}\right), 35.9\left(\mathrm{CH}_{2}\right), 31.3\left(\mathrm{CH}_{2}\right), 29.0\left(\mathrm{CH}_{2}\right), 28.9\left(\mathrm{CH}_{2}\right), 28.7\left(\mathrm{CH}_{2}\right)$, 28.7 $\left(\mathrm{CH}_{2}\right), 28.4\left(\mathrm{CH}_{2}\right), 27.3\left(\mathrm{CH}_{2}\right), 22.9\left(\mathrm{CH}_{2}\right), 22.6\left(\mathrm{CH}_{2}\right), 22.1\left(\mathrm{CH}_{2}\right), 13.9\left(\mathrm{CH}_{3}\right)$; IR (ATR): $v_{\max } 3410,2922,2852,2359,1979,1670,1648,1582,1509,1483,1395,1330,1264,1195,1140$, $1075,915,841,761,698,681 \mathrm{~cm}^{-1}$; HRMS (+ESI): Found $m / z 572.3519[\mathrm{M}]^{+}, \mathrm{C}_{32} \mathrm{H}_{50} \mathrm{~N}_{3} \mathrm{O}_{4} \mathrm{~S}$ required 572.3517 .

3-(2-(4-(Dodecylsulfonamido)-[1,1': $4^{\prime}, 1^{\prime \prime}$-terphenyl]-3-yl)-2-oxoacetamido)- $N, N, N$ trimethylpropan-1-aminium iodide (17d)

The titled compound was synthesised from $\mathrm{N}$-(3-(dimethylamino)propyl)-2-(4(dodecylsulfonamido)-[1, $1^{\prime}: 4^{\prime}, 1^{\prime \prime}$-terphenyl]-3-yl)-2-oxoacetamide 11d (32 mg, $0.051 \mathrm{mmol}$ ) and iodomethane $(10.0 \mu \mathrm{L}, 0.16 \mathrm{mmol})$ following general synthetic procedure $\mathbf{D}$. The product was obtained as a white sticky solid $(16 \mathrm{mg}, 42 \%) ;{ }^{1} \mathrm{H}$ NMR $\left(600 \mathrm{MHz}, \mathrm{DMSO}-d_{6}\right)$ : $\delta 10.12(\mathrm{bs}, 1 \mathrm{H}, \mathrm{ArH}), 9.00(\mathrm{t}, J=5.9 \mathrm{~Hz}, 1 \mathrm{H}, \mathrm{NH}), 8.09-8.03(\mathrm{~m}, 2 \mathrm{H}, \mathrm{ArH}), 7.82-7.75(\mathrm{~m}, 2 \mathrm{H}$, ArH), 7.74-7.71 (m, 2H, ArH), 7.62-7.58 (m, 1H, ArH), 7.52-7.61 (m, 2H, ArH), 7.42-7.37 (m, $2 \mathrm{H}, \mathrm{ArH}), 7.42-7.37(\mathrm{~m}, 1 \mathrm{H}, \mathrm{ArH}), 3.40-3.30\left(\mathrm{~m}, 4 \mathrm{H}, \mathrm{CH}_{2}\right), 3.23-3.17\left(\mathrm{~m}, 2 \mathrm{H}, \mathrm{CH}_{2}\right), 3.07(\mathrm{~s}$, 
9H, $\left.\mathrm{CH}_{3}\right), 2.04-1.96\left(\mathrm{~m}, 2 \mathrm{H}, \mathrm{CH}_{2}\right), 1.71-1.63\left(\mathrm{~m}, 2 \mathrm{H}, \mathrm{CH}_{2}\right), 1.37-1.29\left(\mathrm{~m}, 2 \mathrm{H}, \mathrm{CH}_{2}\right), 1.26-1.14$ $\left(\mathrm{m}, 16 \mathrm{H}, \mathrm{CH}_{2}\right), 0.83\left(\mathrm{t}, J=7.2 \mathrm{~Hz}, 3 \mathrm{H}, \mathrm{CH}_{3}\right) ;{ }^{13} \mathrm{C} \mathrm{NMR}\left(150 \mathrm{MHz}, \mathrm{DMSO}-d_{6}\right): \delta 191.8(\mathrm{CO})$, 163.7 (CO), 139.6 (ArC), 139.4 (ArC), 137.6 (ArC), 137.2 (ArC), 135.7 (ArC), $132.6(\mathrm{ArCH})$, 130.0 (ArCH), $129.0(\mathrm{ArCH}), 127.7(\mathrm{ArCH}), 127.4(\mathrm{ArCH}), 127.0(\mathrm{ArCH}), 126.8(\mathrm{ArC}), 126.6$ $(\mathrm{ArCH}), 122.9(\mathrm{ArCH}), 63.5\left(\mathrm{CH}_{2}\right), 52.3\left(\mathrm{CH}_{3}\right), 51.2\left(\mathrm{CH}_{2}\right), 35.9\left(\mathrm{CH}_{2}\right), 31.3\left(\mathrm{CH}_{2}\right), 29.0$ $\left(\mathrm{CH}_{2}\right), 28.9\left(\mathrm{CH}_{2}\right), 28.7\left(\mathrm{CH}_{2}\right), 28.7\left(\mathrm{CH}_{2}\right), 28.4\left(\mathrm{CH}_{2}\right), 27.3\left(\mathrm{CH}_{2}\right), 22.9\left(\mathrm{CH}_{2}\right), 22.6\left(\mathrm{CH}_{2}\right)$, $22.1\left(\mathrm{CH}_{2}\right), 13.9\left(\mathrm{CH}_{3}\right)$; IR (ATR): $v_{\max } 3751,3376,3264,3029,2920,2850,2723,2485,2295$, 2103, 2075, 1650, 1524, 1480, 1398, 1333, 1272, 1194, 1141, 1073, 1005, 914, 827, 764, 718, 696 $\mathrm{cm}^{-1}$; HRMS (+ESI): Found $m / z 648.3829[\mathrm{M}]^{+}, \mathrm{C}_{38} \mathrm{H}_{54} \mathrm{~N}_{3} \mathrm{O}_{4} \mathrm{~S}$ required 648.3830 .

3-(2-(2-(Hexadecylsulfonamido)phenyl)-2-oxoacetamido)- $N, N, N$-trimethylpropan-1aminium iodide (18a)

The titled compound was synthesised from N-(3-(dimethylamino)propyl)-2-(2(hexadecylsulfonamido) phenyl)-2-oxoacetamide 12a (30 mg, $0.056 \mathrm{mmol}$ ) and iodomethane $(9.0 \mu \mathrm{L}, 0.15 \mathrm{mmol})$ following general synthetic procedure $\mathbf{D}$. The product was obtained as a white sticky solid (33 mg, 87\%); ${ }^{1} \mathrm{H}$ NMR (400 MHz, DMSO- $\left.d_{6}\right): \delta 10.13$ (bs, $\left.1 \mathrm{H}, \mathrm{NH}\right)$, $8.95(\mathrm{t}, J=5.8 \mathrm{~Hz}, 1 \mathrm{H}, \mathrm{NH}), 7.76(\mathrm{dd}, J=7.9,1.3 \mathrm{~Hz}, 1 \mathrm{H}, \mathrm{ArH}), 7.73-7.66(\mathrm{~m}, 1 \mathrm{H}, \mathrm{ArH}), 7.49$ $(\mathrm{d}, J=8.0 \mathrm{~Hz}, 1 \mathrm{H}, \mathrm{ArH}), 7.33(\mathrm{t}, J=7.5 \mathrm{~Hz}, 1 \mathrm{H}, \mathrm{ArH}), 3.39-3.26\left(\mathrm{~m}, 4 \mathrm{H}, \mathrm{CH}_{2}\right), 3.20-3.12(\mathrm{~m}$, $\left.2 \mathrm{H}, \mathrm{CH}_{2}\right), 3.06\left(\mathrm{~s}, 9 \mathrm{H}, \mathrm{CH}_{3}\right), 2.03-1.91\left(\mathrm{~m}, 2 \mathrm{H}, \mathrm{CH}_{2}\right), 1.70-1.57\left(\mathrm{~m}, 2 \mathrm{H}, \mathrm{CH}_{2}\right), 1.37-1.12(\mathrm{~m}$, $\left.26 \mathrm{H}, \mathrm{CH}_{2}\right), 0.84\left(\mathrm{t}, J=7.0 \mathrm{~Hz}, 3 \mathrm{H}, \mathrm{CH}_{3}\right) ;{ }^{13} \mathrm{C} \mathrm{NMR}\left(150 \mathrm{MHz}, \mathrm{DMSO}-d_{6}\right): \delta 192.6(\mathrm{CO}), 164.2$ (CO), $138.8(\mathrm{ArC}), 135.1(\mathrm{ArCH}), 132.7(\mathrm{ArCH}), 125.2(\mathrm{ArC}), 124.4(\mathrm{ArCH}), 121.6(\mathrm{ArCH})$, $63.5\left(\mathrm{CH}_{2}\right), 52.4\left(\mathrm{CH}_{3}\right), 51.2\left(\mathrm{CH}_{2}\right), 35.9\left(\mathrm{CH}_{2}\right), 31.3\left(\mathrm{CH}_{2}\right), 29.1\left(\mathrm{CH}_{2}\right), 29.1\left(\mathrm{CH}_{2}\right), 29.0$ $\left(\mathrm{CH}_{2}\right), 29.0\left(\mathrm{CH}_{2}\right), 28.9\left(\mathrm{CH}_{2}\right), 28.7\left(\mathrm{CH}_{2}\right), 28.7\left(\mathrm{CH}_{2}\right), 28.4\left(\mathrm{CH}_{2}\right), 27.3\left(\mathrm{CH}_{2}\right), 23.9\left(\mathrm{CH}_{2}\right)$, $22.6\left(\mathrm{CH}_{2}\right), 22.1\left(\mathrm{CH}_{2}\right), 14.0\left(\mathrm{CH}_{3}\right)$; IR (ATR): $v_{\max } 3448,3253,3234,3009,2916,2848,2284$, 1663, 1527, 1490, 1452, 1401, 1329, 1262, 1214, 1145, 1066, 919, 882, 800, 757, 721, $673 \mathrm{~cm}^{-1}$; HRMS (+ESI): Found $m / z 552.3830[\mathrm{M}]^{+}, \mathrm{C}_{30} \mathrm{H}_{54} \mathrm{~N}_{3} \mathrm{O}_{4} \mathrm{~S}$ required 552.3830 .

3-(2-(5-Bromo-2-(hexadecylsulfonamido)phenyl)-2-oxoacetamido)- $N, N, N$ trimethylpropan-1-aminium iodide $(\mathbf{1 8 b})$

The titled compound was synthesised from 2-(5-bromo-2-(hexadecylsulfonamido) phenyl)-N-(3-(dimethylamino)propyl)-2-oxoacetamide 12b (38 $\mathrm{mg}, 0.062 \mathrm{mmol}$ ) and iodomethane $(10.0 \mu \mathrm{L}, 0.16 \mathrm{mmol})$ following general synthetic procedure $\mathbf{D}$. The product was obtained as a yellow sticky solid $(31 \mathrm{mg}, 65 \%) ;{ }^{1} \mathrm{H}$ NMR (600 MHz, DMSO- $\left.d_{6}\right): \delta 10.00$ (bs, 1H, NH), $8.94(\mathrm{t}, J=5.9 \mathrm{~Hz}, 1 \mathrm{H}, \mathrm{NH}), 7.92-7.82(\mathrm{~m}, 2 \mathrm{H}, \mathrm{ArH}), 7.40(\mathrm{dd}, J=8.1,0.9 \mathrm{~Hz}$, 1H, ArH), 3.40-3.27 (m, 4H, CH 2$), 3.14-3.02\left(\mathrm{~m}, 2 \mathrm{H}, \mathrm{CH}_{2}\right), 3.06\left(\mathrm{~s}, 9 \mathrm{H}, \mathrm{CH}_{3}\right), 2.03-1.91(\mathrm{~m}$, $\left.2 \mathrm{H}, \mathrm{CH}_{2}\right), 1.69-1.56\left(\mathrm{~m}, 2 \mathrm{H}, \mathrm{CH}_{2}\right), 1.38-1.07\left(\mathrm{~m}, 26 \mathrm{H}, \mathrm{CH}_{2}\right), 0.85\left(\mathrm{t}, J=7.1 \mathrm{~Hz}, 3 \mathrm{H}, \mathrm{CH}_{3}\right)$; ${ }^{13} \mathrm{C}$ NMR (150 MHz, DMSO- $\left.d_{6}\right): \delta 189.8(\mathrm{CO}), 162.8(\mathrm{CO}), 136.7(\mathrm{ArCH}), 134.9(\mathrm{ArC}), 133.8$ $(\mathrm{ArCH}), 129.8(\mathrm{ArC}), 125.3(\mathrm{ArCH}), 117.0(\mathrm{ArC}), 63.5\left(\mathrm{CH}_{2}\right), 52.3\left(\mathrm{CH}_{3}\right), 51.2\left(\mathrm{CH}_{2}\right), 35.9$ $\left(\mathrm{CH}_{2}\right), 31.3\left(\mathrm{CH}_{2}\right), 29.0\left(\mathrm{CH}_{2}\right), 29.0\left(\mathrm{CH}_{2}\right), 28.9\left(\mathrm{CH}_{2}\right), 28.7\left(\mathrm{CH}_{2}\right), 28.4\left(\mathrm{CH}_{2}\right), 27.3\left(\mathrm{CH}_{2}\right)$, $22.8\left(\mathrm{CH}_{2}\right), 22.5\left(\mathrm{CH}_{2}\right), 22.1\left(\mathrm{CH}_{2}\right), 13.9\left(\mathrm{CH}_{3}\right)$; IR (ATR): $v_{\max } 3410,3223,3014,2919,2851$, 2087, 1896, 1651, 1526, 1477, 1390, 1334, 1197, 1144, 918, 821, 767, $717 \mathrm{~cm}^{-1}$; HRMS (+ESI): Found $m / z 630.2933[\mathrm{M}]^{+}, \mathrm{C}_{30} \mathrm{H}_{53} \mathrm{BrN}_{3} \mathrm{O}_{4} \mathrm{~S}$ required 630.2935.

3-(2-(4-(Hexadecylsulfonamido)-[1,1'-biphenyl]-3-yl)-2-oxoacetamido)- $N, N, N$ trimethylpropan-1-aminium iodide (18c)

The titled compound was synthesised from N-(3-(dimethylamino)propyl)-2-(4(hexadecylsulfonamido)-[1,1'-biphenyl]-3-yl)-2-oxoacetamide 12c (31 mg, $0.051 \mathrm{mmol})$ and iodomethane $(10.0 \mu \mathrm{L}, 0.16 \mathrm{mmol})$ following general synthetic procedure $\mathbf{D}$. The product was obtained as a yellow sticky solid $(21 \mathrm{mg}, 53 \%) ;{ }^{1} \mathrm{H}$ NMR $\left(600 \mathrm{MHz}, \mathrm{DMSO}-d_{6}\right)$ : $\delta 10.10$ (bs, 1H, NH), 8.98 (bs, 1H, NH), 8.07-7.93 (m, 2H, ArH), 7.66 (dd, J = 8.5, 1.2 Hz, 2H, ArH), 7.60-7.55 (m, 1H, ArH), 7.52-7.47 (m, 2H, ArH), 7.40 (t, J = 7.4 Hz, 1H, ArH), 3.39-3.35 (m, 2H, CH $), 3.35-3.30\left(\mathrm{~m}, 2 \mathrm{H}, \mathrm{CH}_{2}\right), 3.18\left(\mathrm{t}, \mathrm{J}=7.7 \mathrm{~Hz}, 2 \mathrm{H}, \mathrm{CH}_{2}\right), 3.07(\mathrm{~s}, 9 \mathrm{H}$, $\left.\mathrm{CH}_{3}\right), 2.02-1.95\left(\mathrm{~m}, 2 \mathrm{H}, \mathrm{CH}_{2}\right), 1.70-1.63\left(\mathrm{~m}, 2 \mathrm{H}, \mathrm{CH}_{2}\right), 1.37-1.14\left(\mathrm{~m}, 26 \mathrm{H}, \mathrm{CH}_{2}\right), 0.85(\mathrm{t}$, $\left.J=7.1 \mathrm{~Hz}, 3 \mathrm{H}, \mathrm{CH}_{3}\right) ;{ }^{13} \mathrm{C}$ NMR $\left(150 \mathrm{MHz}, \mathrm{DMSO}-d_{6}\right): \delta 191.8(\mathrm{CO}), 163.7(\mathrm{CO}), 138.3(\mathrm{ArC})$, 
137.5 (ArC), 136.3 (ArC), 132.7 (ArCH), $130.1(\mathrm{ArCH}), 129.1(\mathrm{ArCH}), 127.9$ (ArCH), 126.8 $(\mathrm{ArC}), 126.5(\mathrm{ArCH}), 122.9(\mathrm{ArCH}), 63.5\left(\mathrm{CH}_{2}\right), 52.3\left(\mathrm{CH}_{3}\right), 51.2\left(\mathrm{CH}_{2}\right), 35.9\left(\mathrm{CH}_{2}\right), 31.3$ $\left(\mathrm{CH}_{2}\right), 29.0\left(\mathrm{CH}_{2}\right), 29.0\left(\mathrm{CH}_{2}\right), 28.9\left(\mathrm{CH}_{2}\right), 28.7\left(\mathrm{CH}_{2}\right), 28.4\left(\mathrm{CH}_{2}\right), 27.3\left(\mathrm{CH}_{2}\right), 22.9\left(\mathrm{CH}_{2}\right)$, $22.6\left(\mathrm{CH}_{2}\right), 22.1\left(\mathrm{CH}_{2}\right), 13.9\left(\mathrm{CH}_{3}\right)$; IR (ATR): $v_{\max } 3317,3189,3009,2919,2851,2299,1907$, 1632, 1511, 1486, 1395, 1343, 1266, 1200, 1139, 1088, 924, 848, 761, $683 \mathrm{~cm}^{-1}$; HRMS (+ESI): Found $m / z 628.4142[\mathrm{M}]^{+}, \mathrm{C}_{36} \mathrm{H}_{58} \mathrm{~N}_{3} \mathrm{O}_{4} \mathrm{~S}$ required 628.4143 .

\section{5-([1,1'-Biphenyl]-3-yl)indoline-2,3-dione (19)}

The synthesis of the titled compound followed the procedure previously described [56]. A $2 \mathrm{M}$ potassium carbonate solution $(12.3 \mathrm{~mL}, 24.6 \mathrm{mmol})$ was degassed for $30 \mathrm{~min}$ and then added into a suspension of 5-bromoisatin $(2.71 \mathrm{~g}, 11.98 \mathrm{mmol})$ and 3-biphenylboronic acid $(2.70 \mathrm{~g}, 13.64 \mathrm{mmol})$ in a degassed (for $30 \mathrm{~min})$ 1:1 ethanol/toluene solution $(30 \mathrm{~mL})$. The dark brown solution mixture was further degassed for $30 \mathrm{~min}$, followed by the addition of tetrakis(triphenylphosphine)palladium(0) $(145 \mathrm{mg}, 0.125 \mathrm{mmol})$. The resulting reaction mixture was heated at reflux under an atmosphere of nitrogen for $18 \mathrm{~h}$. The dark brown reaction mixture was concentrated in vacuo. Glacial acetic acid $(30 \mathrm{~mL})$ was added to the dark brown solid, and the resulting reaction mixture was heated at reflux for $20 \mathrm{~min}$, followed by hot filtration of the red reaction mixture. The resulting red solution mixture was allowed to cool to room temperature, and the red precipitate formed was collected by vacuum filtration to give the crude product, which was redissolved in dimethylformamide. The solution mixture was then poured into a 1:1 ice-water mixture, and the red precipitate formed was collected by vacuum filtration to give the product as a red solid $(2.00 \mathrm{~g}, 56 \%)$; mp 233.0-234.7 ${ }^{\circ} \mathrm{C}^{1}{ }^{1} \mathrm{H}$ NMR (400 MHz, DMSO-d 6 ): $\delta 11.14$ (bs, 1H, NH), 8.02 (dd, J = 8.2, $2.0 \mathrm{~Hz}, 1 \mathrm{H}, \mathrm{ArH}), 7.94-7.87$ (m, 2H, ArH), 7.81-7.75 (m, 2H, ArH), 7.68-7.62 (m, 2H, ArH), 7.58-7.45 (m, 3H, ArH), 7.42-7.36 (m, 1H, ArH), 7.02 (dd, J = 8.2, 0.4 Hz, 1H, ArH); HRMS (+ESI): Found $m / z 300.1019[\mathrm{M}+\mathrm{H}]^{+}, \mathrm{C}_{20} \mathrm{H}_{14} \mathrm{NO}_{2}$ required 300.1019.

\section{5-([1,1'-Biphenyl]-3-yl)-1-(octylsulfonyl)indoline-2,3-dione (20)}

Triethylamine $(0.17 \mathrm{~mL}, 1.22 \mathrm{mmol})$ was added slowly to a stirring solution of $5-\left(\left[1,1^{\prime}\right.\right.$ biphenyl]-3-yl)indoline-2,3-dione $19(0.32 \mathrm{~g}, 1.06 \mathrm{mmol})$ in dichloromethane $(20 \mathrm{~mL})$ at $0{ }^{\circ} \mathrm{C}$ under nitrogen atmosphere. The reaction mixture was stirred at $0{ }^{\circ} \mathrm{C}$ for $20 \mathrm{~min}$, followed by the dropwise addition of 1-octanesulfonyl chloride $(0.21 \mathrm{~mL}, 1.07 \mathrm{mmol})$ with stirring. The reaction mixture was then stirred at room temperature for $3 \mathrm{~h}$. After the completion of the reaction, the reaction mixture was concentrated in vacuo and washed with methanol to afford the product as a yellowish orange solid $(0.27 \mathrm{~g}, 53 \%) ; \mathrm{mp} 161.5-161.7^{\circ} \mathrm{C} ;{ }^{1} \mathrm{H} \mathrm{NMR}$ $\left(400 \mathrm{MHz}, \mathrm{DMSO}-d_{6}\right): \delta 8.22-8.11(\mathrm{~m}, 2 \mathrm{H}, \mathrm{ArH}), 7.97(\mathrm{~s}, 1 \mathrm{H}, \mathrm{ArH}), 7.85-7.76(\mathrm{~m}, 3 \mathrm{H}, \mathrm{ArH})$, $7.71(\mathrm{t}, J=8.3 \mathrm{~Hz}, 2 \mathrm{H}, \mathrm{ArH}), 7.58(\mathrm{t}, J=8.0 \mathrm{~Hz}, 1 \mathrm{H}, \mathrm{ArH}), 7.50(\mathrm{t}, J=7.7 \mathrm{~Hz}, 2 \mathrm{H}, \mathrm{ArH}), 7.40$ $(\mathrm{t}, J=7.3 \mathrm{~Hz}, 1 \mathrm{H}, \mathrm{ArH}), 3.69-3.59\left(\mathrm{~m}, 2 \mathrm{H}, \mathrm{CH}_{2}\right), 1.88-1.76\left(\mathrm{~m}, 2 \mathrm{H}, \mathrm{CH}_{2}\right), 1.45-1.15(\mathrm{~m}, 10 \mathrm{H}$, $\left.\mathrm{CH}_{2}\right), 0.83\left(\mathrm{t}, J=6.9 \mathrm{~Hz}, 3 \mathrm{H}, \mathrm{CH}_{3}\right) ;{ }^{13} \mathrm{C} \mathrm{NMR}\left(100 \mathrm{MHz}, \mathrm{DMSO}-d_{6}\right): \delta 178.7(\mathrm{CO}), 156.6$ (CO), 146.2 (ArC), 141.1 (ArC), 139.9 (ArC), 138.7 (ArC), 136.9 (ArC), 136.1 (ArCH), 129.7 $(\mathrm{ArCH}), 128.9(\mathrm{ArCH}), 127.7(\mathrm{ArCH}), 127.0(\mathrm{ArCH}), 126.4(\mathrm{ArCH}), 125.6(\mathrm{ArCH}), 125.0$ $(\mathrm{ArCH}), 122.9(\mathrm{ArCH}), 120.1(\mathrm{ArC}), 114.5(\mathrm{ArCH}), 53.7\left(\mathrm{CH}_{2}\right), 31.1\left(\mathrm{CH}_{2}\right), 28.4\left(\mathrm{CH}_{2}\right), 28.3$ $\left(\mathrm{CH}_{2}\right), 27.3\left(\mathrm{CH}_{2}\right), 22.2\left(\mathrm{CH}_{2}\right), 22.0\left(\mathrm{CH}_{2}\right), 13.9\left(\mathrm{CH}_{3}\right)$; IR (ATR): $v_{\max } 3854,3675,2970,2922$, 1779, 1744, 1616, 1589, 1496, 1471, 1441, 1404, 1394, 1368, 1298, 1232, 1161, 1140, 1075, 1066, 1057, 1027, 948, 891, 866, 840, 795, 776, 755, 725, 698, $654 \mathrm{~cm}^{-1}$; HRMS (+ESI): Found $\mathrm{m} / z$ $498.1710[\mathrm{M}+\mathrm{Na}]^{+}, \mathrm{C}_{28} \mathrm{H}_{29} \mathrm{NO}_{4} \mathrm{SNa}$ required 498.1710 .

N-(3-(Dimethylamino)propyl)-2-(4-(octylsulfonamido)-[1,1':3',1',-terphenyl]-3-yl)-2oxoacetamide $(21)$

3-Dimethylaminopropylamine $(39 \mu \mathrm{L}, 0.31 \mathrm{mmol})$ was added to a stirring solution of 5-([1,1'-biphenyl]-3-yl)-1-(octylsulfonyl)indoline-2,3-dione 20 (0.15 g, $0.31 \mathrm{mmol})$ in dichloromethane $(5 \mathrm{~mL})$ at $0{ }^{\circ} \mathrm{C}$. The resulting reaction mixture was stirred at room temperature for $3 \mathrm{~h}$. After the completion of the reaction, water was added to the reaction mixture and the mixture was extracted into dichloromethane $(3 \times 25 \mathrm{~mL})$, washed with brine, dried 
over anhydrous sodium sulfate and concentrated in vacuo to afford the product as a yellow oil $(0.18 \mathrm{~g}, 99 \%) ;{ }^{1} \mathrm{H}$ NMR $\left(400 \mathrm{MHz}, \mathrm{CDCl}_{3}\right): \delta 8.83$ (bs, $\left.1 \mathrm{H}, \mathrm{ArH}\right), 8.77(\mathrm{~s}, 1 \mathrm{H}, \mathrm{ArH})$, 7.90-7.85 (m, 2H, ArH), 7.77-7.73 (m, 1H, ArH), 7.66-7.43 (m, 7H, ArH), $7.38(\mathrm{t}, J=7.3 \mathrm{~Hz}$, $1 \mathrm{H}, \mathrm{ArH}), 3.52\left(\mathrm{t}, J=5.9 \mathrm{~Hz}, 2 \mathrm{H}, \mathrm{CH}_{2}\right), 3.23-3.14\left(\mathrm{~m}, 2 \mathrm{H}, \mathrm{CH}_{2}\right), 2.50\left(\mathrm{t}, J=6.2 \mathrm{~Hz}, 2 \mathrm{H}, \mathrm{CH}_{2}\right)$, $2.29\left(\mathrm{~s}, 6 \mathrm{H}, \mathrm{CH}_{3}\right), 1.87-1.73\left(\mathrm{~m}, 4 \mathrm{H}, \mathrm{CH}_{2}\right), 1.43-1.17\left(\mathrm{~m}, 10 \mathrm{H}, \mathrm{CH}_{2}\right), 0.85(\mathrm{t}, J=7.1 \mathrm{~Hz}, 3 \mathrm{H}$, $\left.\mathrm{CH}_{3}\right) ;{ }^{13} \mathrm{C}$ NMR $\left(100 \mathrm{MHz}, \mathrm{CDCl}_{3}\right): \delta 192.0(\mathrm{CO}), 162.6(\mathrm{CO}), 142.2$ (ArC), 141.1 (ArC), 141.0 $(\mathrm{ArC}), 139.8(\mathrm{ArC}), 135.8(\mathrm{ArC}), 135.1(\mathrm{ArCH}), 133.8(\mathrm{ArCH}), 129.6(\mathrm{ArCH}), 129.0(\mathrm{ArCH})$, 127.7 (ArCH), $127.4(\mathrm{ArCH}), 126.8(\mathrm{ArCH}), 126.0(\mathrm{ArCH}), 125.9(\mathrm{ArCH}), 119.7(\mathrm{ArC}), 118.6$ (ArCH), $58.9\left(\mathrm{CH}_{2}\right), 52.7\left(\mathrm{CH}_{2}\right), 45.4\left(\mathrm{CH}_{3}\right), 40.1\left(\mathrm{CH}_{2}\right), 31.8\left(\mathrm{CH}_{2}\right), 29.1\left(\mathrm{CH}_{2}\right), 29.0\left(\mathrm{CH}_{2}\right)$, $28.2\left(\mathrm{CH}_{2}\right), 25.3\left(\mathrm{CH}_{2}\right), 23.5\left(\mathrm{CH}_{2}\right), 22.7\left(\mathrm{CH}_{2}\right), 14.2\left(\mathrm{CH}_{3}\right)$; IR (ATR): $v_{\max } 3675,2970,2900$, 1647, 1498, 1473, 1405, 1393, 1337, 1258, 1196, 1142, 1066, 1057, 891, 798, 757, $700 \mathrm{~cm}^{-1}$; HRMS (+ESI): Found $m / z 578.3049[\mathrm{M}+\mathrm{H}]^{+}, \mathrm{C}_{33} \mathrm{H}_{44} \mathrm{~N}_{3} \mathrm{O}_{4} \mathrm{~S}$ required 578.3047.

N,N-Dimethyl-3-(2-(4-(octylsulfonamido)-[1, $1^{\prime}: 3^{\prime}, 1^{\prime \prime}$-terphenyl]-3-yl)-2oxoacetamido)propan-1-aminium chloride (22)

$4 \mathrm{M} \mathrm{HCl}$ in dioxane $(0.10 \mathrm{~mL}, 0.40 \mathrm{mmol})$ was added to a stirring solution of $\mathrm{N}-(3-$ (dimethylamino)propyl)-2-(4-(octylsulfonamido)-[1, $1^{\prime}: 3^{\prime}, 1^{\prime \prime}$-terphenyl]-3-yl)-2-oxoacetamide $21(30 \mathrm{mg}, 0.052 \mathrm{mmol})$ in diethyl ether $(5 \mathrm{~mL})$. The resulting reaction mixture was stirred at room temperature for $20 \mathrm{~min}$. After the completion of the reaction, the reaction solvent was removed under reduced pressure, and the residue was washed three times with diethyl ether and freeze-dried to afford the product as a yellow sticky solid ( $25 \mathrm{mg}, 67 \%) ;{ }^{1} \mathrm{H}$ NMR $\left(600 \mathrm{MHz}, \mathrm{DMSO}-d_{6}\right): \delta 10.18$ (bs, 2H, NH), $9.01(\mathrm{t}, J=5.3 \mathrm{~Hz}, 1 \mathrm{H}, \mathrm{NH}), 8.16-8.03(\mathrm{~m}$, $2 \mathrm{H}, \mathrm{ArH}), 7.89(\mathrm{~s}, 1 \mathrm{H}, \mathrm{ArH}), 7.82-7.55(\mathrm{~m}, 6 \mathrm{H}, \mathrm{ArH}), 7.50(\mathrm{t}, J=7.4 \mathrm{~Hz}, 2 \mathrm{H}, \mathrm{ArH}), 7.41(\mathrm{t}$, $J=7.0 \mathrm{~Hz}, 1 \mathrm{H}, \mathrm{ArH}), 3.37-3.28\left(\mathrm{~m}, 2 \mathrm{H}, \mathrm{CH}_{2}\right), 3.21\left(\mathrm{t}, J=7.6 \mathrm{~Hz}, 2 \mathrm{H}, \mathrm{CH}_{2}\right), 3.09(\mathrm{t}, J=7.6 \mathrm{~Hz}$, $\left.2 \mathrm{H}, \mathrm{CH}_{2}\right), 2.72\left(\mathrm{~s}, 6 \mathrm{H}, \mathrm{CH}_{3}\right), 1.97-1.88\left(\mathrm{~m}, 2 \mathrm{H}, \mathrm{CH}_{2}\right), 1.72-1.63\left(\mathrm{~m}, 2 \mathrm{H}, \mathrm{CH}_{2}\right), 1.38-1.15(\mathrm{~m}$, $\left.10 \mathrm{H}, \mathrm{CH}_{2}\right), 0.82\left(\mathrm{t}, J=6.9 \mathrm{~Hz}, 3 \mathrm{H}, \mathrm{CH}_{3}\right) ;{ }^{13} \mathrm{C} \mathrm{NMR}\left(150 \mathrm{MHz}, \mathrm{DMSO}-d_{6}\right): \delta 191.9(\mathrm{CO})$, 163.6 (CO), 141.1 (ArC), 139.9 (ArC), 139.1 ( $\mathrm{ArC}), 137.8(\mathrm{ArC}), 136.1(\mathrm{ArC}), 133.0(\mathrm{ArCH})$, 130.4 (ArCH), $129.8(\mathrm{ArCH}), 129.0(\mathrm{ArCH}), 127.7(\mathrm{ArCH}), 127.0(\mathrm{ArCH}), 126.4(\mathrm{ArC}), 126.3$ $(\mathrm{ArCH}), 125.7(\mathrm{ArCH}), 125.0(\mathrm{ArCH}), 122.6(\mathrm{ArCH}), 54.5\left(\mathrm{CH}_{2}\right), 51.3\left(\mathrm{CH}_{2}\right), 42.1\left(\mathrm{CH}_{3}\right), 36.0$ $\left(\mathrm{CH}_{2}\right), 31.1\left(\mathrm{CH}_{2}\right), 28.4\left(\mathrm{CH}_{2}\right), 28.3\left(\mathrm{CH}_{2}\right), 27.3\left(\mathrm{CH}_{2}\right), 23.9\left(\mathrm{CH}_{2}\right), 22.9\left(\mathrm{CH}_{2}\right), 22.0\left(\mathrm{CH}_{2}\right)$, $13.9\left(\mathrm{CH}_{3}\right)$; IR (ATR): $v_{\max } 3365,2923,2853,2695,2361,1654,1647,1497,1474,1400,1332$, 1246, 1195, 1143, 1075, 975, 917, 890, 840, 797, 757, 720, 700, $680 \mathrm{~cm}^{-1}$; HRMS (+ESI): Found $m / z 578.3049[\mathrm{M}+\mathrm{H}]^{+}, \mathrm{C}_{33} \mathrm{H}_{44} \mathrm{~N}_{3} \mathrm{O}_{4} \mathrm{~S}$ required 578.3047.

$N, N, N$-Trimethyl-3-(2-(4-(octylsulfonamido)-[1,1': $3^{\prime}, 1^{\prime \prime}$-terphenyl]-3-yl)-2oxoacetamido)propan-1-aminium iodide (23)

Iodomethane $(10.0 \mu \mathrm{L}, 0.16 \mathrm{mmol})$ was added to a stirring solution of $\mathrm{N}$-(3-(dimethylamino)propyl)-2-(4-(octylsulfonamido)-[1,1':3',1"'-terphenyl]-3-yl)-2-oxoacetamide 21 $(31 \mathrm{mg}, 0.054 \mathrm{mmol})$ in tetrahydrofuran $(3 \mathrm{~mL})$. The resulting reaction mixture was stirred at room temperature for $24 \mathrm{~h}$. After the completion of the reaction, the reaction solvent was removed under reduced pressure, and the residue was washed three times with diethyl ether and freeze-dried to afford the product as a yellow sticky solid (33 mg, 86\%); ${ }^{1} \mathrm{H}$ NMR $\left(600 \mathrm{MHz}, \mathrm{DMSO}-d_{6}\right): \delta 10.09(\mathrm{bs}, 1 \mathrm{H}, \mathrm{ArH}), 8.98(\mathrm{t}, J=6.1 \mathrm{~Hz}, 1 \mathrm{H}, \mathrm{NH}), 8.13-8.06(\mathrm{~m}$, $2 \mathrm{H}, \mathrm{ArH}), 7.90(\mathrm{t}, J=6.1 \mathrm{~Hz}, 1 \mathrm{H}, \mathrm{ArH}), 7.78-7.63(\mathrm{~m}, 4 \mathrm{H}, \mathrm{ArH}), 7.62-7.56(\mathrm{~m}, 2 \mathrm{H}, \mathrm{ArH})$, 7.52-7.47 (m, 2H, ArH), 7.43-7.39 (m, 1H, ArH), 3.39-3.29 (m, 4H, CH $)_{2}, 3.18(\mathrm{t}, J=8.0 \mathrm{~Hz}$, $\left.2 \mathrm{H}, \mathrm{CH}_{2}\right), 3.05\left(\mathrm{~s}, 9 \mathrm{H}, \mathrm{CH}_{3}\right), 2.02-1.93\left(\mathrm{~m}, 2 \mathrm{H}, \mathrm{CH}_{2}\right), 1.73-1.63\left(\mathrm{~m}, 2 \mathrm{H}, \mathrm{CH}_{2}\right), 1.40-1.15(\mathrm{~m}$, $\left.10 \mathrm{H}, \mathrm{CH}_{2}\right), 0.82\left(\mathrm{t}, J=7.2 \mathrm{~Hz}, 3 \mathrm{H}, \mathrm{CH}_{3}\right) ;{ }^{13} \mathrm{C} \mathrm{NMR}\left(150 \mathrm{MHz}, \mathrm{DMSO}-d_{6}\right): \delta 191.6(\mathrm{CO})$, 163.6 (CO), 141.1 (ArC), 139.9 (ArC), 139.1 (ArC), $137.4(\mathrm{ArC}), 136.4(\mathrm{ArC}), 132.9(\mathrm{ArCH})$, 130.2 (ArCH), $129.8(\mathrm{ArCH}), 129.0(\mathrm{ArCH}), 127.7(\mathrm{ArCH}), 127.4(\mathrm{ArC}), 127.0(\mathrm{ArCH}), 126.4$ $(\mathrm{ArCH}), 125.7(\mathrm{ArCH}), 125.0(\mathrm{ArCH}), 123.2(\mathrm{ArCH}), 63.5\left(\mathrm{CH}_{2}\right), 52.3\left(\mathrm{CH}_{3}\right), 51.2\left(\mathrm{CH}_{2}\right), 35.9$ $\left(\mathrm{CH}_{2}\right), 31.1\left(\mathrm{CH}_{2}\right), 28.4\left(\mathrm{CH}_{2}\right), 28.3\left(\mathrm{CH}_{2}\right), 27.3\left(\mathrm{CH}_{2}\right), 22.9\left(\mathrm{CH}_{2}\right), 22.6\left(\mathrm{CH}_{2}\right), 22.0\left(\mathrm{CH}_{2}\right)$, $13.9\left(\mathrm{CH}_{3}\right)$; IR (ATR): $v_{\max } 3404,2925,2854,2360,1979,1670,1642,1475,1400,1332,1260$, 1194, 1140, 1075, 916, 889, 842, 798, 758, 701, $680 \mathrm{~cm}^{-1}$; HRMS (+ESI): Found $m / z 592.3206$ $[\mathrm{M}]^{+}, \mathrm{C}_{34} \mathrm{H}_{46} \mathrm{~N}_{3} \mathrm{O}_{4} \mathrm{~S}$ required 592.3204. 


\section{General synthetic procedure E for Boc-protected glyoxamides}

A solution of $\mathrm{N}$-Boc-1,3-propanediamine (1.0 equivalent) in dichloromethane $(3 \mathrm{~mL})$ was added dropwise to a stirring solution of $N$-sulfonylisatin (1.0 equivalent) in dichloromethane $(10 \mathrm{~mL})$ at $0{ }^{\circ} \mathrm{C}$. The resulting reaction mixture was stirred at room temperature for $6 \mathrm{~h}$. After the completion of the reaction, water was added to the reaction mixture, and the mixture was extracted into dichloromethane $(3 \times 25 \mathrm{~mL})$, washed with brine, dried over anhydrous sodium sulfate and concentrated in vacuo to afford the product.

tert-Butyl (3-(2-(4-(octylsulfonamido)-[1,1': $4^{\prime}, 1^{\prime \prime}$-terphenyl]-3-yl)-2-oxoacetamido)propyl) carbamate $(24 \mathrm{~d})$

The titled compound was synthesised from 5-([1,1'-biphenyl]-4-yl)-1-(octylsulfonyl) indoline-2,3-dione $7 \mathbf{d}(0.35 \mathrm{~g}, 0.73 \mathrm{mmol})$ and $\mathrm{N}$-Boc-1,3-propandiamine $(0.13 \mathrm{~g}, 0.75 \mathrm{mmol})$ following general synthetic procedure $\mathrm{E}$. The product was obtained as a brown solid $(0.47 \mathrm{~g}, 98 \%) ; \mathrm{mp} 129.4-129.6^{\circ} \mathrm{C}^{1}{ }^{1} \mathrm{H}$ NMR $\left(400 \mathrm{MHz}, \mathrm{CDCl}_{3}\right): \delta 10.50(\mathrm{~s}, 1 \mathrm{H}, \mathrm{NH}), 8.81$ (s, 1H, ArH), 7.91-7.84 (m, 2H, ArH), 7.77-7.59 (m, 7H, NH, ArH), $7.47(\mathrm{t}, J=7.8 \mathrm{~Hz}, 2 \mathrm{H}$, ArH), $7.37(\mathrm{t}, J=7.1 \mathrm{~Hz}, 1 \mathrm{H}, \mathrm{ArH}), 4.81(\mathrm{bs}, 1 \mathrm{H}, \mathrm{NH}), 3.49\left(\mathrm{q}, J=6.3 \mathrm{~Hz}, 2 \mathrm{H}, \mathrm{CH}_{2}\right), 3.30-3.15$ $\left(\mathrm{m}, 4 \mathrm{H}, \mathrm{CH}_{2}\right), 1.88-1.71\left(\mathrm{~m}, 4 \mathrm{H}, \mathrm{CH}_{2}\right), 1.45\left(\mathrm{~s}, 9 \mathrm{H}, \mathrm{CH}_{3}\right), 1.49-1.16\left(\mathrm{~m}, 10 \mathrm{H}, \mathrm{CH}_{2}\right), 0.86(\mathrm{t}$, $\left.J=7.1 \mathrm{~Hz}, 3 \mathrm{H}, \mathrm{CH}_{3}\right) ;{ }^{13} \mathrm{C}$ NMR $\left(100 \mathrm{MHz}, \mathrm{CDCl}_{3}\right): \delta 191.5(\mathrm{CO}), 162.9(\mathrm{CO}), 156.9(\mathrm{CO})$, 141.1 (ArC), $140.8(\mathrm{ArC}), 140.6(\mathrm{ArC}), 137.9(\mathrm{ArC}), 135.2(\mathrm{ArC}), 135.0(\mathrm{ArCH}), 133.5(\mathrm{ArCH})$, 129.0 (ArCH), 127.9 ( $\mathrm{ArCH}), 127.7(\mathrm{ArCH}), 127.3(\mathrm{ArCH}), 127.2(\mathrm{ArCH}), 119.4(\mathrm{ArC}), 118.6$ (ArCH), $79.9(\mathrm{C}), 52.8\left(\mathrm{CH}_{2}\right), 37.3\left(\mathrm{CH}_{2}\right), 36.4\left(\mathrm{CH}_{2}\right), 31.8\left(\mathrm{CH}_{2}\right), 30.2\left(\mathrm{CH}_{2}\right), 29.1\left(\mathrm{CH}_{2}\right)$, $29.0\left(\mathrm{CH}_{2}\right), 28.5\left(\mathrm{CH}_{3}\right), 28.2\left(\mathrm{CH}_{2}\right), 23.6\left(\mathrm{CH}_{2}\right), 22.7\left(\mathrm{CH}_{2}\right), 14.2\left(\mathrm{CH}_{3}\right) ; \mathrm{IR}(\mathrm{ATR}): v_{\max } 3350$, 2924, 2869, 2360, 1685, 1666, 1641, 1521, 1481, 1449, 1387, 1364, 1341, 1267, 1245, 1213, 1195, 1154, 1070, 1039, 1006, 977, 912, 900, 883, 866, 830, 762, 716, 689, $673 \mathrm{~cm}^{-1}$; HRMS (+ESI): Found $m / z 672.3082[\mathrm{M}+\mathrm{Na}]^{+}, \mathrm{C}_{36} \mathrm{H}_{47} \mathrm{~N}_{3} \mathrm{O}_{6} \mathrm{SNa}$ required 672.3078 .

tert-Butyl (3-(2-(2-(dodecylsulfonamido)phenyl)-2-oxoacetamido)propyl)carbamate (25a)

The titled compound was synthesised from 1-(dodecylsulfonyl)indoline-2,3-dione 8a $(0.32 \mathrm{~g}, 0.84 \mathrm{mmol})$ and $\mathrm{N}$-Boc-1,3-propandiamine $(0.15 \mathrm{~g}, 0.84 \mathrm{mmol})$ following general synthetic procedure $\mathrm{E}$. The product was obtained as a pale yellow solid $(0.42 \mathrm{~g}, 89 \%) ; \mathrm{mp}$ 77.2-80.5 ${ }^{\circ} \mathrm{C} ;{ }^{1} \mathrm{H}$ NMR $\left(400 \mathrm{MHz}, \mathrm{CDCl}_{3}\right): \delta 10.49(\mathrm{~s}, 1 \mathrm{H}, \mathrm{NH}), 8.44(\mathrm{~d}, J=7.9 \mathrm{~Hz}, 1 \mathrm{H}$, ArH), $7.77(\mathrm{~d}, J=8.5 \mathrm{~Hz}, 1 \mathrm{H}, \mathrm{ArH}), 7.68-7.55(\mathrm{~m}, 2 \mathrm{H}, \mathrm{NH}, \mathrm{ArH}), 7.19-7.11(\mathrm{~m}, 1 \mathrm{H}, \mathrm{ArH})$, 4.87 (bs, $1 \mathrm{H}, \mathrm{NH}), 3.46\left(\mathrm{q}, J=6.3 \mathrm{~Hz}, 2 \mathrm{H}, \mathrm{CH}_{2}\right), 3.28-3.11\left(\mathrm{~m}, 4 \mathrm{H}, \mathrm{CH}_{2}\right), 1.85-1.69(\mathrm{~m}, 4 \mathrm{H}$, $\left.\mathrm{CH}_{2}\right), 1.44\left(\mathrm{~s}, 9 \mathrm{H}, \mathrm{CH}_{3}\right), 1.41-1.15\left(\mathrm{~m}, 18 \mathrm{H}, \mathrm{CH}_{2}\right), 0.87\left(\mathrm{t}, J=7.0 \mathrm{~Hz}, 3 \mathrm{H}, \mathrm{CH}_{3}\right) ;{ }^{13} \mathrm{C} \mathrm{NMR}$ $\left(100 \mathrm{MHz}, \mathrm{CDCl}_{3}\right)$ : $\delta 191.7$ (CO), 163.1 (CO), 156.9 (CO), 142.1 (ArC), $136.7(\mathrm{ArCH}), 135.3$ $(\mathrm{ArCH}), 122.6(\mathrm{ArCH}), 118.8(\mathrm{ArC}), 117.9(\mathrm{ArCH}), 79.9(\mathrm{C}), 52.7\left(\mathrm{CH}_{2}\right), 37.3\left(\mathrm{CH}_{2}\right), 36.4$ $\left(\mathrm{CH}_{2}\right), 32.0\left(\mathrm{CH}_{2}\right), 30.2\left(\mathrm{CH}_{2}\right), 29.7\left(\mathrm{CH}_{2}\right), 29.7\left(\mathrm{CH}_{2}\right), 29.6\left(\mathrm{CH}_{2}\right), 29.4\left(\mathrm{CH}_{2}\right), 29.4\left(\mathrm{CH}_{2}\right)$, $29.1\left(\mathrm{CH}_{2}\right), 28.5\left(\mathrm{CH}_{3}\right), 28.2\left(\mathrm{CH}_{2}\right), 23.5\left(\mathrm{CH}_{2}\right), 22.8\left(\mathrm{CH}_{2}\right), 14.2\left(\mathrm{CH}_{3}\right) ; \mathrm{IR}(\mathrm{ATR}): v_{\max } 3363$, 3238, 2918, 2850, 2297, 2106, 1684, 1637, 1602, 1571, 1523, 1449, 1398, 1334, 1247, 1220, 1152, $1077,1039,1005,918,817,753,671 \mathrm{~cm}^{-1}$; HRMS (+ESI): Found $m / z 576.3078[\mathrm{M}+\mathrm{Na}]^{+}$, $\mathrm{C}_{28} \mathrm{H}_{47} \mathrm{~N}_{3} \mathrm{O}_{6} \mathrm{SNa}$ required 576.3078.

tert-Butyl (3-(2-(5-bromo-2-(dodecylsulfonamido)phenyl)-2-oxoacetamido)propyl) carbamate (25b)

The titled compound was synthesised from 5-bromo-1-(dodecylsulfonyl)indoline-2,3dione $8 \mathbf{b}(0.28 \mathrm{~g}, 0.60 \mathrm{mmol})$ and $\mathrm{N}$-Boc-1,3-propandiamine $(0.11 \mathrm{~g}, 0.60 \mathrm{mmol})$ following general synthetic procedure $\mathrm{E}$. The product was obtained as a yellow solid $(0.34 \mathrm{~g}, 89 \%)$; mp 98.0-98.2 ${ }^{\circ} \mathrm{C} ;{ }^{1} \mathrm{H}$ NMR $\left(400 \mathrm{MHz}, \mathrm{CDCl}_{3}\right): \delta 10.38(\mathrm{~s}, 1 \mathrm{H}, \mathrm{NH}), 8.66(\mathrm{~s}, 1 \mathrm{H}, \mathrm{ArH}), 7.76$ (bs, 1H, NH), 7.71-7.66 (m, 2H, ArH), 4.80 (bs, $1 \mathrm{H}, \mathrm{NH}), 3.46\left(\mathrm{q}, J=6.4 \mathrm{~Hz}, 2 \mathrm{H}, \mathrm{CH}_{2}\right)$, 3.29-3.19 (m, 2H, CH $), 3.19-3.09\left(\mathrm{~m}, 2 \mathrm{H}, \mathrm{CH}_{2}\right), 1.83-1.70\left(\mathrm{~m}, 4 \mathrm{H}, \mathrm{CH}_{2}\right), 1.45\left(\mathrm{~s}, 9 \mathrm{H}, \mathrm{CH}_{3}\right)$, 1.41-1.17 (m, 18H, $\left.\mathrm{CH}_{2}\right), 0.87\left(\mathrm{t}, J=7.1 \mathrm{~Hz}, 3 \mathrm{H}, \mathrm{CH}_{3}\right) ;{ }^{13} \mathrm{C} \mathrm{NMR}\left(100 \mathrm{MHz}, \mathrm{CDCl}_{3}\right): \delta 190.4$ (CO), $162.2(\mathrm{CO}), 157.0(\mathrm{CO}), 141.0(\mathrm{ArC}), 139.3(\mathrm{ArCH}), 137.4(\mathrm{ArCH}), 120.4(\mathrm{ArCH}), 119.8$ (ArC), $115.2(\mathrm{ArC}), 80.0(\mathrm{C}), 52.9\left(\mathrm{CH}_{2}\right), 37.2\left(\mathrm{CH}_{2}\right), 36.4\left(\mathrm{CH}_{2}\right), 32.0\left(\mathrm{CH}_{2}\right), 30.2\left(\mathrm{CH}_{2}\right), 29.7$ $\left(\mathrm{CH}_{2}\right), 29.7\left(\mathrm{CH}_{2}\right), 29.6\left(\mathrm{CH}_{2}\right), 29.5\left(\mathrm{CH}_{2}\right), 29.4\left(\mathrm{CH}_{2}\right), 29.1\left(\mathrm{CH}_{2}\right), 28.5\left(\mathrm{CH}_{3}\right), 28.2\left(\mathrm{CH}_{2}\right)$, 
$23.5\left(\mathrm{CH}_{2}\right), 22.8\left(\mathrm{CH}_{2}\right), 14.3\left(\mathrm{CH}_{3}\right)$; IR (ATR): $v_{\max } 3382,3329,3173,2918,2850,1683,1664$, 1630, 1560, 1519, 1479, 1452, 1392, 1366, 1339, 1315, 1283, 1249, 1198, 1170, 1147, 1066, 1039, $1012,988,916,889,860,823,776,719,708,659 \mathrm{~cm}^{-1}$; HRMS (+ESI): Found $\mathrm{m} / z 654.2187$ $[\mathrm{M}+\mathrm{Na}]^{+}, \mathrm{C}_{28} \mathrm{H}_{46} \mathrm{BrN}_{3} \mathrm{O}_{6} \mathrm{SNa}$ required 654.2183.

tert-Butyl (3-(2-(4-(dodecylsulfonamido)-[1,1'-biphenyl]-3-yl)-2-oxoacetamido)propyl) carbamate $(25 \mathrm{c})$

The titled compound was synthesised from 1-(dodecylsulfonyl)-5-phenylindoline-2,3dione $8 \mathrm{c}(0.32 \mathrm{~g}, 0.71 \mathrm{mmol})$ and $N$-Boc-1,3-propandiamine $(0.13 \mathrm{~g}, 0.71 \mathrm{mmol})$ following general synthetic procedure E. The product was obtained as a yellow solid (0.39 $\mathrm{g}, 88 \%)$; mp 120.8-121.0 ${ }^{\circ} \mathrm{C} ;{ }^{1} \mathrm{H}$ NMR (400 MHz, $\left.\mathrm{CDCl}_{3}\right): \delta 10.48$ (s, 1H, NH), 8.75 (s, 1H, ArH), 7.89-7.79 (m, 2H, ArH), 7.71 (bs, 1H, NH), 7.60-7.53 (m, 2H, ArH), 7.48-7.41 (m, 2H, ArH), 7.39-7.33 (m, 1H, ArH), 4.81 (bs, 1H, NH), 3.48 (q, J = 6.3 Hz, 2H, CH $), 3.29-3.14(\mathrm{~m}, 4 \mathrm{H}$, $\left.\mathrm{CH}_{2}\right), 1.87-1.71\left(\mathrm{~m}, 4 \mathrm{H}, \mathrm{CH}_{2}\right), 1.44\left(\mathrm{~s}, 9 \mathrm{H}, \mathrm{CH}_{3}\right), 1.43-1.17\left(\mathrm{~m}, 18 \mathrm{H}, \mathrm{CH}_{2}\right), 0.87(\mathrm{t}, J=7.1 \mathrm{~Hz}$, $\left.3 \mathrm{H}, \mathrm{CH}_{3}\right) ;{ }^{13} \mathrm{C}$ NMR $\left(100 \mathrm{MHz}, \mathrm{CDCl}_{3}\right): \delta 191.5$ (CO), 162.9 (CO), 156.9 (CO), 141.1 (ArC), 139.1 (ArC), 135.7 (ArC), $135.1(\mathrm{ArCH}), 133.6(\mathrm{ArCH}), 129.2(\mathrm{ArCH}), 127.9(\mathrm{ArCH}), 126.9$ $(\mathrm{ArCH}), 119.3(\mathrm{ArC}), 118.5(\mathrm{ArCH}), 79.9(\mathrm{C}), 52.8\left(\mathrm{CH}_{2}\right), 37.3\left(\mathrm{CH}_{2}\right), 36.4\left(\mathrm{CH}_{2}\right), 32.0\left(\mathrm{CH}_{2}\right)$, $30.2\left(\mathrm{CH}_{2}\right), 29.7\left(\mathrm{CH}_{2}\right), 29.7\left(\mathrm{CH}_{2}\right), 29.6\left(\mathrm{CH}_{2}\right), 29.4\left(\mathrm{CH}_{2}\right), 29.4\left(\mathrm{CH}_{2}\right), 29.1\left(\mathrm{CH}_{2}\right), 28.5$ $\left(\mathrm{CH}_{3}\right), 28.2\left(\mathrm{CH}_{2}\right), 23.5\left(\mathrm{CH}_{2}\right), 22.8\left(\mathrm{CH}_{2}\right), 14.2\left(\mathrm{CH}_{3}\right)$; IR (ATR): $v_{\max } 3351,3308,2922,2851$, 1683, 1666, 1644, 1582, 1518, 1483, 1443, 1386, 1364, 1347, 1325, 1294, 1247, 1196, 1155, 1070, 1040, 1011, 977, 906, 895, 882, 864, 850, 804, 776, 758, 740, 716, $684 \mathrm{~cm}^{-1}$; HRMS (+ESI): Found $m / z 652.3394[\mathrm{M}+\mathrm{Na}]^{+}, \mathrm{C}_{34} \mathrm{H}_{51} \mathrm{~N}_{3} \mathrm{O}_{6} \mathrm{SNa}$ required 652.3391.

tert-Butyl (3-(2-(2-(hexadecylsulfonamido)phenyl)-2-oxoacetamido)propyl)carbamate (26a)

The titled compound was synthesised from 1-(hexadecylsulfonyl)indoline-2,3-dione 9a $(0.21 \mathrm{~g}, 0.47 \mathrm{mmol})$ and $N$-Boc-1,3-propandiamine $(85 \mathrm{mg}, 0.47 \mathrm{mmol})$ following general synthetic procedure E. The product was obtained as a yellow solid $(0.28 \mathrm{~g}, 97 \%)$; $\mathrm{mp}$ 86.7-90.1 ${ }^{\circ} \mathrm{C} ;{ }^{1} \mathrm{H}$ NMR (400 MHz, $\left.\mathrm{CDCl}_{3}\right): \delta 10.50(\mathrm{~s}, 1 \mathrm{H}, \mathrm{NH}), 8.45$ (d, J = 7.9 Hz, 1H, ArH), $7.77(\mathrm{~d}, J=8.4 \mathrm{~Hz}, 1 \mathrm{H}, \mathrm{ArH}), 7.68-7.56(\mathrm{~m}, 2 \mathrm{H}, \mathrm{NH}, \mathrm{ArH}), 7.19-7.11(\mathrm{~m}, 1 \mathrm{H}, \mathrm{ArH}), 4.84$ (bs, $1 \mathrm{H}, \mathrm{NH}), 3.47$ (q, $\left.J=6.5 \mathrm{~Hz}, 2 \mathrm{H}, \mathrm{CH}_{2}\right), 3.29-3.11\left(\mathrm{~m}, 4 \mathrm{H}, \mathrm{CH}_{2}\right), 1.85-1.69\left(\mathrm{~m}, 4 \mathrm{H}, \mathrm{CH}_{2}\right), 1.44$ $\left(\mathrm{s}, 9 \mathrm{H}, \mathrm{CH}_{3}\right), 1.40-1.16\left(\mathrm{~m}, 26 \mathrm{H}, \mathrm{CH}_{2}\right), 0.87\left(\mathrm{t}, \mathrm{J}=7.0 \mathrm{~Hz}, 3 \mathrm{H}, \mathrm{CH}_{3}\right) ;{ }^{13} \mathrm{C} \mathrm{NMR}(150 \mathrm{MHz}$, $\left.\mathrm{CDCl}_{3}\right)$ : $\delta 191.7(\mathrm{CO}), 163.1(\mathrm{CO}), 156.9(\mathrm{CO}), 142.1(\mathrm{ArC}), 136.7(\mathrm{ArCH}), 135.3(\mathrm{ArCH})$, $122.6(\mathrm{ArCH}), 118.8(\mathrm{ArC}), 118.0(\mathrm{ArCH}), 79.9(\mathrm{C}), 52.7\left(\mathrm{CH}_{2}\right), 37.3\left(\mathrm{CH}_{2}\right), 36.4\left(\mathrm{CH}_{2}\right), 32.1$ $\left(\mathrm{CH}_{2}\right), 30.2\left(\mathrm{CH}_{2}\right), 29.8\left(\mathrm{CH}_{2}\right), 29.8\left(\mathrm{CH}_{2}\right), 29.8\left(\mathrm{CH}_{2}\right), 29.8\left(\mathrm{CH}_{2}\right), 29.8\left(\mathrm{CH}_{2}\right), 29.7\left(\mathrm{CH}_{2}\right)$, $29.6\left(\mathrm{CH}_{2}\right), 29.5\left(\mathrm{CH}_{2}\right), 29.4\left(\mathrm{CH}_{2}\right), 29.1\left(\mathrm{CH}_{2}\right), 28.5\left(\mathrm{CH}_{3}\right), 28.2\left(\mathrm{CH}_{2}\right), 23.5\left(\mathrm{CH}_{2}\right), 22.8$ $\left(\mathrm{CH}_{2}\right), 14.3\left(\mathrm{CH}_{3}\right)$; IR (ATR): $v_{\max } 3362,3253,2916,2849,2113,1684,1637,1602,1571,1523$, 1467, 1391, 1335, 1247, 1220, 1152, 1077, 1057, 1006, 918, 818, 753, $671 \mathrm{~cm}^{-1}$; HRMS (+ESI): Found $m / z 632.3703[\mathrm{M}+\mathrm{Na}]^{+}, \mathrm{C}_{32} \mathrm{H}_{55} \mathrm{~N}_{3} \mathrm{O}_{6} \mathrm{SNa}$ required 632.3704 .

tert-Butyl (3-(2-(5-bromo-2-(hexadecylsulfonamido)phenyl)-2-oxoacetamido)propyl) carbamate $(\mathbf{2 6 b})$

The titled compound was synthesised from 5-bromo-1-(hexadecylsulfonyl)indoline2,3-dione $9 \mathrm{~b}(0.33 \mathrm{~g}, 0.64 \mathrm{mmol})$ and $N$-Boc-1,3-propandiamine $(0.12 \mathrm{~g}, 0.65 \mathrm{mmol})$ following general synthetic procedure $\mathrm{E}$. The product was obtained as a yellow solid $(0.41 \mathrm{~g}$, 91\%); mp 81.7-83.1 ${ }^{\circ} \mathrm{C} ;{ }^{1} \mathrm{H}$ NMR (400 MHz, $\mathrm{CDCl}_{3}$ ): $\delta 10.38$ (s, 1H, NH), 8.66 (s, 1H, ArH), 7.76 (bs, 1H, NH), 7.73-7.64 (m, 2H, NH, ArH), 4.80 (bs, 1H, NH), 3.46 (q, J = 6.5 Hz, 2H, $\left.\mathrm{CH}_{2}\right), 3.28-3.19\left(\mathrm{~m}, 2 \mathrm{H}, \mathrm{CH}_{2}\right), 3.17-3.10\left(\mathrm{~m}, 2 \mathrm{H}, \mathrm{CH}_{2}\right), 1.83-1.70\left(\mathrm{~m}, 4 \mathrm{H}, \mathrm{CH}_{2}\right), 1.45(\mathrm{~s}, 9 \mathrm{H}$, $\left.\mathrm{CH}_{3}\right), 1.41-1.17\left(\mathrm{~m}, 26 \mathrm{H}, \mathrm{CH}_{2}\right), 0.87\left(\mathrm{t}, J=7.1 \mathrm{~Hz}, 3 \mathrm{H}, \mathrm{CH}_{3}\right) ;{ }^{13} \mathrm{C} \mathrm{NMR}\left(100 \mathrm{MHz}, \mathrm{CDCl}_{3}\right): \delta$ 190.4 (CO), 162.2 (CO), 157.0 (CO), 141.0 (ArC), 139.3 (ArCH), $137.4(\mathrm{ArCH}), 120.4(\mathrm{ArC})$, $119.8(\mathrm{ArCH}), 115.2(\mathrm{ArC}), 80.0(\mathrm{C}), 52.9\left(\mathrm{CH}_{2}\right), 37.2\left(\mathrm{CH}_{2}\right), 36.4\left(\mathrm{CH}_{2}\right), 32.1\left(\mathrm{CH}_{2}\right), 30.2$ $\left(\mathrm{CH}_{2}\right), 29.8\left(\mathrm{CH}_{2}\right), 29.8\left(\mathrm{CH}_{2}\right), 29.8\left(\mathrm{CH}_{2}\right), 29.8\left(\mathrm{CH}_{2}\right), 29.8\left(\mathrm{CH}_{2}\right), 29.7\left(\mathrm{CH}_{2}\right), 29.6\left(\mathrm{CH}_{2}\right)$, $29.5\left(\mathrm{CH}_{2}\right), 29.4\left(\mathrm{CH}_{2}\right), 29.1\left(\mathrm{CH}_{2}\right), 28.5\left(\mathrm{CH}_{3}\right), 28.2\left(\mathrm{CH}_{2}\right), 23.5\left(\mathrm{CH}_{2}\right), 22.8\left(\mathrm{CH}_{2}\right), 14.3$ $\left(\mathrm{CH}_{3}\right)$; IR (ATR): $v_{\max } 3370,3184,3113,2918,2850,1685,1635,1519,1479,1389,1335$, 
$1248,1145,1010,918,826.782,709 \mathrm{~cm}^{-1}$; HRMS (+ESI): Found $m / z 710.2810[\mathrm{M}+\mathrm{Na}]^{+}$, $\mathrm{C}_{32} \mathrm{H}_{54} \mathrm{BrN}_{3} \mathrm{O}_{6} \mathrm{SNa}$ required 710.2809.

tert-Butyl (3-(2-(4-(hexadecylsulfonamido)-[1,1'-biphenyl]-3-yl)-2-oxoacetamido)propyl) carbamate (26c)

The titled compound was synthesised from 1-(hexadecylsulfonyl)-5-phenylindoline2,3-dione $9 \mathrm{c}(0.26 \mathrm{~g}, 0.51 \mathrm{mmol})$ and $\mathrm{N}$-Boc-1,3-propandiamine $(91 \mathrm{mg}, 0.51 \mathrm{mmol})$ following general synthetic procedure $\mathrm{E}$. The product was obtained as a yellow solid $(0.32 \mathrm{~g}, 93 \%)$; $\mathrm{mp}$ 121.6-128.3 ${ }^{\circ} \mathrm{C} ;{ }^{1} \mathrm{H}$ NMR (400 MHz, $\left.\mathrm{CDCl}_{3}\right): \delta 10.48$ (s, $\left.1 \mathrm{H}, \mathrm{NH}\right), 8.75$ (s, $\left.1 \mathrm{H}, \mathrm{ArH}\right)$, 7.89-7.80 (m, 2H, ArH), 7.70 (bs, 1H, NH), 7.60-7.53 (m, 2H, ArH), 7.48-7.41 (m, 2H, ArH), 7.39-7.34 (m, 1H, ArH), 4.80 (bs, 1H, NH), $3.48\left(\mathrm{q}, J=6.4 \mathrm{~Hz}, 2 \mathrm{H}, \mathrm{CH}_{2}\right), 3.29-3.14(\mathrm{~m}, 4 \mathrm{H}$, $\left.\mathrm{CH}_{2}\right), 1.87-1.70\left(\mathrm{~m}, 4 \mathrm{H}, \mathrm{CH}_{2}\right), 1.44\left(\mathrm{~s}, 9 \mathrm{H}, \mathrm{CH}_{3}\right), 1.43-1.17\left(\mathrm{~m}, 26 \mathrm{H}, \mathrm{CH}_{2}\right), 0.87(\mathrm{t}, J=7.1 \mathrm{~Hz}$, 3H, $\left.\mathrm{CH}_{3}\right) ;{ }^{13} \mathrm{C} \mathrm{NMR}\left(100 \mathrm{MHz}, \mathrm{CDCl}_{3}\right): \delta 191.5(\mathrm{CO}), 162.9(\mathrm{CO}), 156.9(\mathrm{CO}), 141.1(\mathrm{ArC})$, 139.1 (ArC), $135.7(\mathrm{ArC}), 135.1(\mathrm{ArCH}), 133.7(\mathrm{ArCH}), 129.2(\mathrm{ArCH}), 127.9(\mathrm{ArCH}), 126.9$ $(\mathrm{ArCH}), 119.3(\mathrm{ArC}), 118.5(\mathrm{ArCH}), 79.9(\mathrm{C}), 52.8\left(\mathrm{CH}_{2}\right), 37.3\left(\mathrm{CH}_{2}\right), 36.4\left(\mathrm{CH}_{2}\right), 32.0\left(\mathrm{CH}_{2}\right)$, $30.2\left(\mathrm{CH}_{2}\right), 29.8\left(\mathrm{CH}_{2}\right), 29.8\left(\mathrm{CH}_{2}\right), 29.8\left(\mathrm{CH}_{2}\right), 29.8\left(\mathrm{CH}_{2}\right), 29.8\left(\mathrm{CH}_{2}\right), 29.7\left(\mathrm{CH}_{2}\right), 29.6$ $\left(\mathrm{CH}_{2}\right), 29.5\left(\mathrm{CH}_{2}\right), 29.4\left(\mathrm{CH}_{2}\right), 29.1\left(\mathrm{CH}_{2}\right), 28.5\left(\mathrm{CH}_{3}\right), 28.3\left(\mathrm{CH}_{2}\right), 23.6\left(\mathrm{CH}_{2}\right), 22.8\left(\mathrm{CH}_{2}\right)$, $14.3\left(\mathrm{CH}_{3}\right)$; IR (ATR): $v_{\max } 3350,3306,2918,2848,2288,2110,1681,1644,1518,1482,1383$, $1347,1247,1154,1069,1011,975,906,864,757,684 \mathrm{~cm}^{-1}$; HRMS (+ESI): Found $m / z 708.4018$ $[\mathrm{M}+\mathrm{Na}]^{+}, \mathrm{C}_{38} \mathrm{H}_{59} \mathrm{~N}_{3} \mathrm{O}_{6} \mathrm{SNa}$ required 708.4017.

General synthetic procedure $\mathrm{F}$ for aminoglyoxamides

$4 \mathrm{M} \mathrm{HCl}$ in dioxane $(3 \mathrm{~mL})$ was added to a stirring solution of Boc-protected glyoxamide (1.0 equivalent) in dichloromethane $(10 \mathrm{~mL})$ at $0{ }^{\circ} \mathrm{C}$. The reaction mixture was stirred at room temperature for $6 \mathrm{~h}$. After the completion of the reaction, the reaction solvent was removed under reduced pressure, and the residue was washed three times with diethyl ether and freeze-dried to afford the product.

$N$-(3-Aminopropyl)-2-(4-(octylsulfonamido)-[1,1':4', $1^{\prime \prime}$-terphenyl]-3-yl)-2-oxoacetamide hydrochloride (27d)

The titled compound was synthesised from tert-butyl (3-(2-(4-(octylsulfonamido)$\left[1,1^{\prime}: 4^{\prime}, 1^{\prime \prime}\right.$-terphenyl]-3-yl)-2-oxoacetamido)propyl)carbamate $24 \mathrm{~d}(0.43 \mathrm{~g}, 0.67 \mathrm{mmol})$ following general synthetic procedure $\mathbf{F}$. The product was obtained as a yellow solid $(0.34 \mathrm{~g}$, 88\%); mp 165.1-165.4 ${ }^{\circ} \mathrm{C} ;{ }^{1} \mathrm{H}$ NMR (400 MHz, DMSO- $\left.d_{6}\right): \delta 10.22(\mathrm{~s}, 1 \mathrm{H}, \mathrm{NH}), 9.07(\mathrm{t}$, $J=5.9 \mathrm{~Hz}, 1 \mathrm{H}, \mathrm{NH}), 8.12-8.04(\mathrm{~m}, 2 \mathrm{H}, \mathrm{ArH}), 8.00(\mathrm{bs}, 3 \mathrm{H}, \mathrm{NH}), 7.82(\mathrm{~d}, J=8.3 \mathrm{~Hz}, 2 \mathrm{H}$, ArH), 7.78-7.70 (m, 4H, ArH), $7.66(\mathrm{~d}, J=9.3 \mathrm{~Hz}, 1 \mathrm{H}, \mathrm{ArH}), 7.50(\mathrm{t}, J=7.7 \mathrm{~Hz}, 2 \mathrm{H}, \mathrm{ArH})$, $7.39(\mathrm{t}, J=7.2 \mathrm{~Hz}, 1 \mathrm{H}, \mathrm{ArH}), 3.39-3.31\left(\mathrm{~m}, 2 \mathrm{H}, \mathrm{CH}_{2}\right), 3.31-3.22\left(\mathrm{~m}, 2 \mathrm{H}, \mathrm{CH}_{2}\right), 2.93-2.81$ $\left(\mathrm{m}, 2 \mathrm{H}, \mathrm{CH}_{2}\right), 1.92-1.79\left(\mathrm{~m}, 2 \mathrm{H}, \mathrm{CH}_{2}\right), 1.74-1.62\left(\mathrm{~m}, 2 \mathrm{H}, \mathrm{CH}_{2}\right), 1.40-1.13\left(\mathrm{~m}, 10 \mathrm{H}, \mathrm{CH}_{2}\right)$, $0.82\left(\mathrm{t}, J=7.0 \mathrm{~Hz}, 3 \mathrm{H}, \mathrm{CH}_{3}\right) ;{ }^{13} \mathrm{C}$ NMR $\left(150 \mathrm{MHz}, \mathrm{DMSO}-d_{6}\right): \delta 192.4(\mathrm{CO}), 163.8(\mathrm{CO})$, 139.6 (ArC), $139.4(\mathrm{ArC}), 138.3(\mathrm{ArC}), 137.1(\mathrm{ArC}), 135.0(\mathrm{ArC}), 133.0(\mathrm{ArCH}), 130.3(\mathrm{ArCH})$, 129.0 (ArCH), $127.7(\mathrm{ArCH}), 127.5(\mathrm{ArCH}), 126.9(\mathrm{ArCH}), 126.6(\mathrm{ArCH}), 124.5(\mathrm{ArC}), 121.7$ (ArCH), $51.5\left(\mathrm{CH}_{2}\right), 36.7\left(\mathrm{CH}_{2}\right), 35.9\left(\mathrm{CH}_{2}\right), 31.1\left(\mathrm{CH}_{2}\right), 28.4\left(\mathrm{CH}_{2}\right), 28.3\left(\mathrm{CH}_{2}\right), 27.3\left(\mathrm{CH}_{2}\right)$, $26.9\left(\mathrm{CH}_{2}\right), 22.9\left(\mathrm{CH}_{2}\right), 22.0\left(\mathrm{CH}_{2}\right), 13.9\left(\mathrm{CH}_{3}\right)$; IR (ATR): $v_{\max } 2924,2854,1719,1648,1497$, 1396, 1332, 1255, 1195, 1139, 1051, 1006, 916, 826, 763, 717, 695, $673 \mathrm{~cm}^{-1}$; HRMS (+ESI): Found $m / z 550.2736[\mathrm{M}+\mathrm{H}]^{+}, \mathrm{C}_{31} \mathrm{H}_{40} \mathrm{~N}_{3} \mathrm{O}_{4} \mathrm{~S}$ required 550.2734 .

$\mathrm{N}$-(3-Aminopropyl)-2-(2-(dodecylsulfonamido)phenyl)-2-oxoacetamide hydrochloride (28a)

The titled compound was synthesised from tert-butyl (3-(2-(2-(dodecylsulfonamido) phenyl)-2-oxoacetamido)propyl)carbamate $25 \mathrm{a}(0.38 \mathrm{~g}, 0.68 \mathrm{mmol})$ following general synthetic procedure $\mathbf{F}$. The product was obtained as a pale yellow solid $(0.29 \mathrm{~g}, 86 \%)$; $\mathrm{mp}$ 160.0-162. ${ }^{\circ} \mathrm{C} ;{ }^{1} \mathrm{H}$ NMR $\left(400 \mathrm{MHz}, \mathrm{DMSO}-d_{6}\right): \delta 10.27(\mathrm{~s}, 1 \mathrm{H}, \mathrm{NH}), 9.03(\mathrm{t}, J=5.9 \mathrm{~Hz}, 1 \mathrm{H}$, $\mathrm{NH}), 8.03$ (bs, 3H, NH), $7.78(\mathrm{dd}, J=7.9,1.2 \mathrm{~Hz}, 1 \mathrm{H}, \mathrm{ArH}), 7.73-7.67(\mathrm{~m}, 1 \mathrm{H}, \mathrm{ArH}), 7.56$ $(\mathrm{d}, J=8.0 \mathrm{~Hz}, 1 \mathrm{H}, \mathrm{ArH}), 7.34-7.26(\mathrm{~m}, 1 \mathrm{H}, \mathrm{ArH}), 3.37-3.21\left(\mathrm{~m}, 4 \mathrm{H}, \mathrm{CH}_{2}\right), 2.91-2.77(\mathrm{~m}$, $\left.2 \mathrm{H}, \mathrm{CH}_{2}\right), 1.90-1.78\left(\mathrm{~m}, 2 \mathrm{H}, \mathrm{CH}_{2}\right), 1.71-1.59\left(\mathrm{~m}, 2 \mathrm{H}, \mathrm{CH}_{2}\right), 1.38-1.13\left(\mathrm{~m}, 18 \mathrm{H}, \mathrm{CH}_{2}\right), 0.85$ $\left(\mathrm{t}, J=7.0 \mathrm{~Hz}, 3 \mathrm{H}, \mathrm{CH}_{3}\right) ;{ }^{13} \mathrm{C}$ NMR $\left(100 \mathrm{MHz}, \mathrm{DMSO}-d_{6}\right): \delta 193.3(\mathrm{CO}), 164.3(\mathrm{CO}), 139.6$ 
$(\mathrm{ArC}), 135.5(\mathrm{ArCH}), 133.2(\mathrm{ArCH}), 123.6(\mathrm{ArCH}), 122.5(\mathrm{ArC}), 120.2(\mathrm{ArCH}), 51.4\left(\mathrm{CH}_{2}\right)$, $36.7\left(\mathrm{CH}_{2}\right), 35.8\left(\mathrm{CH}_{2}\right), 31.3\left(\mathrm{CH}_{2}\right), 29.0\left(\mathrm{CH}_{2}\right), 28.9\left(\mathrm{CH}_{2}\right), 28.7\left(\mathrm{CH}_{2}\right), 28.7\left(\mathrm{CH}_{2}\right), 28.4$ $\left(\mathrm{CH}_{2}\right), 27.3\left(\mathrm{CH}_{2}\right), 26.9\left(\mathrm{CH}_{2}\right), 22.9\left(\mathrm{CH}_{2}\right), 22.1\left(\mathrm{CH}_{2}\right), 14.0\left(\mathrm{CH}_{3}\right)$; IR (ATR): $v_{\max } 3336,3238$, 2916, 2849, 2765, 2674, 2635, 2522, 2299, 2033, 1635, 1602, 1568, 1523, 1490, 1445, 1399, 1337, $1259,1211,1153,1080,958,913,849,816,753,670 \mathrm{~cm}^{-1}$; HRMS (+ESI): Found $\mathrm{m} / z 454.2733$ $[\mathrm{M}+\mathrm{H}]^{+}, \mathrm{C}_{23} \mathrm{H}_{40} \mathrm{~N}_{3} \mathrm{O}_{4} \mathrm{~S}$ required 454.2734 .

N-(3-Aminopropyl)-2-(5-bromo-2-(dodecylsulfonamido)phenyl)-2-oxoacetamide hydrochloride $(\mathbf{2 8 b})$

The titled compound was synthesised from tert-butyl (3-(2-(5-bromo-2(dodecylsulfonamido)phenyl)-2-oxoacetamido)propyl)carbamate $25 \mathrm{~b}$ (0.33 g, $0.52 \mathrm{mmol})$ following general synthetic procedure $\mathbf{F}$. The product was obtained as a white solid $(0.20 \mathrm{~g}$, $66 \%) ; \operatorname{mp} 73.7-74.2{ }^{\circ} \mathrm{C} ;{ }^{1} \mathrm{H}$ NMR $\left(400 \mathrm{MHz}, \mathrm{DMSO}-d_{6}\right): \delta 10.07(\mathrm{~s}, 1 \mathrm{H}, \mathrm{NH}), 8.98(\mathrm{t}, J=5.9 \mathrm{~Hz}$, 1H, NH), 7.92 (bs, 3H, NH), 7.90-7.82 (m, 2H, ArH), 7.46 (d, J = 8.6 Hz, 1H, ArH), 3.36-3.25 $\left(\mathrm{m}, 2 \mathrm{H}, \mathrm{CH}_{2}\right), 3.21-3.13\left(\mathrm{~m}, 2 \mathrm{H}, \mathrm{CH}_{2}\right), 2.92-2.78\left(\mathrm{~m}, 2 \mathrm{H}, \mathrm{CH}_{2}\right), 1.87-1.76\left(\mathrm{~m}, 2 \mathrm{H}, \mathrm{CH}_{2}\right)$, 1.69-1.57 (m, 2H, $\left.\mathrm{CH}_{2}\right), 1.37-1.13\left(\mathrm{~m}, 18 \mathrm{H}, \mathrm{CH}_{2}\right), 0.85\left(\mathrm{t}, \mathrm{J}=7.0 \mathrm{~Hz}, 3 \mathrm{H}, \mathrm{CH}_{3}\right) ;{ }^{13} \mathrm{C} \mathrm{NMR}(100$ MHz, DMSO-d 6 ): $\delta 190.3(\mathrm{CO}), 162.9(\mathrm{CO}), 137.6$ (ArC), $137.0(\mathrm{ArCH}), 134.2(\mathrm{ArCH}), 127.7$ (ArC), $124.3(\mathrm{ArCH}), 116.2(\mathrm{ArC}), 51.4\left(\mathrm{CH}_{2}\right), 36.7\left(\mathrm{CH}_{2}\right), 35.9\left(\mathrm{CH}_{2}\right), 31.3\left(\mathrm{CH}_{2}\right), 29.0\left(\mathrm{CH}_{2}\right)$, $28.9\left(\mathrm{CH}_{2}\right), 28.7\left(\mathrm{CH}_{2}\right), 28.7\left(\mathrm{CH}_{2}\right), 28.4\left(\mathrm{CH}_{2}\right), 27.3\left(\mathrm{CH}_{2}\right), 26.8\left(\mathrm{CH}_{2}\right), 22.8\left(\mathrm{CH}_{2}\right), 22.1$ $\left(\mathrm{CH}_{2}\right), 14.0\left(\mathrm{CH}_{3}\right)$; IR (ATR): $v_{\max } 3375,2915,2849,2048,1667,1641,1565,1516,1485,1437$, 1389, 1339, 1323, 1293, 1274, 1256, 1194, 1141, 1075, 1021, 992, 967, 923, 872, 819, 765, 722, $662 \mathrm{~cm}^{-1} ; \mathrm{HRMS}$ (+ESI): Found $m / z 532.1841[\mathrm{M}+\mathrm{H}]^{+}, \mathrm{C}_{23} \mathrm{H}_{39} \mathrm{BrN}_{3} \mathrm{O}_{4} \mathrm{~S}$ required 532.1839

N-(3-Aminopropyl)-2-(4-(dodecylsulfonamido)-[1,1'-biphenyl]-3-yl)-2-oxoacetamide hydrochloride $(28 \mathrm{c})$

The titled compound was synthesised from tert-butyl (3-(2-(4-(dodecylsulfonamido)[1,1'-biphenyl]-3-yl)-2-oxoacetamido)propyl)carbamate 25c (0.35 g, $0.55 \mathrm{mmol})$ following general synthetic procedure $\mathbf{F}$. The product was obtained as a yellow solid $(0.19 \mathrm{~g}, 60 \%)$; mp 118.0 ${ }^{\circ} \mathrm{C} ;{ }^{1} \mathrm{H}$ NMR (600 MHz, DMSO-d 6 ): $\delta 10.19(\mathrm{~s}, 1 \mathrm{H}, \mathrm{NH}), 9.03(\mathrm{t}, J=6.0 \mathrm{~Hz}, 1 \mathrm{H}$, $\mathrm{NH}), 8.03-7.98$ (m, 2H, ArH), 7.91 (bs, 3H, NH), 7.66-7.60 (m, 3H, ArH), 7.53-7.48 (m, 2H, ArH), 7.43-7.39 (m, 1H, ArH), 3.40-3.28 (m, 2H, $\left.\mathrm{CH}_{2}\right), 3.27-3.22\left(\mathrm{~m}, 2 \mathrm{H}, \mathrm{CH}_{2}\right), 2.90-2.82$ $\left(\mathrm{m}, 2 \mathrm{H}, \mathrm{CH}_{2}\right), 1.88-1.80\left(\mathrm{~m}, 2 \mathrm{H}, \mathrm{CH}_{2}\right), 1.71-1.62\left(\mathrm{~m}, 2 \mathrm{H}, \mathrm{CH}_{2}\right), 1.37-1.29\left(\mathrm{~m}, 2 \mathrm{H}, \mathrm{CH}_{2}\right)$, 1.28-1.12 (m, 16H, CH $\left.\mathrm{CH}_{2}\right), 0.84\left(\mathrm{t}, J=7.1 \mathrm{~Hz}, 3 \mathrm{H}, \mathrm{CH}_{3}\right) ;{ }^{13} \mathrm{C}$ NMR (150 MHz, DMSO- $\left.d_{6}\right): \delta$ 192.4 (CO), 163.8 (CO), 138.3 (ArC), 138.2 (ArC), 135.6 (ArC), $133.2(\mathrm{ArCH}), 130.5(\mathrm{ArCH})$, $129.2(\mathrm{ArCH}), 127.9(\mathrm{ArCH}), 126.4(\mathrm{ArCH}), 124.6(\mathrm{ArC}), 121.7(\mathrm{ArCH}), 51.4\left(\mathrm{CH}_{2}\right), 36.7$ $\left(\mathrm{CH}_{2}\right), 35.9\left(\mathrm{CH}_{2}\right), 31.3\left(\mathrm{CH}_{2}\right), 29.0\left(\mathrm{CH}_{2}\right), 28.9\left(\mathrm{CH}_{2}\right), 28.7\left(\mathrm{CH}_{2}\right), 28.7\left(\mathrm{CH}_{2}\right), 28.4\left(\mathrm{CH}_{2}\right)$, $27.3\left(\mathrm{CH}_{2}\right), 26.9\left(\mathrm{CH}_{2}\right), 22.9\left(\mathrm{CH}_{2}\right), 22.1\left(\mathrm{CH}_{2}\right), 14.0\left(\mathrm{CH}_{3}\right)$; IR (ATR): $v_{\max } 3351,3307,2921$, 2851, 1682, 1666, 1644, 1582, 1518, 1483, 1444, 1386, 1364, 1347, 1326, 1294, 1247, 1197, 1155, $1138,1070,1011,978,907,895,881,864,851,830,805,758,741,716,684 \mathrm{~cm}^{-1}$; HRMS (+ESI): Found $m / z 530.3048[\mathrm{M}+\mathrm{H}]^{+}, \mathrm{C}_{29} \mathrm{H}_{44} \mathrm{~N}_{3} \mathrm{O}_{4} \mathrm{~S}$ required 530.3047 .

N-(3-Aminopropyl)-2-(2-(hexadecylsulfonamido)phenyl)-2-oxoacetamide hydrochloride (29a)

The titled compound was synthesised from tert-butyl (3-(2-(2-(hexadecylsulfonamido) phenyl)-2-oxoacetamido)propyl)carbamate 26 a $(0.24 \mathrm{~g}, 0.39 \mathrm{mmol})$ following general synthetic procedure $\mathbf{F}$. The product was obtained as a pale yellow solid $(0.19 \mathrm{~g}, 86 \%)$; $\mathrm{mp}$ 157.3-160.0 ${ }^{\circ} \mathrm{C} ;{ }^{1} \mathrm{H}$ NMR (400 MHz, DMSO-d $\left.d_{6}\right): \delta 10.26(\mathrm{~s}, 1 \mathrm{H}, \mathrm{NH}), 9.02(\mathrm{t}, J=5.9 \mathrm{~Hz}, 1 \mathrm{H}$, $\mathrm{NH}), 7.95$ (bs, 3H, NH), 7.77 (dd, $J=7.9,1.3 \mathrm{~Hz}, 1 \mathrm{H}, \mathrm{ArH}), 7.73-7.67(\mathrm{~m}, 1 \mathrm{H}, \mathrm{ArH}), 7.55(\mathrm{~d}$, $J=8.2 \mathrm{~Hz}, 1 \mathrm{H}, \mathrm{ArH}), 7.30(\mathrm{~d}, J=7.3 \mathrm{~Hz}, 1 \mathrm{H}, \mathrm{ArH}), 3.31\left(\mathrm{q}, J=6.6 \mathrm{~Hz}, 2 \mathrm{H}, \mathrm{CH}_{2}\right), 3.28-3.21$ $\left(\mathrm{m}, 2 \mathrm{H}, \mathrm{CH}_{2}\right), 2.90-2.79\left(\mathrm{~m}, 2 \mathrm{H}, \mathrm{CH}_{2}\right), 1.87-1.77\left(\mathrm{~m}, 2 \mathrm{H}, \mathrm{CH}_{2}\right), 1.70-1.59\left(\mathrm{~m}, 2 \mathrm{H}, \mathrm{CH}_{2}\right)$, 1.37-1.13 (m, 26H, CH 2$), 0.85\left(\mathrm{t}, J=7.0 \mathrm{~Hz}, 3 \mathrm{H}, \mathrm{CH}_{3}\right) ;{ }^{13} \mathrm{C}$ NMR (100 MHz, DMSO- $\left.d_{6}\right)$ :

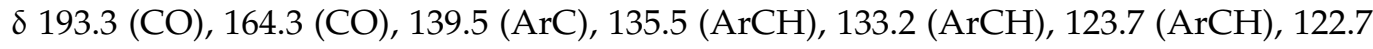
$(\mathrm{ArC}), 120.3(\mathrm{ArCH}), 51.4\left(\mathrm{CH}_{2}\right), 36.7\left(\mathrm{CH}_{2}\right), 35.8\left(\mathrm{CH}_{2}\right), 31.3\left(\mathrm{CH}_{2}\right), 29.1\left(\mathrm{CH}_{2}\right), 29.1\left(\mathrm{CH}_{2}\right)$, $29.0\left(\mathrm{CH}_{2}\right), 29.0\left(\mathrm{CH}_{2}\right), 28.9\left(\mathrm{CH}_{2}\right), 28.7\left(\mathrm{CH}_{2}\right), 28.7\left(\mathrm{CH}_{2}\right), 28.4\left(\mathrm{CH}_{2}\right), 27.3\left(\mathrm{CH}_{2}\right), 26.9$ $\left(\mathrm{CH}_{2}\right), 22.9\left(\mathrm{CH}_{2}\right), 22.1\left(\mathrm{CH}_{2}\right), 14.0\left(\mathrm{CH}_{3}\right)$; IR (ATR): $v_{\max } 3336,3237,2915,2848,2780$, 
2673, 2636, 2521, 2322, 2033, 1634, 1602, 1569, 1524, 1491, 1446, 1399, 1338, 1259, 1211, 1154, $1080,958,913,850,818,753,739,670 \mathrm{~cm}^{-1}$; HRMS (+ESI): Found $m / z 510.3361[\mathrm{M}+\mathrm{H}]^{+}$, $\mathrm{C}_{27} \mathrm{H}_{48} \mathrm{~N}_{3} \mathrm{O}_{4} \mathrm{~S}$ required 510.3360 .

N-(3-Aminopropyl)-2-(5-bromo-2-(hexadecylsulfonamido)phenyl)-2-oxoacetamide hydrochloride $(\mathbf{2 9 b})$

The titled compound was synthesised from tert-butyl (3-(2-(5-bromo-2(hexadecylsulfonamido) phenyl)-2-oxoacetamido)propyl)carbamate $\mathbf{2 6 b}$ (0.36 g, $0.53 \mathrm{mmol})$ following general synthetic procedure $\mathbf{F}$. The product was obtained as a yellow solid (0.31 g, 95\%); mp 81.4-83.9 ${ }^{\circ} \mathrm{C} ;{ }^{1} \mathrm{H}$ NMR (400 MHz, DMSO-d 6 ): $\delta 10.07$ (s, 1H, NH), 8.98 $(\mathrm{t}, J=6.0 \mathrm{~Hz}, 1 \mathrm{H}, \mathrm{NH}), 8.13-7.79(\mathrm{~m}, 5 \mathrm{H}, \mathrm{NH}, \mathrm{ArH}), 7.45(\mathrm{~d}, J=8.7 \mathrm{~Hz}, 1 \mathrm{H}, \mathrm{ArH}), 3.29(\mathrm{q}$, $\left.J=6.8 \mathrm{~Hz}, 2 \mathrm{H}, \mathrm{CH}_{2}\right), 3.21-3.13\left(\mathrm{~m}, 2 \mathrm{H}, \mathrm{CH}_{2}\right), 2.91-2.79\left(\mathrm{~m}, 2 \mathrm{H}, \mathrm{CH}_{2}\right), 1.87-1.76(\mathrm{~m}, 2 \mathrm{H}$, $\left.\mathrm{CH}_{2}\right), 1.68-1.57\left(\mathrm{~m}, 2 \mathrm{H}, \mathrm{CH}_{2}\right), 1.36-1.13\left(\mathrm{~m}, 26 \mathrm{H}, \mathrm{CH}_{2}\right), 0.85\left(\mathrm{t}, \mathrm{J}=7.0 \mathrm{~Hz}, 3 \mathrm{H}, \mathrm{CH}_{3}\right) ;{ }^{13} \mathrm{C}$ NMR (100 MHz, DMSO-d d $_{\text {) }} \delta 190.3$ (CO), 162.9 (CO), 137.6 (ArC), 137.0 (ArCH), 134.2 $(\mathrm{ArCH}), 127.7(\mathrm{ArC}), 124.3(\mathrm{ArCH}), 116.2(\mathrm{ArC}), 51.4\left(\mathrm{CH}_{2}\right), 36.7\left(\mathrm{CH}_{2}\right), 35.9\left(\mathrm{CH}_{2}\right), 31.3$ $\left(\mathrm{CH}_{2}\right), 29.0\left(\mathrm{CH}_{2}\right), 29.0\left(\mathrm{CH}_{2}\right), 28.9\left(\mathrm{CH}_{2}\right), 28.7\left(\mathrm{CH}_{2}\right), 28.3\left(\mathrm{CH}_{2}\right), 27.3\left(\mathrm{CH}_{2}\right), 26.8\left(\mathrm{CH}_{2}\right)$, $22.8\left(\mathrm{CH}_{2}\right), 22.1\left(\mathrm{CH}_{2}\right), 14.0\left(\mathrm{CH}_{3}\right)$; IR (ATR): $v_{\max } 3379,3174,2916,2848,2342,2051,1920$, $1642,1525,1479,1384,1337,1197,1146,1074,1017,908,823,718 \mathrm{~cm}^{-1}$; HRMS (+ESI): Found $m / z 588.2466[\mathrm{M}+\mathrm{H}]^{+}, \mathrm{C}_{27} \mathrm{H}_{47} \mathrm{BrN}_{3} \mathrm{O}_{4} \mathrm{~S}$ required 588.2465.

N-(3-Aminopropyl)-2-(4-(hexadecylsulfonamido)-[1,1'-biphenyl]-3-yl)-2-oxoacetamide hydrochloride $(29 \mathrm{c})$

The titled compound was synthesised from tert-butyl (3-(2-(4-(hexadecylsulfonamido)[1,1'-biphenyl]-3-yl)-2-oxoacetamido)propyl)carbamate 26c (0.30 g, $0.43 \mathrm{mmol})$ following general synthetic procedure $\mathbf{F}$. The product was obtained as a yellow solid $(0.24 \mathrm{~g}, 89 \%)$; $\mathrm{mp}$ 81.9-84.1 ${ }^{\circ} \mathrm{C} ;{ }^{1} \mathrm{H}$ NMR (400 MHz, DMSO-d 6 ): $\delta 10.20(\mathrm{~s}, 1 \mathrm{H}, \mathrm{NH}), 9.05(\mathrm{t}, J=6.0 \mathrm{~Hz}$, $1 \mathrm{H}, \mathrm{NH}), 8.08-7.90(\mathrm{~m}, 5 \mathrm{H}, \mathrm{NH}, \mathrm{ArH}), 7.66-7.60(\mathrm{~m}, 3 \mathrm{H}, \mathrm{ArH}), 7.50(\mathrm{t}, J=7.8 \mathrm{~Hz}, 2 \mathrm{H}, \mathrm{ArH})$, 7.43-7.37 (m, 1H, ArH), 3.40-3.29 (m, 2H, CH $), 3.29-3.21\left(\mathrm{~m}, 2 \mathrm{H}, \mathrm{CH}_{2}\right), 2.92-2.80(\mathrm{~m}, 2 \mathrm{H}$, $\left.\mathrm{CH}_{2}\right), 1.89-1.79\left(\mathrm{~m}, 2 \mathrm{H}, \mathrm{CH}_{2}\right), 1.72-1.61\left(\mathrm{~m}, 2 \mathrm{H}, \mathrm{CH}_{2}\right), 1.39-1.12\left(\mathrm{~m}, 26 \mathrm{H}, \mathrm{CH}_{2}\right), 0.84(\mathrm{t}$, $\left.J=7.0 \mathrm{~Hz}, 3 \mathrm{H}, \mathrm{CH}_{3}\right) ;{ }^{13} \mathrm{C} \mathrm{NMR}\left(100 \mathrm{MHz}, \mathrm{DMSO}-d_{6}\right): \delta 192.4(\mathrm{CO}), 163.8(\mathrm{CO}), 138.3(\mathrm{ArC})$, 138.2 (ArC), 135.6 (ArC), $133.1(\mathrm{ArCH}), 130.5(\mathrm{ArCH}), 129.2(\mathrm{ArCH}), 127.9$ (ArCH), 126.4 $(\mathrm{ArCH}), 124.4(\mathrm{ArC}), 121.7(\mathrm{ArCH}), 51.5\left(\mathrm{CH}_{2}\right), 36.7\left(\mathrm{CH}_{2}\right), 35.9\left(\mathrm{CH}_{2}\right), 31.3\left(\mathrm{CH}_{2}\right), 29.0$ $\left(\mathrm{CH}_{2}\right), 29.0\left(\mathrm{CH}_{2}\right), 28.9\left(\mathrm{CH}_{2}\right), 28.7\left(\mathrm{CH}_{2}\right), 28.7\left(\mathrm{CH}_{2}\right), 28.4\left(\mathrm{CH}_{2}\right), 27.3\left(\mathrm{CH}_{2}\right), 26.9\left(\mathrm{CH}_{2}\right)$, $22.9\left(\mathrm{CH}_{2}\right), 22.1\left(\mathrm{CH}_{2}\right), 13.9\left(\mathrm{CH}_{3}\right)$; IR (ATR): $v_{\max } 3346,3184,2917,2849,2648,2529,2342$, 2053, 1631, 1525, 1484, 1392, 1342, 1265, 1199, 1140, 1078, 1022, 922, 865, 840, 761, $682 \mathrm{~cm}^{-1}$; HRMS (+ESI): Found $m / z 586.3673[\mathrm{M}+\mathrm{H}]^{+}, \mathrm{C}_{33} \mathrm{H}_{52} \mathrm{~N}_{3} \mathrm{O}_{4} \mathrm{~S}$ required 586.3673.

General synthetic procedure $G$ for Boc-protected guanidine glyoxamides

A solution of triethylamine (2.5 equivalents) in acetonitrile $(3 \mathrm{~mL})$ was added dropwise to a stirring solution of aminoglyoxamide (1.0 equivalent) and $N, N^{\prime}$-di-Boc- $1 H$-pyrazole1-carboxamidine (1.3 equivalents) in acetonitrile $(10 \mathrm{~mL})$ at $0{ }^{\circ} \mathrm{C}$ under an atmosphere of nitrogen. The resulting reaction mixture was stirred at room temperature for $24 \mathrm{~h}$. After the completion of the reaction, the reaction solvent was removed under reduced pressure. The resulting residue was purified by flash column chromatography on silica, using ethyl acetate/n-hexane (1:4) as an eluent to afford the product.

(E)-1-tert-Butyl-N-(N'-((tert-butyloxidanyl)carbonyl)- $N$-(3-(2-(4-(octylsulfonamido)$\left[1,1^{\prime}: 4^{\prime}, 1^{\prime \prime}\right.$-terphenyl]-3-yl)-2-oxoacetamido)propyl)carbamimidoyl)-1oxidanecarboxamide (30d)

The titled compound was synthesised from $N$-(3-aminopropyl)-2-(4-(octylsulfonamido)$\left[1,1^{\prime}: 4^{\prime}, 1^{\prime \prime}\right.$-terphenyl]-3-yl)-2-oxoacetamide hydrochloride $27 \mathrm{~d}(0.29 \mathrm{~g}, 0.49 \mathrm{mmol}), N, N^{\prime}$ di-Boc- $1 H$-pyrazole-1-carboxamidine $(0.20 \mathrm{~g}, 0.64 \mathrm{mmol})$ and triethylamine $(0.17 \mathrm{~mL}$, $1.23 \mathrm{mmol}$ ) following general synthetic procedure $\mathrm{G}$. The product was obtained as a yellow solid (0.27 g, 70\%); mp 81.5-81.8 ${ }^{\circ} \mathrm{C} ;{ }^{1} \mathrm{H} \mathrm{NMR}\left(400 \mathrm{MHz}, \mathrm{CDCl}_{3}\right): \delta 11.47(\mathrm{~s}, 1 \mathrm{H}$, $\mathrm{NH}), 10.64$ (s, 1H, NH), 8.68-8.60 (m, 2H, NH, ArH), 8.54 (bs, 1H, NH), 7.91-7.85 (m, 2H, ArH), 7.71-7.60 (m, 6H, ArH), 7.50-7.43 (m, 2H, ArH), 7.40-7.34 (m, 1H, ArH), 3.57 (q, 
$\left.J=6.3 \mathrm{~Hz}, 2 \mathrm{H}, \mathrm{CH}_{2}\right), 3.47\left(\mathrm{q}, J=6.3 \mathrm{~Hz}, 2 \mathrm{H}, \mathrm{CH}_{2}\right), 3.22-3.14\left(\mathrm{~m}, 2 \mathrm{H}, \mathrm{CH}_{2}\right), 1.87-1.77(\mathrm{~m}, 4 \mathrm{H}$, $\left.\mathrm{CH}_{2}\right), 1.50\left(\mathrm{~s}, 9 \mathrm{H}, \mathrm{CH}_{3}\right), 1.38\left(\mathrm{~s}, 9 \mathrm{H}, \mathrm{CH}_{3}\right), 1.43-1.17\left(\mathrm{~m}, 10 \mathrm{H}, \mathrm{CH}_{2}\right), 0.86(\mathrm{t}, J=7.1 \mathrm{~Hz}, 3 \mathrm{H}$, $\left.\mathrm{CH}_{3}\right) ;{ }^{13} \mathrm{C}$ NMR $\left(100 \mathrm{MHz}, \mathrm{CDCl}_{3}\right): \delta 192.5(\mathrm{CO}), 163.7(\mathrm{CO}), 163.0(\mathrm{CN}), 157.4(\mathrm{CO}), 153.3$ (CO), 141.2 (ArC), $140.8(\mathrm{ArC}), 140.6(\mathrm{ArC}), 138.0(\mathrm{ArC}), 135.1(\mathrm{ArC}), 134.8(\mathrm{ArCH}), 133.4$ $(\mathrm{ArCH}), 129.0(\mathrm{ArCH}), 127.9(\mathrm{ArCH}), 127.7(\mathrm{ArCH}), 127.3(\mathrm{ArCH}), 127.2(\mathrm{ArCH}), 119.0$ $(\mathrm{ArC}), 118.4(\mathrm{ArCH}), 83.8(\mathrm{C}), 79.8(\mathrm{C}), 52.8\left(\mathrm{CH}_{2}\right), 37.3\left(\mathrm{CH}_{2}\right), 35.9\left(\mathrm{CH}_{2}\right), 31.8\left(\mathrm{CH}_{2}\right), 30.1$ $\left(\mathrm{CH}_{2}\right), 29.1\left(\mathrm{CH}_{2}\right), 29.0\left(\mathrm{CH}_{2}\right), 28.4\left(\mathrm{CH}_{2}\right), 28.3\left(\mathrm{CH}_{3}\right), 28.2\left(\mathrm{CH}_{3}\right), 23.6\left(\mathrm{CH}_{2}\right), 22.7\left(\mathrm{CH}_{2}\right)$, $14.2\left(\mathrm{CH}_{3}\right)$; IR (ATR): $v_{\max } 3322,2929,1720,1638,1572,1482,1408,1367,1328,1285,1254$, 1228, 1194, 1130, 1051, 1026, 1007, 979, 907, 857, 828, 808, 764, 697, $673 \mathrm{~cm}^{-1}$; HRMS (+ESI): Found $m / z 792.4009[\mathrm{M}+\mathrm{H}]^{+}, \mathrm{C}_{42} \mathrm{H}_{58} \mathrm{~N}_{5} \mathrm{O}_{8} \mathrm{~S}$ required 792.4001 .

(E)-1-tert-Butyl-N-(N'-(tert-butyloxidanyl)carbonyl)-N-(3-(2-(2-(dodecylsulfonamido) phenyl)-2-oxoacetamido)propyl)carbamimidoyl)-1-oxidanecarboxamide (31a)

The titled compound was synthesised from $N$-(3-aminopropyl)-2-(2-(dodecylsulfonamido) phenyl)-2-oxoacetamide hydrochloride $28 \mathrm{a}(0.25 \mathrm{~g}, 0.50 \mathrm{mmol}), N, N^{\prime}$-di-Boc- $1 \mathrm{H}$-pyrazole1-carboxamidine $(0.19 \mathrm{~g}, 0.63 \mathrm{mmol})$ and triethylamine $(0.18 \mathrm{~mL}, 1.26 \mathrm{mmol})$ following general synthetic procedure $\mathrm{G}$. The product was obtained as a yellow oil $(0.31 \mathrm{~g}, 87 \%) ;{ }^{1} \mathrm{H}$ NMR (600 MHz, CDCl $)$ ): $\delta 11.46(\mathrm{~s}, 1 \mathrm{H}, \mathrm{NH}), 10.62(\mathrm{~s}, 1 \mathrm{H}, \mathrm{NH}), 8.65(\mathrm{bs}, 1 \mathrm{H}, \mathrm{NH}), 8.55(\mathrm{t}$, $J=6.4 \mathrm{~Hz}, 1 \mathrm{H}, \mathrm{NH}), 8.24(\mathrm{dd}, J=8.1,1.5 \mathrm{~Hz}, 1 \mathrm{H}, \mathrm{ArH}), 7.77(\mathrm{dd}, J=8.4,0.7 \mathrm{~Hz}, 1 \mathrm{H}, \mathrm{ArH})$, 8.60-8.56 (m, 1H, ArH), 7.16-7.12 (m, 1H, ArH), 3.67-3.56 (m, 2H, CH $\mathrm{CH}_{2}, 3.46(\mathrm{q}, J=6.3 \mathrm{~Hz}$, $\left.2 \mathrm{H}, \mathrm{CH}_{2}\right), 3.16-3.10\left(\mathrm{~m}, 2 \mathrm{H}, \mathrm{CH}_{2}\right), 1.86-1.75\left(\mathrm{~m}, 4 \mathrm{H}, \mathrm{CH}_{2}\right), 1.50\left(\mathrm{~s}, 9 \mathrm{H}, \mathrm{CH}_{3}\right), 1.37(\mathrm{~s}, 9 \mathrm{H}$, $\left.\mathrm{CH}_{3}\right), 1.40-1.19\left(\mathrm{~m}, 18 \mathrm{H}, \mathrm{CH}_{2}\right), 0.87\left(\mathrm{t}, J=7.1 \mathrm{~Hz}, 3 \mathrm{H}, \mathrm{CH}_{3}\right) ;{ }^{13} \mathrm{C} \mathrm{NMR}\left(150 \mathrm{MHz}, \mathrm{CDCl}_{3}\right): \delta$ 192.8 (CO), 164.0 (CO), 162.3 (CN), 157.0 (CO), 153.2 (CO), 142.0 (ArC), $136.4(\mathrm{ArCH}), 135.1$ $(\mathrm{ArCH}), 122.6(\mathrm{ArCH}), 118.8(\mathrm{ArC}), 118.0(\mathrm{ArCH}), 84.2(\mathrm{C}), 80.5(\mathrm{C}), 52.7\left(\mathrm{CH}_{2}\right), 37.9\left(\mathrm{CH}_{2}\right)$, 35.8 $\left(\mathrm{CH}_{2}\right), 32.0\left(\mathrm{CH}_{2}\right), 29.9\left(\mathrm{CH}_{2}\right), 29.7\left(\mathrm{CH}_{2}\right), 29.7\left(\mathrm{CH}_{2}\right), 29.6\left(\mathrm{CH}_{2}\right), 29.4\left(\mathrm{CH}_{2}\right), 29.4$ $\left(\mathrm{CH}_{2}\right), 29.1\left(\mathrm{CH}_{2}\right), 28.3\left(\mathrm{CH}_{2}\right), 28.2\left(\mathrm{CH}_{3}\right), 28.2\left(\mathrm{CH}_{3}\right), 23.5\left(\mathrm{CH}_{2}\right), 22.8\left(\mathrm{CH}_{2}\right), 14.2\left(\mathrm{CH}_{3}\right) ; \mathrm{IR}$ (ATR): $v_{\max } 3327,3194,2926,2855,1722,1640,1574,1491,1452,1410,1328,1283,1219,1131$, $1050,978,913,753,671 \mathrm{~cm}^{-1}$; HRMS (+ESI): Found $m / z 696.4000[\mathrm{M}+\mathrm{H}]^{+}, \mathrm{C}_{34} \mathrm{H}_{58} \mathrm{~N}_{5} \mathrm{O}_{8} \mathrm{~S}$ required 696.4001.

(E)-1-tert-Butyl- $N-\left(N^{\prime}-((t e r t-b u t y l o x i d a n y l)\right.$ carbonyl)-N-(3-(2-(5-bromo-2(dodecylsulfonamido)phenyl)-2-oxoacetamido)propyl)carbamimidoyl)

-1-oxidanecarboxamide (31b)

The titled compound was synthesised from $\mathrm{N}$-(3-aminopropyl)-2-(5-bromo-2(dodecylsulfonamido) phenyl)-2-oxoacetamide hydrochloride $28 \mathrm{~b}(0.17 \mathrm{~g}, 0.29 \mathrm{mmol})$, $\mathrm{N}, \mathrm{N}^{\prime}$-di-Boc- $1 \mathrm{H}$-pyrazole-1-carboxamidine $(0.13 \mathrm{~g}, 0.43 \mathrm{mmol})$ and triethylamine $(0.10 \mathrm{~mL}$, $0.73 \mathrm{mmol}$ ) following general synthetic procedure $\mathrm{G}$. The product was obtained as a yellow oil $(0.12 \mathrm{~g}, 55 \%) ;{ }^{1} \mathrm{H}$ NMR $\left(400 \mathrm{MHz}, \mathrm{CDCl}_{3}\right): \delta 11.46(\mathrm{~s}, 1 \mathrm{H}, \mathrm{NH}), 10.51(\mathrm{~s}, 1 \mathrm{H}, \mathrm{NH})$, $8.68(\mathrm{t}, J=6.4 \mathrm{~Hz}, 1 \mathrm{H}, \mathrm{NH}), 8.52(\mathrm{t}, J=6.4 \mathrm{~Hz}, 1 \mathrm{H}, \mathrm{NH}), 8.45(\mathrm{~d}, J=2.1 \mathrm{~Hz}, 1 \mathrm{H}, \mathrm{ArH})$, 7.71-7.64 (m, 2H, ArH), $3.54\left(\mathrm{q}, J=6.4 \mathrm{~Hz}, 2 \mathrm{H}, \mathrm{CH}_{2}\right), 3.44\left(\mathrm{q}, J=6.2 \mathrm{~Hz}, 2 \mathrm{H}, \mathrm{CH}_{2}\right), 3.15-3.07$ $\left(\mathrm{m}, 2 \mathrm{H}, \mathrm{CH}_{2}\right), 1.83-1.72\left(\mathrm{~m}, 4 \mathrm{H}, \mathrm{CH}_{2}\right), 1.49\left(\mathrm{~s}, 9 \mathrm{H}, \mathrm{CH}_{3}\right), 1.37\left(\mathrm{~s}, 9 \mathrm{H}, \mathrm{CH}_{3}\right), 1.41-1.17(\mathrm{~m}$, $\left.18 \mathrm{H}, \mathrm{CH}_{2}\right), 0.86\left(\mathrm{t}, J=7.1 \mathrm{~Hz}, 3 \mathrm{H}, \mathrm{CH}_{3}\right) ;{ }^{13} \mathrm{C} \mathrm{NMR}\left(100 \mathrm{MHz}, \mathrm{CDCl}_{3}\right): \delta 191.4(\mathrm{CO}), 163.0$ (CO), 157.4 (CO), $156.3(\mathrm{CN}), 153.3(\mathrm{CO}), 141.1$ (ArC), 139.1 (ArCH), $137.3(\mathrm{ArCH}), 120.1$ $(\mathrm{ArC}), 119.6(\mathrm{ArCH}), 115.1(\mathrm{ArC}), 83.8(\mathrm{C}), 79.8(\mathrm{C}), 52.9\left(\mathrm{CH}_{2}\right), 37.2\left(\mathrm{CH}_{2}\right), 35.9\left(\mathrm{CH}_{2}\right), 32.0$ $\left(\mathrm{CH}_{2}\right), 30.0\left(\mathrm{CH}_{2}\right), 29.7\left(\mathrm{CH}_{2}\right), 29.7\left(\mathrm{CH}_{2}\right), 29.6\left(\mathrm{CH}_{2}\right), 29.4\left(\mathrm{CH}_{2}\right), 29.3\left(\mathrm{CH}_{2}\right), 29.1\left(\mathrm{CH}_{2}\right)$, $28.2\left(\mathrm{CH}_{3}\right), 28.2\left(\mathrm{CH}_{2}\right), 28.2\left(\mathrm{CH}_{3}\right), 23.5\left(\mathrm{CH}_{2}\right), 22.8\left(\mathrm{CH}_{2}\right), 14.2\left(\mathrm{CH}_{3}\right) ; \mathrm{IR}(\mathrm{ATR}): v_{\max } 3327$, 2925, 2854, 2323, 1718, 1637, 1617, 1560, 1541, 1522, 1476, 1457, 1411, 1390, 1367, 1327, 1285, $1253,1227,1153,1132,1050,1026,979,906,808,768,712,653 \mathrm{~cm}^{-1}$; HRMS (+ESI): Found $m / z 774.3108[\mathrm{M}+\mathrm{H}]^{+}, \mathrm{C}_{34} \mathrm{H}_{57} \mathrm{BrN}_{5} \mathrm{O}_{8} \mathrm{~S}$ required 774.3106.

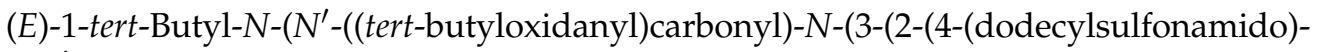
[1,1'-biphenyl]-3-yl)-2-oxoacetamido)propyl)carbamimidoyl)-1-oxidanecarboxamide (31c)

The titled compound was synthesised from $\mathrm{N}$-(3-aminopropyl)-2-(4-(dodecylsulfonamido)[1,1'-biphenyl]-3-yl)-2-oxoacetamide hydrochloride 28c ( $0.15 \mathrm{~g}, 0.27 \mathrm{mmol}), N, N^{\prime}$-di-Boc- 
1H-pyrazole-1-carboxamidine $(0.17 \mathrm{~g}, 0.55 \mathrm{mmol})$ and triethylamine $(92 \mu \mathrm{L}, 0.66 \mathrm{mmol})$ following general synthetic procedure $\mathrm{G}$. The product was obtained as a yellow solid $(0.17 \mathrm{~g}, 83 \%)$; mp 63.6-63.8 ${ }^{\circ} \mathrm{C} ;{ }^{1} \mathrm{H}$ NMR $\left(600 \mathrm{MHz}, \mathrm{CDCl}_{3}\right): \delta 11.47(\mathrm{~s}, 1 \mathrm{H}, \mathrm{NH}), 10.62(\mathrm{~s}$, $1 \mathrm{H}, \mathrm{NH}), 8.63(\mathrm{t}, J=6.6 \mathrm{~Hz}, 1 \mathrm{H}, \mathrm{NH}), 8.56(\mathrm{~d}, J=2.2 \mathrm{~Hz}, 1 \mathrm{H}, \mathrm{ArH}), 8.52(\mathrm{t}, J=6.2 \mathrm{~Hz}, 1 \mathrm{H}$, $\mathrm{NH}), 7.86(\mathrm{~d}, J=8.7 \mathrm{~Hz}, 1 \mathrm{H}, \mathrm{ArH}), 7.82(\mathrm{dd}, J=8.7,2.2 \mathrm{~Hz}, 1 \mathrm{H}, \mathrm{ArH}), 7.58-7.55(\mathrm{~m}, 2 \mathrm{H}$, ArH), 7.46-7.42 (m, 2H, ArH), 7.38-7.34 (m, 1H, ArH), $3.55\left(\mathrm{q}, J=6.4 \mathrm{~Hz}, 2 \mathrm{H}, \mathrm{CH}_{2}\right), 3.46(\mathrm{q}$, $\left.J=6.3 \mathrm{~Hz}, 2 \mathrm{H}, \mathrm{CH}_{2}\right), 3.19-3.15\left(\mathrm{~m}, 2 \mathrm{H}, \mathrm{CH}_{2}\right), 1.84-1.77\left(\mathrm{~m}, 4 \mathrm{H}, \mathrm{CH}_{2}\right), 1.49\left(\mathrm{~s}, 9 \mathrm{H}, \mathrm{CH}_{3}\right), 1.37$ (s, 9H, $\left.\mathrm{CH}_{3}\right), 1.41-1.34\left(\mathrm{~m}, 2 \mathrm{H}, \mathrm{CH}_{2}\right), 1.31-1.19\left(\mathrm{~m}, 16 \mathrm{H}, \mathrm{CH}_{2}\right), 0.87\left(\mathrm{t}, J=7.1 \mathrm{~Hz}, 3 \mathrm{H}, \mathrm{CH}_{3}\right)$; ${ }^{13} \mathrm{C}$ NMR $\left(150 \mathrm{MHz}, \mathrm{CDCl}_{3}\right)$ : $\delta 192.6(\mathrm{CO}), 163.7(\mathrm{CO}), 163.1(\mathrm{CN}), 157.4(\mathrm{CO}), 153.3(\mathrm{CO})$, 141.2 (ArC), 139.1 (ArC), 135.6 (ArC), $135.0(\mathrm{ArCH}), 133.5(\mathrm{ArCH}), 129.1(\mathrm{ArCH}), 127.9$ $(\mathrm{ArCH}), 126.9(\mathrm{ArCH}), 118.9(\mathrm{ArC}), 118.3(\mathrm{ArCH}), 83.7(\mathrm{C}), 79.8(\mathrm{C}), 52.8\left(\mathrm{CH}_{2}\right), 37.2\left(\mathrm{CH}_{2}\right)$, 35.8 $\left(\mathrm{CH}_{2}\right), 32.0\left(\mathrm{CH}_{2}\right), 30.1\left(\mathrm{CH}_{2}\right), 29.7\left(\mathrm{CH}_{2}\right), 29.7\left(\mathrm{CH}_{2}\right), 29.6\left(\mathrm{CH}_{2}\right), 29.4\left(\mathrm{CH}_{2}\right), 29.4$ $\left(\mathrm{CH}_{2}\right), 29.1\left(\mathrm{CH}_{2}\right), 28.3\left(\mathrm{CH}_{3}\right), 28.2\left(\mathrm{CH}_{2}\right), 28.2\left(\mathrm{CH}_{3}\right), 23.6\left(\mathrm{CH}_{2}\right), 22.8\left(\mathrm{CH}_{2}\right), 14.2\left(\mathrm{CH}_{3}\right)$; IR (ATR): $v_{\max } 3326,2926,2854,1719,1636,1615,1570,1507,1483,1411,1366,1326,1285$, 1253, 1228, 1130, 1051, 1025, 979, 907, 854, 807, 760, 698, $681 \mathrm{~cm}^{-1}$; HRMS (+ESI): Found $m / z 772.4320[\mathrm{M}+\mathrm{H}]^{+}, \mathrm{C}_{40} \mathrm{H}_{62} \mathrm{~N}_{5} \mathrm{O}_{8} \mathrm{~S}$ required 772.4314 .

(E)-1-tert-Butyl- $N-\left(N^{\prime}-((\right.$ tert-butyloxidanyl)carbonyl)-N-(3-(2-(2-(hexadecylsulfonamido) phenyl)-2-oxoacetamido)propyl)carbamimidoyl)-1-oxidanecarboxamide (32a)

The titled compound was synthesised from $\mathrm{N}$-(3-aminopropyl)-2-(2-(hexadecylsulfonamido)phenyl)-2-oxoacetamide hydrochloride 29 a $(0.16 \mathrm{~g}, 0.28 \mathrm{mmol}), N, N^{\prime}$-di-Boc- $1 H$ pyrazole-1-carboxamidine $(0.11 \mathrm{~g}, 0.36 \mathrm{mmol})$ and triethylamine $(0.10 \mathrm{~mL}, 0.72 \mathrm{mmol})$ following general synthetic procedure $\mathrm{G}$. The product was obtained as a yellow oil $(0.14 \mathrm{~g}$, $67 \%) ;{ }^{1} \mathrm{H}$ NMR $\left(400 \mathrm{MHz}, \mathrm{CDCl}_{3}\right): \delta 11.46(\mathrm{~s}, 1 \mathrm{H}, \mathrm{NH}), 10.63(\mathrm{~s}, 1 \mathrm{H}, \mathrm{NH}), 8.58(\mathrm{t}, J=6.4 \mathrm{~Hz}$, $1 \mathrm{H}, \mathrm{NH}), 8.52(\mathrm{t}, J=6.3 \mathrm{~Hz}, 1 \mathrm{H}, \mathrm{NH}), 8.26(\mathrm{dd}, J=8.0,1.5 \mathrm{~Hz}, 1 \mathrm{H}, \mathrm{ArH}), 7.77(\mathrm{dd}, J=8.4$, $0.7 \mathrm{~Hz}, 1 \mathrm{H}, \mathrm{ArH}), 7.62-7.55(\mathrm{~m}, 1 \mathrm{H}, \mathrm{ArH}), 7.17-7.11(\mathrm{~m}, 1 \mathrm{H}, \mathrm{ArH}), 3.55(\mathrm{q}, J=6.6 \mathrm{~Hz}, 2 \mathrm{H}$, $\left.\mathrm{CH}_{2}\right), 3.44\left(\mathrm{q}, \mathrm{J}=6.1 \mathrm{~Hz}, 2 \mathrm{H}, \mathrm{CH}_{2}\right), 3.17-3.10\left(\mathrm{~m}, 2 \mathrm{H}, \mathrm{CH}_{2}\right), 1.84-1.73\left(\mathrm{~m}, 4 \mathrm{H}, \mathrm{CH}_{2}\right), 1.49$ (s, 9H, $\left.\mathrm{CH}_{3}\right), 1.35\left(\mathrm{~s}, 9 \mathrm{H}, \mathrm{CH}_{3}\right), 1.39-1.18\left(\mathrm{~m}, 26 \mathrm{H}, \mathrm{CH}_{2}\right), 0.87\left(\mathrm{t}, J=7.0 \mathrm{~Hz}, 3 \mathrm{H}, \mathrm{CH}_{3}\right) ;{ }^{13} \mathrm{C}$ NMR (100 MHz, CDCl $)$ : $\delta 192.8$ (CO), 163.9 (CO), 163.1 (CN), 157.4 (CO), $153.4(\mathrm{CO})$, 142.2 (ArC), $136.5(\mathrm{ArCH}), 135.2(\mathrm{ArCH}), 122.5(\mathrm{ArCH}), 118.5(\mathrm{ArC}), 117.8(\mathrm{ArCH}), 83.7$ (C), $79.7(\mathrm{C}), 52.7\left(\mathrm{CH}_{2}\right), 37.2\left(\mathrm{CH}_{2}\right), 35.8\left(\mathrm{CH}_{2}\right), 32.1\left(\mathrm{CH}_{2}\right), 30.1\left(\mathrm{CH}_{2}\right), 29.8\left(\mathrm{CH}_{2}\right), 29.8$ $\left(\mathrm{CH}_{2}\right), 29.8\left(\mathrm{CH}_{2}\right), 29.8\left(\mathrm{CH}_{2}\right), 29.8\left(\mathrm{CH}_{2}\right), 29.7\left(\mathrm{CH}_{2}\right), 29.6\left(\mathrm{CH}_{2}\right), 29.5\left(\mathrm{CH}_{2}\right), 29.4\left(\mathrm{CH}_{2}\right)$, $29.1\left(\mathrm{CH}_{2}\right), 28.3\left(\mathrm{CH}_{2}\right), 28.2\left(\mathrm{CH}_{3}\right), 28.2\left(\mathrm{CH}_{3}\right), 23.5\left(\mathrm{CH}_{2}\right), 22.8\left(\mathrm{CH}_{2}\right), 14.3\left(\mathrm{CH}_{3}\right)$; IR (ATR): $v_{\max } 3327,3195,2923,2853,2340,1723,1640,1614,1574,1491,1452,1409,1330,1283,1221$, $1133,1050,914,753,672 \mathrm{~cm}^{-1}$; HRMS (+ESI): Found $m / z 752.4626[\mathrm{M}+\mathrm{H}]^{+}, \mathrm{C}_{38} \mathrm{H}_{66} \mathrm{~N}_{5} \mathrm{O}_{8} \mathrm{~S}$ required 752.4627 .

(E)-1-tert-Butyl- $N-\left(N^{\prime}-((\right.$ tert-butyloxidanyl)carbonyl)-N-(3-(2-(5-bromo-2(hexadecylsulfonamido) phenyl)-2-oxoacetamido)propyl)carbamimidoyl) -1-oxidanecarboxamide (32b)

The titled compound was synthesised from $\mathrm{N}$-(3-aminopropyl)-2-(5-bromo-2(hexadecylsulfonamido) phenyl)-2-oxoacetamide hydrochloride $29 \mathrm{~b}(0.24 \mathrm{~g}, 0.38 \mathrm{mmol})$, $\mathrm{N}, \mathrm{N}^{\prime}$-di-Boc- $1 \mathrm{H}$-pyrazole-1-carboxamidine $(0.14 \mathrm{~g}, 0.46 \mathrm{mmol})$ and triethylamine $(0.13 \mathrm{~mL}$, $0.95 \mathrm{mmol}$ ) following general synthetic procedure $\mathrm{G}$. The product was obtained as a yellow oil $(0.16 \mathrm{~g}, 51 \%) ;{ }^{1} \mathrm{H}$ NMR $\left(600 \mathrm{MHz}, \mathrm{CDCl}_{3}\right): \delta 11.47(\mathrm{~s}, 1 \mathrm{H}, \mathrm{NH}), 10.52(\mathrm{~s}, 1 \mathrm{H}, \mathrm{NH})$, $8.69(\mathrm{t}, J=6.4 \mathrm{~Hz}, 1 \mathrm{H}, \mathrm{NH}), 8.53(\mathrm{t}, J=6.4 \mathrm{~Hz}, 1 \mathrm{H}, \mathrm{NH}), 8.46(\mathrm{~d}, J=2.2 \mathrm{~Hz}, 1 \mathrm{H}, \mathrm{ArH})$, 7.71-7.65 (m, 2H, ArH), $3.54\left(\mathrm{q}, J=6.4 \mathrm{~Hz}, 2 \mathrm{H}, \mathrm{CH}_{2}\right), 3.44\left(\mathrm{q}, J=6.2 \mathrm{~Hz}, 2 \mathrm{H}, \mathrm{CH}_{2}\right), 3.15-3.08$ $\left(\mathrm{m}, 2 \mathrm{H}, \mathrm{CH}_{2}\right), 1.82-1.73\left(\mathrm{~m}, 4 \mathrm{H}, \mathrm{CH}_{2}\right), 1.50\left(\mathrm{~s}, 9 \mathrm{H}, \mathrm{CH}_{3}\right), 1.37\left(\mathrm{~s}, 9 \mathrm{H}, \mathrm{CH}_{3}\right), 1.40-1.32(\mathrm{~m}, 2 \mathrm{H}$, $\left.\mathrm{CH}_{2}\right), 1.31-1.19\left(\mathrm{~m}, 24 \mathrm{H}, \mathrm{CH}_{2}\right), 0.87\left(\mathrm{t}, J=7.1 \mathrm{~Hz}, 3 \mathrm{H}, \mathrm{CH}_{3}\right) ;{ }^{13} \mathrm{C} \mathrm{NMR}\left(150 \mathrm{MHz}, \mathrm{CDCl}_{3}\right): \delta$ 191.4 (CO), 163.0 (CO), 163.0 (CN), 157.5 (CO), $153.3(\mathrm{CO}), 141.1$ (ArC), $139.2(\mathrm{ArCH}), 137.3$ $(\mathrm{ArCH}), 120.0(\mathrm{ArC}), 119.6(\mathrm{ArCH}), 115.1(\mathrm{ArC}), 83.8(\mathrm{C}), 79.8(\mathrm{C}), 52.9\left(\mathrm{CH}_{2}\right), 37.2\left(\mathrm{CH}_{2}\right)$, $35.9\left(\mathrm{CH}_{2}\right), 32.1\left(\mathrm{CH}_{2}\right), 30.0\left(\mathrm{CH}_{2}\right), 29.8\left(\mathrm{CH}_{2}\right), 29.8\left(\mathrm{CH}_{2}\right), 29.8\left(\mathrm{CH}_{2}\right), 29.8\left(\mathrm{CH}_{2}\right), 29.8$ $\left(\mathrm{CH}_{2}\right), 29.7\left(\mathrm{CH}_{2}\right), 29.6\left(\mathrm{CH}_{2}\right), 29.5\left(\mathrm{CH}_{2}\right), 29.4\left(\mathrm{CH}_{2}\right), 29.1\left(\mathrm{CH}_{2}\right), 28.3\left(\mathrm{CH}_{3}\right), 28.2\left(\mathrm{CH}_{2}\right)$, $28.2\left(\mathrm{CH}_{3}\right), 23.5\left(\mathrm{CH}_{2}\right), 22.8\left(\mathrm{CH}_{2}\right), 14.3\left(\mathrm{CH}_{3}\right)$; IR (ATR): $v_{\max } 3326,2924,2854,2097,1721$, 
$1642,1569,1477,1413,1327,1285,1227,1131,1050,979,906,808,767,713 \mathrm{~cm}^{-1}$; HRMS (+ESI): Found $m / z$ 830.3731 $[\mathrm{M}+\mathrm{H}]^{+}, \mathrm{C}_{36} \mathrm{H}_{65} \mathrm{BrN}_{5} \mathrm{O}_{8} \mathrm{~S}$ required 830.3732.

(E)-1-tert-Butyl-N-(N'-((tert-butyloxidanyl)carbonyl)-N-(3-(2-(4-(hexadecylsulfonamido)[1,1'-biphenyl]-3-yl)-2-oxoacetamido)propyl)carbamimidoyl)-1-oxidanecarboxamide (32c)

The titled compound was synthesised from $N$-(3-aminopropyl)-2-(4-(hexadecylsulfonamido)-[1,1'-biphenyl]-3-yl)-2-oxoacetamide hydrochloride 29c $(0.20 \mathrm{~g}, 0.31 \mathrm{mmol}), N, N^{\prime}$ di-Boc- $1 H$-pyrazole-1-carboxamidine $(0.12 \mathrm{~g}, 0.39 \mathrm{mmol})$ and triethylamine $(0.10 \mathrm{~mL}$, $0.79 \mathrm{mmol}$ ) following general synthetic procedure $\mathrm{G}$. The product was obtained as a yellow oil $(0.17 \mathrm{~g}, 66 \%)$; ${ }^{1} \mathrm{H}$ NMR $\left(600 \mathrm{MHz}, \mathrm{CDCl}_{3}\right): \delta 11.47(\mathrm{~s}, 1 \mathrm{H}, \mathrm{NH}), 10.62(\mathrm{~s}, 1 \mathrm{H}$, $\mathrm{NH}), 8.62(\mathrm{t}, J=6.3 \mathrm{~Hz}, 1 \mathrm{H}, \mathrm{NH}), 8.60(\mathrm{bs}, 1 \mathrm{H}, \mathrm{NH}), 8.55(\mathrm{~d}, J=2.1 \mathrm{~Hz}, 1 \mathrm{H}, \mathrm{ArH}), 7.86(\mathrm{~d}$, $J=8.7 \mathrm{~Hz}, 1 \mathrm{H}, \mathrm{ArH}), 7.82(\mathrm{dd}, J=8.7,2.2 \mathrm{~Hz}, 1 \mathrm{H}, \mathrm{ArH}), 7.58-7.55$ (m, 2H, ArH), 7.46-7.42 (m, 2H, ArH), 7.38-7.34 (m, 1H, ArH), 3.64-3.54 (m, 2H, $\left.\mathrm{CH}_{2}\right), 3.46(\mathrm{q}, J=6.4 \mathrm{~Hz}, 2 \mathrm{H}$, $\left.\mathrm{CH}_{2}\right), 3.19-3.15\left(\mathrm{~m}, 2 \mathrm{H}, \mathrm{CH}_{2}\right), 1.85-1.78\left(\mathrm{~m}, 4 \mathrm{H}, \mathrm{CH}_{2}\right), 1.50\left(\mathrm{~s}, 9 \mathrm{H}, \mathrm{CH}_{3}\right), 1.38\left(\mathrm{~s}, 9 \mathrm{H}, \mathrm{CH}_{3}\right)$, 1.41-1.33 (m, 2H, $\left.\mathrm{CH}_{2}\right), 1.32-1.20\left(\mathrm{~m}, 24 \mathrm{H}, \mathrm{CH}_{2}\right), 0.87\left(\mathrm{t}, J=7.2 \mathrm{~Hz}, 3 \mathrm{H}, \mathrm{CH}_{3}\right) ;{ }^{13} \mathrm{C} \mathrm{NMR}$ (150 MHz, $\mathrm{CDCl}_{3}$ ): $\delta 192.6(\mathrm{CO}), 163.8(\mathrm{CO}), 163.8(\mathrm{CN}), 157.2(\mathrm{CO}), 153.3(\mathrm{CO}), 141.1(\mathrm{ArC})$, 139.1 (ArC), 135.7 (ArC), 134.9 (ArCH), 133.5 (ArCH), $129.1(\mathrm{ArCH}), 127.9$ (ArCH), 127.0 $(\mathrm{ArCH}), 119.2(\mathrm{ArC}), 118.4(\mathrm{ArCH}), 84.0(\mathrm{C}), 80.3(\mathrm{C}), 52.8\left(\mathrm{CH}_{2}\right), 37.6\left(\mathrm{CH}_{2}\right), 35.9\left(\mathrm{CH}_{2}\right)$, $32.1\left(\mathrm{CH}_{2}\right), 30.0\left(\mathrm{CH}_{2}\right), 29.8\left(\mathrm{CH}_{2}\right), 29.8\left(\mathrm{CH}_{2}\right), 29.8\left(\mathrm{CH}_{2}\right), 29.7\left(\mathrm{CH}_{2}\right), 29.6\left(\mathrm{CH}_{2}\right), 29.5$ $\left(\mathrm{CH}_{2}\right), 29.4\left(\mathrm{CH}_{2}\right), 29.1\left(\mathrm{CH}_{2}\right), 28.3\left(\mathrm{CH}_{2}\right), 28.2\left(\mathrm{CH}_{3}\right), 28.2\left(\mathrm{CH}_{3}\right), 23.5\left(\mathrm{CH}_{2}\right), 22.8\left(\mathrm{CH}_{2}\right)$, $14.3\left(\mathrm{CH}_{3}\right)$; IR (ATR): $v_{\max } 3326,3194,2922,2852,2321,2090,1720,1638,1575,1482,1410$, 1326, 1283, 1130, 1050, 978, 907, 854, 806, 759, $697 \mathrm{~cm}^{-1}$; HRMS (+ESI): Found $\mathrm{m} / z$ 828.4939 $[\mathrm{M}+\mathrm{H}]^{+}, \mathrm{C}_{44} \mathrm{H}_{70} \mathrm{~N}_{5} \mathrm{O}_{8} \mathrm{~S}$ required 828.4940.

General synthetic procedure $\mathbf{H}$ for guanidinium hydrochloride salts

Trifluoroacetic acid $(2 \mathrm{~mL})$ was added to a stirring solution of Boc-protected guanidine glyoxamide (1.0 equivalent) in dichloromethane $(2 \mathrm{~mL})$. The resulting reaction mixture was stirred at room temperature for $3 \mathrm{~h}$. After the completion of the reaction, the reaction solvent was removed under reduced pressure and the residue was washed thrice with diethyl ether. To the residue redissolved in dichloromethane $(2 \mathrm{~mL})$ was added $4 \mathrm{M} \mathrm{HCl}$ in dioxane $(2 \mathrm{~mL})$, and the resulting reaction mixture was stirred at room temperature for $30 \mathrm{~min}$. After the completion of the reaction, the reaction solvent was removed under reduced pressure. The residue was washed thrice with diethyl ether and freeze-dried to afford the product.

N-(3-Guanidinopropyl)-2-(4-(octylsulfonamido)-[1,1':4',1'-terphenyl]-3-yl)-2oxoacetamide hydrochloride (33d)

The titled compound was synthesised from $(E)-1$-tert-butyl- $N-\left(N^{\prime}-((\right.$ tert-butyloxidanyl $)$ carbonyl)-N-(3-(2-(4-(octylsulfonamido)-[1,1':4',1"'-terphenyl]-3-yl)-2-oxoacetamido)propyl) carbamimidoyl)-1-oxidanecarboxamide $30 \mathrm{~d}(0.15 \mathrm{~g}, 0.19 \mathrm{mmol})$ following general synthetic procedure $\mathbf{H}$. The product was obtained as a yellow solid $(58 \mathrm{mg}, 48 \%) ; \mathrm{mp} 49.6-50.1{ }^{\circ} \mathrm{C} ;{ }^{1} \mathrm{H}$ NMR (600 MHz, DMSO-d $\left._{6}\right): \delta 10.22(\mathrm{~s}, 1 \mathrm{H}, \mathrm{NH}), 9.03$ (t, $\left.J=5.8 \mathrm{~Hz}, 1 \mathrm{H}, \mathrm{NH}\right), 8.12-8.02$ (m, $2 \mathrm{H}, \mathrm{ArH}), 7.81(\mathrm{~d}, J=8.5 \mathrm{~Hz}, 2 \mathrm{H}, \mathrm{ArH}), 7.76-7.69(\mathrm{~m}, 5 \mathrm{H}, \mathrm{NH}, \mathrm{ArH}), 7.66(\mathrm{~d}, J=8.7 \mathrm{~Hz}, 1 \mathrm{H}$, $\mathrm{ArH}), 7.57-6.83(\mathrm{~m}, 7 \mathrm{H}, \mathrm{NH}, \mathrm{ArH}), 3.32\left(\mathrm{q}, J=6.7 \mathrm{~Hz}, 2 \mathrm{H}, \mathrm{CH}_{2}\right), 3.29-3.25\left(\mathrm{~m}, 2 \mathrm{H}, \mathrm{CH}_{2}\right)$, $3.21\left(\mathrm{q}, J=6.7 \mathrm{~Hz}, 2 \mathrm{H}, \mathrm{CH}_{2}\right), 1.79-1.72\left(\mathrm{~m}, 2 \mathrm{H}, \mathrm{CH}_{2}\right), 1.72-1.65\left(\mathrm{~m}, 2 \mathrm{H}, \mathrm{CH}_{2}\right), 1.38-1.31$ $\left(\mathrm{m}, 2 \mathrm{H}, \mathrm{CH}_{2}\right), 1.27-1.16\left(\mathrm{~m}, 8 \mathrm{H}, \mathrm{CH}_{2}\right), 0.82\left(\mathrm{t}, \mathrm{J}=7.1 \mathrm{~Hz}, 3 \mathrm{H}, \mathrm{CH}_{3}\right) ;{ }^{13} \mathrm{C} \mathrm{NMR}(150 \mathrm{MHz}$, DMSO- $\left.d_{6}\right): \delta 192.5(\mathrm{CO}), 163.8(\mathrm{CO}), 156.4(\mathrm{CN}), 139.6$ (ArC), $139.4(\mathrm{ArC}), 138.4(\mathrm{ArC}), 137.2$ (ArC), 135.0 (ArC), 133.0 (ArCH), $130.4(\mathrm{ArCH}), 129.0(\mathrm{ArCH}), 127.7(\mathrm{ArCH}), 127.4(\mathrm{ArCH})$, $126.9(\mathrm{ArCH}), 126.6(\mathrm{ArCH}), 124.4(\mathrm{ArC}), 121.7(\mathrm{ArCH}), 51.5\left(\mathrm{CH}_{2}\right), 38.4\left(\mathrm{CH}_{2}\right), 36.1\left(\mathrm{CH}_{2}\right)$, $31.1\left(\mathrm{CH}_{2}\right), 28.4\left(\mathrm{CH}_{2}\right), 28.4\left(\mathrm{CH}_{2}\right), 28.3\left(\mathrm{CH}_{2}\right), 27.3\left(\mathrm{CH}_{2}\right), 22.9\left(\mathrm{CH}_{2}\right), 22.0\left(\mathrm{CH}_{2}\right), 13.9$ $\left(\mathrm{CH}_{3}\right)$; IR (ATR): $v_{\max } 3808,3273,3162,2924,2854,2359,1650,1529,1497,1482,1400,1333$, 1272, 1196, 1142, 1076, 1006, 917, 827, 764, 719, 695, $674 \mathrm{~cm}^{-1} ;$ HRMS (+ESI): Found $\mathrm{m} / z$ $592.2956[\mathrm{M}+\mathrm{H}]^{+}, \mathrm{C}_{32} \mathrm{H}_{42} \mathrm{~N}_{5} \mathrm{O}_{4} \mathrm{~S}$ required 592.2952. 
2-(2-(Dodecylsulfonamido)phenyl)-N-(3-guanidinopropyl)-2-oxoacetamide hydrochloride (34a)

The titled compound was synthesised from (E)-1-tert-butyl- $N-\left(N^{\prime}-((\right.$ tert-butyloxidanyl) carbonyl)- $\mathrm{N}$-(3-(2-(2-(dodecylsulfonamido)phenyl)-2-oxoacetamido)propyl)carbamimidoyl)1-oxidanecarboxamide $31 \mathrm{a}(0.11 \mathrm{~g}, 0.16 \mathrm{mmol})$ following general synthetic procedure $\mathbf{H}$. The product was obtained as a pale yellow solid $(71 \mathrm{~g}, 82 \%) ; \mathrm{mp} 70.0-72.8{ }^{\circ} \mathrm{C} ;{ }^{1} \mathrm{H} \mathrm{NMR}$ $\left(600 \mathrm{MHz}, \mathrm{DMSO}-d_{6}\right): \delta 10.27(\mathrm{~s}, 1 \mathrm{H}, \mathrm{NH}), 8.98(\mathrm{t}, J=5.7 \mathrm{~Hz}, 1 \mathrm{H}, \mathrm{NH}), 7.78(\mathrm{dd}, J=7.9$, $1.5 \mathrm{~Hz}, 1 \mathrm{H}, \mathrm{ArH}), 7.74(\mathrm{t}, J=5.8 \mathrm{~Hz}, 1 \mathrm{H}, \mathrm{NH}), 7.72-7.68(\mathrm{~m}, 1 \mathrm{H}, \mathrm{ArH}), 7.63-6.78(\mathrm{~m}, 6 \mathrm{H}$, $\mathrm{NH}, \mathrm{ArH}), 3.31-3.23\left(\mathrm{~m}, 4 \mathrm{H}, \mathrm{CH}_{2}\right), 3.18\left(\mathrm{q}, J=6.7 \mathrm{~Hz}, 2 \mathrm{H}, \mathrm{CH}_{2}\right), 1.76-1.69\left(\mathrm{~m}, 2 \mathrm{H}, \mathrm{CH}_{2}\right)$, 1.68-1.61 (m, 2H, $\left.\mathrm{CH}_{2}\right), 1.35-1.15\left(\mathrm{~m}, 18 \mathrm{H}, \mathrm{CH}_{2}\right), 0.85\left(\mathrm{t}, J=7.2 \mathrm{~Hz}, 3 \mathrm{H}, \mathrm{CH}_{3}\right) ;{ }^{13} \mathrm{C} \mathrm{NMR}$ $\left(150 \mathrm{MHz}, \mathrm{DMSO}-d_{6}\right): \delta 193.4(\mathrm{CO}), 164.3(\mathrm{CO}), 157.0(\mathrm{CN}), 139.6(\mathrm{ArC}), 135.5(\mathrm{ArCH})$, 133.2 (ArCH), 123.6 (ArCH), $122.4(\mathrm{ArC}), 120.1(\mathrm{ArCH}), 51.4\left(\mathrm{CH}_{2}\right), 38.4\left(\mathrm{CH}_{2}\right), 36.0\left(\mathrm{CH}_{2}\right)$, $31.3\left(\mathrm{CH}_{2}\right), 29.0\left(\mathrm{CH}_{2}\right), 28.9\left(\mathrm{CH}_{2}\right), 28.7\left(\mathrm{CH}_{2}\right), 28.7\left(\mathrm{CH}_{2}\right), 28.4\left(\mathrm{CH}_{2}\right), 28.3\left(\mathrm{CH}_{2}\right), 27.2$ $\left(\mathrm{CH}_{2}\right), 22.9\left(\mathrm{CH}_{2}\right), 22.1\left(\mathrm{CH}_{2}\right), 14.0\left(\mathrm{CH}_{3}\right)$; IR (ATR): $v_{\max } 3329,3249,3157,2917,2850,1635$, 1572, 1528, 1492, 1451, 1398, 1337, 1224, 1149, 1065, 912, 822, 750, $673 \mathrm{~cm}^{-1}$; HRMS (+ESI): Found $m / z 496.2951[\mathrm{M}+\mathrm{H}]^{+}, \mathrm{C}_{24} \mathrm{H}_{42} \mathrm{~N}_{5} \mathrm{O}_{4} \mathrm{~S}$ required 496.2952.

2-(5-Bromo-2-(dodecylsulfonamido)phenyl)- $\mathrm{N}$-(3-guanidinopropyl)-2-oxoacetamide hydrochloride (34b)

The titled compound was synthesised from (E)-1-tert-butyl- $N-\left(N^{\prime}-((t e r t-b u t y l o x i d a n y l)\right.$ carbonyl)- $\mathrm{N}$-(3-(2-(5-bromo-2-(dodecylsulfonamido)phenyl)-2-oxoacetamido)propyl) carbamimidoyl)-1-oxidanecarboxamide $31 \mathbf{b}(71 \mathrm{mg}, 0.092 \mathrm{mmol})$ following general synthetic procedure $\mathbf{H}$. The product was obtained as a white solid $(47 \mathrm{mg}, 84 \%) ; \mathrm{mp} 50.0-50.1^{\circ} \mathrm{C} ;{ }^{1} \mathrm{H}$ NMR (600 MHz, DMSO- $\left.d_{6}\right): \delta 10.08(\mathrm{~s}, 1 \mathrm{H}, \mathrm{NH}), 8.94(\mathrm{bs}, 1 \mathrm{H}, \mathrm{NH}), 7.93-7.79(\mathrm{~m}, 2 \mathrm{H}, \mathrm{ArH})$, 7.70-6.72 (m, 6H, NH, ArH), $3.26\left(\mathrm{q}, J=6.8 \mathrm{~Hz}, 2 \mathrm{H}, \mathrm{CH}_{2}\right), 3.21-3.14\left(\mathrm{~m}, 4 \mathrm{H}, \mathrm{CH}_{2}\right), 1.76-1.68$ $\left(\mathrm{m}, 2 \mathrm{H}, \mathrm{CH}_{2}\right), 1.67-1.59\left(\mathrm{~m}, 2 \mathrm{H}, \mathrm{CH}_{2}\right), 1.34-1.15\left(\mathrm{~m}, 18 \mathrm{H}, \mathrm{CH}_{2}\right), 0.85\left(\mathrm{t}, J=7.2 \mathrm{~Hz}, 3 \mathrm{H}, \mathrm{CH}_{3}\right)$; ${ }^{13} \mathrm{C}$ NMR $\left(150 \mathrm{MHz}\right.$, DMSO- $\left.d_{6}\right): \delta 190.4(\mathrm{CO}), 163.0(\mathrm{CO}), 156.9(\mathrm{CN}), 137.6(\mathrm{ArC}), 137.0$ $(\mathrm{ArCH}), 134.2(\mathrm{ArCH}), 127.6(\mathrm{ArC}), 124.2(\mathrm{ArCH}), 116.2(\mathrm{ArC}), 51.4\left(\mathrm{CH}_{2}\right), 38.3\left(\mathrm{CH}_{2}\right), 36.1$ $\left(\mathrm{CH}_{2}\right), 31.3\left(\mathrm{CH}_{2}\right), 29.0\left(\mathrm{CH}_{2}\right), 28.9\left(\mathrm{CH}_{2}\right), 28.7\left(\mathrm{CH}_{2}\right), 28.7\left(\mathrm{CH}_{2}\right), 28.4\left(\mathrm{CH}_{2}\right), 28.3\left(\mathrm{CH}_{2}\right)$, $27.3\left(\mathrm{CH}_{2}\right), 22.8\left(\mathrm{CH}_{2}\right), 22.1\left(\mathrm{CH}_{2}\right), 14.0\left(\mathrm{CH}_{3}\right)$; IR (ATR): $v_{\max } 3171,2919,2851,2360,1642$, 1562, 1530, 1479, 1385, 1337, 1293, 1223, 1198, 1147, 907, 823, 710, $654 \mathrm{~cm}^{-1}$; HRMS (+ESI): Found $m / z 574.2061[\mathrm{M}+\mathrm{H}]^{+}, \mathrm{C}_{24} \mathrm{H}_{41} \mathrm{BrN}_{5} \mathrm{O}_{4} \mathrm{~S}$ required 574.2057.

2-(4-(Dodecylsulfonamido)-[1,1'-biphenyl]-3-yl)-N-(3-guanidinopropyl)-2-oxoacetamide hydrochloride (34c)

The titled compound was synthesised from (E)-1-tert-butyl- $N-\left(N^{\prime}-((\right.$ tert-butyloxidanyl) carbonyl)- $N$-(3-(2-(4-(dodecylsulfonamido)-[1,1'-biphenyl]-3-yl)-2-oxoacetamido)propyl) carbamimidoyl)-1-oxidanecarboxamide 31c $(82 \mathrm{mg}, 0.11 \mathrm{mmol})$ following general synthetic procedure $\mathrm{H}$. The product was obtained as a yellow solid $(41 \mathrm{mg}, 63 \%) ; \mathrm{mp} 73.2-73.5^{\circ} \mathrm{C} ;{ }^{1} \mathrm{H}$ NMR $\left(600 \mathrm{MHz}, \mathrm{DMSO}-d_{6}\right): \delta 10.21$ (s, $\left.1 \mathrm{H}, \mathrm{NH}\right), 9.02(\mathrm{bs}, 1 \mathrm{H}, \mathrm{NH}), 8.03-7.98(\mathrm{~m}, 2 \mathrm{H}, \mathrm{ArH})$, 7.71 (bs, 1H, NH), 7.66-7.60 (m, 3H, ArH), 7.56-6.78 (m, 7H, NH, ArH), $3.30(\mathrm{q}, J=6.7 \mathrm{~Hz}$, $\left.2 \mathrm{H}, \mathrm{CH}_{2}\right), 3.28-3.23\left(\mathrm{~m}, 2 \mathrm{H}, \mathrm{CH}_{2}\right), 2.22-2.15\left(\mathrm{~m}, 2 \mathrm{H}, \mathrm{CH}_{2}\right), 1.78-1.71\left(\mathrm{~m}, 2 \mathrm{H}, \mathrm{CH}_{2}\right), 1.70-1.63$ $\left(\mathrm{m}, 2 \mathrm{H}, \mathrm{CH}_{2}\right), 1.36-1.30\left(\mathrm{~m}, 2 \mathrm{H}, \mathrm{CH}_{2}\right), 1.28-1.14\left(\mathrm{~m}, 16 \mathrm{H}, \mathrm{CH}_{2}\right), 0.84\left(\mathrm{t}, J=7.2 \mathrm{~Hz}, 3 \mathrm{H}, \mathrm{CH}_{3}\right)$; ${ }^{13} \mathrm{C}$ NMR $\left(150 \mathrm{MHz}\right.$, DMSO- $\left.d_{6}\right): \delta 192.6(\mathrm{CO}), 163.8(\mathrm{CO}), 157.0(\mathrm{CN}), 138.3(\mathrm{ArC}), 138.2$ (ArC), $135.5(\mathrm{ArC}), 133.2(\mathrm{ArCH}), 130.5(\mathrm{ArCH}), 129.2(\mathrm{ArCH}), 127.9(\mathrm{ArCH}), 126.4(\mathrm{ArCH})$, 124.3 (ArC), 121.6 (ArCH), 51.4 $\left(\mathrm{CH}_{2}\right), 38.4\left(\mathrm{CH}_{2}\right), 36.1\left(\mathrm{CH}_{2}\right), 31.3\left(\mathrm{CH}_{2}\right), 29.0\left(\mathrm{CH}_{2}\right), 28.9$ $\left(\mathrm{CH}_{2}\right), 28.7\left(\mathrm{CH}_{2}\right), 28.7\left(\mathrm{CH}_{2}\right), 28.4\left(\mathrm{CH}_{2}\right), 28.4\left(\mathrm{CH}_{2}\right), 27.3\left(\mathrm{CH}_{2}\right), 22.9\left(\mathrm{CH}_{2}\right), 22.1\left(\mathrm{CH}_{2}\right)$, $14.0\left(\mathrm{CH}_{3}\right)$; IR (ATR): $v_{\max } 3365,3167,2919,2850,2359,1767,1736,1676,1626,1582,1527$, 1512, 1487, 1467, 1396, 1376, 1347, 1309, 1266, 1214, 1200, 1175, 1139, 1094, 925, 910, 853, 824, 780, 759, 720, 683, $651 \mathrm{~cm}^{-1}$; HRMS (+ESI): Found $m / z 572.3267[\mathrm{M}+\mathrm{H}]^{+}, \mathrm{C}_{30} \mathrm{H}_{46} \mathrm{~N}_{5} \mathrm{O}_{4} \mathrm{~S}$ required 572.3265 . 
N-(3-Guanidinopropyl)-2-(2-(hexadecylsulfonamido)phenyl)-2-oxoacetamide hydrochloride (35a)

The titled compound was synthesised from $(E)-1$-tert-butyl- $N-\left(N^{\prime}-((\right.$ tert-butyloxidanyl) carbonyl)-N-(3-(2-(2-(hexadecylsulfonamido)phenyl)-2-oxoacetamido)propyl)carbamimidoyl)1-oxidanecarboxamide 32a $(61 \mathrm{mg}, 0.081 \mathrm{mmol})$ following general synthetic procedure H. The product was obtained as a white sticky solid $(31 \mathrm{mg}, 65 \%) ;{ }^{1} \mathrm{H} \mathrm{NMR}(600 \mathrm{MHz}$, DMSO- $\left.d_{6}\right): \delta 10.27(\mathrm{~s}, 1 \mathrm{H}, \mathrm{NH}), 8.97(\mathrm{t}, J=5.8 \mathrm{~Hz}, 1 \mathrm{H}, \mathrm{NH}), 7.78(\mathrm{dd}, J=7.9,1.5 \mathrm{~Hz}, 1 \mathrm{H}$, ArH), 7.74-7.68 (m, 2H, NH, ArH), 7.62-6.78 (m, 6H, NH, ArH), 3.31-3.23 (m, 4H, $\left.\mathrm{CH}_{2}\right)$, $3.18\left(\mathrm{q}, \mathrm{J}=6.7 \mathrm{~Hz}, 2 \mathrm{H}, \mathrm{CH}_{2}\right), 1.77-1.70\left(\mathrm{~m}, 2 \mathrm{H}, \mathrm{CH}_{2}\right), 1.68-1.61\left(\mathrm{~m}, 2 \mathrm{H}, \mathrm{CH}_{2}\right), 1.36-1.15$ $\left(\mathrm{m}, 26 \mathrm{H}, \mathrm{CH}_{2}\right), 0.85\left(\mathrm{t}, J=7.1 \mathrm{~Hz}, 3 \mathrm{H}, \mathrm{CH}_{3}\right) ;{ }^{13} \mathrm{C} \mathrm{NMR}\left(150 \mathrm{MHz}, \mathrm{DMSO}-d_{6}\right): \delta 193.4(\mathrm{CO})$, $164.3(\mathrm{CO}), 156.9(\mathrm{CN}), 139.6(\mathrm{ArC}), 135.5(\mathrm{ArCH}), 133.2(\mathrm{ArCH}), 123.6(\mathrm{ArCH}), 122.5(\mathrm{ArC})$, $120.1(\mathrm{ArCH}), 51.4\left(\mathrm{CH}_{2}\right), 38.4\left(\mathrm{CH}_{2}\right), 36.0\left(\mathrm{CH}_{2}\right), 31.3\left(\mathrm{CH}_{2}\right), 29.0\left(\mathrm{CH}_{2}\right), 29.0\left(\mathrm{CH}_{2}\right), 29.0$ $\left(\mathrm{CH}_{2}\right), 29.0\left(\mathrm{CH}_{2}\right), 29.0\left(\mathrm{CH}_{2}\right), 28.9\left(\mathrm{CH}_{2}\right), 28.7\left(\mathrm{CH}_{2}\right), 28.7\left(\mathrm{CH}_{2}\right), 28.4\left(\mathrm{CH}_{2}\right), 28.3\left(\mathrm{CH}_{2}\right)$, $27.3\left(\mathrm{CH}_{2}\right), 22.9\left(\mathrm{CH}_{2}\right), 22.1\left(\mathrm{CH}_{2}\right), 14.0\left(\mathrm{CH}_{3}\right)$; IR (ATR): $v_{\max } 3343,3245,3173,2915,2849$, 2290, 2106, 1626, 1573, 1543, 1493, 1453, 1398, 1339, 1219, 1150, 1070, 913, 885, 821, 750, 675 $\mathrm{cm}^{-1}$; HRMS (+ESI): Found $m / z 552.3578[\mathrm{M}+\mathrm{H}]^{+}, \mathrm{C}_{28} \mathrm{H}_{50} \mathrm{~N}_{5} \mathrm{O}_{4} \mathrm{~S}$ required 552.3578 .

2-(5-Bromo-2-(hexadecylsulfonamido)phenyl)-N-(3-guanidinopropyl)-2-oxoacetamide hydrochloride (35b)

The titled compound was synthesised from $(E)-1$-tert-butyl- $N-\left(N^{\prime}-((\right.$ tert-butyloxidanyl) carbonyl)-N-(3-(2-(5-bromo-2-(hexadecylsulfonamido)phenyl)-2-oxoacetamido)propyl) carbamimidoyl)-1-oxidanecarboxamide $32 \mathrm{~b}(85 \mathrm{mg}, 0.10 \mathrm{mmol})$ following general synthetic procedure $\mathbf{H}$. The product was obtained as a yellow solid $(66 \mathrm{mg}, 97 \%) ; \mathrm{mp} 64.3-66.6{ }^{\circ} \mathrm{C} ;{ }^{1} \mathrm{H}$ NMR (400 MHz, DMSO- $\left.d_{6}\right): \delta 10.08(\mathrm{~s}, 1 \mathrm{H}, \mathrm{NH}), 8.95(\mathrm{t}, J=5.8 \mathrm{~Hz}, 1 \mathrm{H}, \mathrm{NH}), 7.90-7.82(\mathrm{~m}$, 2H, ArH), 7.66 (bs, 1H, NH), 7.57-6.81 (m, 5H, NH, ArH), 3.31-3.11 (m, 6H, CH $\mathrm{CH}_{2}, 1.79-1.57$ $\left(\mathrm{m}, 4 \mathrm{H}, \mathrm{CH}_{2}\right), 1.39-1.13\left(\mathrm{~m}, 26 \mathrm{H}, \mathrm{CH}_{2}\right), 0.85\left(\mathrm{t}, \mathrm{J}=7.1 \mathrm{~Hz}, 3 \mathrm{H}, \mathrm{CH}_{3}\right) ;{ }^{13} \mathrm{C} \mathrm{NMR}(100 \mathrm{MHz}$, DMSO- $\left.d_{6}\right): \delta 190.4(\mathrm{CO}), 163.0(\mathrm{CO}), 156.9(\mathrm{CN}), 137.7(\mathrm{ArC}), 137.0(\mathrm{ArCH}), 134.2(\mathrm{ArCH})$, 127.6 (ArC), $124.2(\mathrm{ArCH}), 116.2(\mathrm{ArC}), 51.4\left(\mathrm{CH}_{2}\right), 38.3\left(\mathrm{CH}_{2}\right), 36.1\left(\mathrm{CH}_{2}\right), 31.3\left(\mathrm{CH}_{2}\right), 29.0$ $\left(\mathrm{CH}_{2}\right), 29.0\left(\mathrm{CH}_{2}\right), 28.9\left(\mathrm{CH}_{2}\right), 28.7\left(\mathrm{CH}_{2}\right), 28.7\left(\mathrm{CH}_{2}\right), 28.4\left(\mathrm{CH}_{2}\right), 28.3\left(\mathrm{CH}_{2}\right), 27.3\left(\mathrm{CH}_{2}\right)$, $22.8\left(\mathrm{CH}_{2}\right), 22.1\left(\mathrm{CH}_{2}\right), 14.0\left(\mathrm{CH}_{3}\right)$; IR (ATR): $v_{\max } 3342,3165,2918,2850,2342,2104,1642$, $1529,1478,1385,1337,1197,1148,905,822,718 \mathrm{~cm}^{-1}$; HRMS (+ESI): Found $\mathrm{m} / z 630.2683$ $[\mathrm{M}+\mathrm{H}]^{+}, \mathrm{C}_{28} \mathrm{H}_{49} \mathrm{BrN}_{5} \mathrm{O}_{4} \mathrm{~S}$ required 630.2683.

N-(3-Guanidinopropyl)-2-(4-(hexadecylsulfonamido)-[1,1'-biphenyl]-3-yl)-2oxoacetamide hydrochloride (35c)

The titled compound was synthesised from $(E)-1$-tert-butyl- $N-\left(N^{\prime}-((\right.$ tert-butyloxidanyl $)$ carbonyl)-N-(3-(2-(4-(hexadecylsulfonamido)-[1,1'-biphenyl]-3-yl)-2-oxoacetamido)propyl) carbamimidoyl)-1-oxidanecarboxamide 32c (75 mg, $0.091 \mathrm{mmol})$ following general synthetic procedure $\mathbf{H}$. The product was obtained as a yellow solid (42 $\mathrm{mg}, 71 \%) ; \mathrm{mp} 74.5-77.1{ }^{\circ} \mathrm{C}$; ${ }^{1} \mathrm{H}$ NMR (400 MHz, DMSO- $\left.d_{6}\right): \delta 10.21(\mathrm{~s}, 1 \mathrm{H}, \mathrm{NH}), 9.01(\mathrm{t}, J=5.8 \mathrm{~Hz}, 1 \mathrm{H}, \mathrm{NH}), 8.03-7.96$ $(\mathrm{m}, 2 \mathrm{H}, \mathrm{ArH}), 7.71(\mathrm{t}, J=5.9 \mathrm{~Hz}, 1 \mathrm{H}, \mathrm{NH}), 7.67-7.60(\mathrm{~m}, 3 \mathrm{H}, \mathrm{ArH}), 7.55-6.78(\mathrm{~m}, 7 \mathrm{H}, \mathrm{NH}$, ArH), 3.35-3.16 (m, 6H, CH $), 1.80-1.61\left(\mathrm{~m}, 4 \mathrm{H}, \mathrm{CH}_{2}\right), 1.38-1.13\left(\mathrm{~m}, 26 \mathrm{H}, \mathrm{CH}_{2}\right), 0.84(\mathrm{t}$, $\left.J=7.0 \mathrm{~Hz}, 3 \mathrm{H}, \mathrm{CH}_{3}\right) ;{ }^{13} \mathrm{C} \mathrm{NMR}\left(100 \mathrm{MHz}, \mathrm{DMSO}-d_{6}\right): \delta 192.6(\mathrm{CO}), 163.8(\mathrm{CO}), 156.9(\mathrm{CN})$, 138.3 (ArC), 138.2 (ArC), 135.5 (ArC), 133.2 (ArCH), $130.5(\mathrm{ArCH}), 129.2(\mathrm{ArCH}), 127.9$ $(\mathrm{ArCH}), 126.4(\mathrm{ArCH}), 124.3(\mathrm{ArC}), 121.6(\mathrm{ArCH}), 51.4\left(\mathrm{CH}_{2}\right), 38.4\left(\mathrm{CH}_{2}\right), 36.1\left(\mathrm{CH}_{2}\right), 31.3$ $\left(\mathrm{CH}_{2}\right), 29.0\left(\mathrm{CH}_{2}\right), 29.0\left(\mathrm{CH}_{2}\right), 28.9\left(\mathrm{CH}_{2}\right), 28.7\left(\mathrm{CH}_{2}\right), 28.7\left(\mathrm{CH}_{2}\right), 28.4\left(\mathrm{CH}_{2}\right), 27.3\left(\mathrm{CH}_{2}\right)$, $22.8\left(\mathrm{CH}_{2}\right), 22.1\left(\mathrm{CH}_{2}\right), 13.9\left(\mathrm{CH}_{3}\right)$; IR (ATR): $v_{\max } 3365,3164,2917,2849,2343,2084,1625$, 1525, 1486, 1395, 1345, 1266, 1200, 1138, 924, 851, 759, 720, $682 \mathrm{~cm}^{-1}$; HRMS (+ESI): Found $m / z 628.3891[\mathrm{M}+\mathrm{H}]^{+}, \mathrm{C}_{34} \mathrm{H}_{54} \mathrm{~N}_{5} \mathrm{O}_{4} \mathrm{~S}$ required 628.3891 .

\subsection{Minimum Inhibitory Concentration (MIC)}

A MIC assay was conducted to evaluate the antimicrobial activity of the synthesised peptidomimetics. In brief, a single colony of bacteria ( $S$. aureus, E. coli and P. aeruginosa) was cultured in trypticase soy broth (TSB; Oxoid, Basingstoke, U.K.) and Muller Hinton 
broth (MHB; Oxoid, Basingstoke, UK) at $37^{\circ} \mathrm{C}$ with shaking at $120 \mathrm{rpm}$ for $18-24 \mathrm{~h}$. The resulting bacterial culture was washed twice with the media with centrifugation after each wash. The bacterial solution was then diluted with fresh media to a turbidity of $\mathrm{OD}_{660}=0.1$ in TSB (equivalent to $10^{8}$ colony forming unit (CFU) $/ \mathrm{mL}$ of bacteria), followed by diluting to $10^{6} \mathrm{CFU} / \mathrm{mL}$ in media. A total of $100 \mu \mathrm{L}$ of the bacterial solution was added to wells of a 96-well polystyrene plate (Costar; Sigma-Aldrich, St. Louis, MO, USA) containing $100 \mu \mathrm{L}$ serially diluted peptidomimetics, with final concentrations ranging from $1-250 \mu \mathrm{M}$. The final concentration of DMSO was at or below $1.0 \%$, and wells with $1.0 \%$ DMSO was used as the solvent control. Wells with only media were set as blank, while wells with bacteria and media but no compounds were used as a negative control. Plates wrapped with parafilm were then incubated at $37^{\circ} \mathrm{C}$ with shaking at $120 \mathrm{rpm}$ for $18-24 \mathrm{~h}$, and the OD value at $660 \mathrm{~nm}$ was measured, using a FLUOstar Omega (BMG Labtech) microplate reader. The MIC value of each compound was determined as the lowest concentration that completely inhibited the growth of bacteria. Each experiment was performed in triplicate and was repeated in three independent experiments.

\subsection{Biofilm Disruption}

Bacterial cultures (S. aureus and E. coli) were cultured in $\mathrm{MHB}$ at $37^{\circ} \mathrm{C}$ with shaking at $120 \mathrm{rpm}$ for $24 \mathrm{~h}$. The resulting bacterial culture was washed twice with MHB with centrifugation after each wash. The bacterial solution was then diluted with fresh MHB to a turbidity of $\mathrm{OD}_{660}=0.1$ in MHB (equivalent to $10^{8}$ colony forming unit (CFU) $/ \mathrm{mL}$ of bacteria), followed by diluting to $10^{6} \mathrm{CFU} / \mathrm{mL}$ in MHB. A total of $200 \mu \mathrm{L}$ of the bacterial solution was dispensed to wells in a flat-bottom 96-well plate (Costar). The biofilm was then grown in the plate at $37^{\circ} \mathrm{C}$ for $24 \mathrm{~h}$. After incubation, loosely bound cells were washed away with $1 \times$ phosphate-buffered saline (PBS, pH 7.4). The biofilms were then supplemented with different concentrations of peptidomimetics dissolved in DMSO and incubated at $37^{\circ} \mathrm{C}$ with shaking at $120 \mathrm{rpm}$ for a further $24 \mathrm{~h}$. Biofilms adhered on the plate substratum were quantified, using crystal violet staining as described previously [72,73]. The experiment was performed in triplicate.

\subsection{Biofilm Inhibition}

S. aureus was cultured in Muller Hinton broth (MHB; Oxoid) at $37^{\circ} \mathrm{C}$ with shaking at $120 \mathrm{rpm}$ for $24 \mathrm{~h}$. The resulting bacterial culture was washed twice with MHB with centrifugation after each wash. The bacterial solution was then diluted with fresh MHB to a turbidity of $\mathrm{OD}_{660}=0.1$ in $\mathrm{MHB}$ (equivalent to $10^{8}$ colony forming unit (CFU) $/ \mathrm{mL}$ of bacteria), followed by diluting to $10^{6} \mathrm{CFU} / \mathrm{mL}$ in MHB. A total of $100 \mu \mathrm{L}$ of the bacterial solution was added to wells of a 96-well plate (Costar; Sigma-Aldrich, St. Louis, MO, USA) containing $100 \mu \mathrm{L}$ serially diluted peptidomimetics. After incubation at $37^{\circ} \mathrm{C}$ for $24 \mathrm{~h}$, loosely bound cells were washed away with $1 \times$ phosphate-buffered saline (PBS, $\mathrm{pH}$ 7.4). Biofilms adhered on the plate substratum were quantified, using crystal violet staining as described previously $[72,73]$. Untreated bacteria were used as a negative control, where the percentage of biofilm mass reflected 100\% biofilm growth. The experiment was performed in triplicate.

\subsection{Cytoplasmic Membrane Permeability Assay}

Membrane potential sensitive dye diSC3-5 (3,3'-dipropylthiadicarbocyanine iodide), which penetrates inside bacterial cells depending on the membrane potential gradient of the cytoplasmic membrane, was used to determine the bacterial cytoplasmic membrane permeability following the procedure previously described [71,74] with slight modification. Bacteria (S. aureus) were incubated in MHB with shaking at $37^{\circ} \mathrm{C}$ for $16 \mathrm{~h}$. After incubation, the bacteria were washed with $5 \mathrm{mM}$ HEPES, supplemented with $20 \mathrm{mM}$ glucose at $\mathrm{pH} 7.2$ and diluted in the same buffer to an $\mathrm{OD}_{600} 0.05-0.06$ (equivalent to a final concentration of $10^{7} \mathrm{CFU} / \mathrm{mL}$ bacteria). The diSC $3-5$ dye was added at $4 \mu \mathrm{M}$ to the bacterial suspension. The suspensions were incubated at room temperature in darkness for $1 \mathrm{~h}$ for maximum 
dye take-up by the bacterial cells. A total of $100 \mathrm{mM} \mathrm{KCl}$ was then added to balance the $\mathrm{K}^{+}$outside and inside the bacterial cell to prevent the release or further uptake of the dye. Then, $100 \mu \mathrm{L}$ of bacterial suspension was added to a 96-well microtiter plate containing $100 \mu \mathrm{L}$ of serially diluted peptidomimetics. The final concentration of DMSO was at or below $1.0 \%$, and wells with $1.0 \%$ DMSO were used as a solvent control. $10 \%$ DMSO was used as a positive control, while wells with only dye and bacterial cells were set as the negative control. Fluorescence due to the release of dye was measured with a FLUOstar Omega (BMG Labtech) microplate reader at 5 min intervals at an excitation wavelength of $621 \mathrm{~nm}$ and an emission wavelength of $670 \mathrm{~nm}$.

\subsection{Toxicity Assays}

The toxicity of the peptidomimetics against normal human lung fibroblasts MRC-5 cells was measured, using an MTT (3-(4,5-dimethylthiazol-2-yl)-2,5-diphenyltetrazolium bromide) (Sigma Aldrich, St. Louis, MO, USA) colorimetric assay. The cells were cultured in minimal essential medium (MEM, Invitrogen) containing 10\% foetal bovine serum (FBS). The cells were maintained at $37^{\circ} \mathrm{C}$ in $5 \% \mathrm{CO}_{2}$ as an adherent monolayer and was passaged upon reaching confluence by standard cell culture techniques. MRC-5 cells were seeded at 5000 cells/well in 96-well plates to ensure full confluence (quiescence) and left overnight to adhere to the plate wells. The adherent cells were treated with $1-500 \mu \mathrm{M}$ of compounds by dissolving in DMSO and serially diluting with media. TY-01 was used as the positive control. The final concentration of DMSO was $0.5 \%(v / v)$. After the $72 \mathrm{~h}$ drug incubation, $20 \mathrm{~mL}$ stock MTT solution $(5 \mathrm{mg} / \mathrm{mL})$ was added, and the cells were incubated for another 3.5-4 h. The MTT solution containing media was carefully aspirated without displacing the purple crystals from the bottom, and $80 \mathrm{~mL}$ acid-isopropanol was added to all wells and mixed slowly by shaking with an orbital shaker to dissolve the dark blue crystals. The metabolic activity was detected by spectrophotometric analysis by assessing the read absorbance $(590 / 620 \mathrm{~nm})$ on the EnSight plate reader (PerkinElmer, Waltham, MA, USA), and cell viability was expressed as a percentage of the untreated control cells. The determination of $\mathrm{IC}_{50}$ values was performed using GraphPad Prism 7 (GraphPad, San Diego, CA, USA). Each experiment was performed in triplicate and was repeated in three independent experiments.

A total of $20 \mathrm{~mL}$ of human blood collected in EDTA coated tubes was transferred into a $50 \mathrm{~mL}$ centrifuge tube and centrifuged at $500 \times g(700)$ for $5 \mathrm{~min}$. The supernatant plasma was discarded and an equal volume of $1 \times$ PBS was added. The washing was repeated five times with cells mixed by inversion. The washed pallet was then resuspended in 1:10 with PBS to yield an RBC concentration of $\sim 5 \times 10^{8} \mathrm{RBC} / \mathrm{mL}$. The peptidomimetics were serially diluted with PBS, with final concentrations ranging from 8 to $500 \mu \mathrm{M}$. Milli-Q water and $1 \times$ PBS were used as positive and negative controls. The cells were then incubated at $37^{\circ} \mathrm{C}$ for $3 \mathrm{~h}$. Following incubation, the suspension was centrifuged at $1100 \times g$ for $5 \mathrm{~min}$. The final optical density was measured at $540 \mathrm{~nm}$. The percentage of haemolysis was calculated, using the following equation.

$$
\% \text { haemolysis }=\frac{(\text { absorbance of test sample }- \text { absorbance of diluent })}{(\text { absorbance of positive control }- \text { absorbance of diluent })} \times 100 \%
$$

\section{Conclusions}

A library of glyoxamide-based small molecular peptidomimetics was synthesised. These peptidomimetics contained different phenyl ring systems appended to the glyoxamide group core, various $\mathrm{N}$-alkylsulfonyl chains as the hydrophobic group, and either a tertiary ammonium hydrochloride, quaternary ammonium iodide or guanidinium hydrochloride cationic group. In the MIC assay, quaternary ammonium iodide salts $\mathbf{1 6 d}, \mathbf{1 7 b}$, 17c, 18a and guanidinium hydrochloride salt 34a showed excellent antibacterial activity against Gram-positive S. aureus. Moreover, quaternary ammonium iodide salts $\mathbf{1 7 b}-\mathbf{1 7 c}$ and guanidinium hydrochloride salt $34 \mathbf{a}$ also showed good antibacterial activity against Gram-negative E. coli. The SAR studies suggested an inverse relationship between the 
bulkiness of the phenyl system and the length of the alkylsulfonyl chain for the high antibacterial activity of peptidomimetics. This observation was also supported by analysis of $\mathrm{Alog} P$ values, which suggested that there is an optimum $\mathrm{Alog} P$ range for a peptidomimetic to show high antibacterial activity. The more potent peptidomimetics $17 \mathrm{c}, 34 \mathbf{a}, 34 \mathbf{b}$ and $17 \mathrm{~b}$ managed to disrupt $44 \%, 42 \%, 42 \%$ and $38 \%$, respectively, of pre-established S. aureus biofilms at $4 \times$ MIC. Additionally, peptidomimetics $17 \mathrm{~b}$ and $\mathbf{1 7} \mathrm{c}$ were also able to disrupt $31 \%$ and $28 \%$, respectively, of the pre-established E. coli biofilms at $2 \times$ MIC. Moreover, peptidomimetic $17 \mathrm{c}$ also demonstrated its ability to inhibit $70 \%$ and $65 \%$ S. aureus biofilm formation at $2 \times$ and $4 \times$ of its MIC, respectively. Cytoplasmic membrane permeability studies suggested that the disruption and depolarisation of the bacterial cell membrane could be a possible mechanism of action of the peptidomimetics. Furthermore, in vitro toxicity assays against human MRC- 5 fibroblast cells and human red blood cells demonstrated the relatively low cytotoxicity of quaternary ammonium iodide salts $16 \mathrm{~d}, 17 \mathrm{c}$ and $18 \mathrm{a}$. Overall, the quaternary ammonium iodide salt $17 \mathrm{c}$ possesses good antibacterial activity against both Gram-positive and Gram-negative planktonic bacteria and their biofilms, and is identified to be a new lead in this study.

Supplementary Materials: The following are available online at https:/ /www.mdpi.com/article/10 $.3390 / \mathrm{ijms} 22147344 / \mathrm{s} 1,{ }^{1} \mathrm{H}$ and ${ }^{13} \mathrm{C}$ NMR spectra of the synthesised compounds.

Author Contributions: N.K., D.S.B. and M.D.P.W. directed this project. The synthesis and spectroscopic characterization of compounds, MIC assays and biofilm disruption assay was conducted by T.T.Y. Computational studies were conducted by T.T.Y. and J.H. The cytoplasmic membrane depolarisation assay was conducted by T.T.Y., R.K. and M.Y. The cytotoxicity assay was conducted by M.M.H. The haemolysis assay was conducted by M.S. The manuscript was prepared by T.T.Y. All authors have read and agreed to the published version of the manuscript.

Funding: This research was funded by a Discovery Project from Australian Research Council grant (DP 180100845).

Institutional Review Board Statement: Ethical review and approval were waived for this study as the person performing the research on the human red blood cells decided to collect samples themselves of their own blood. In such cases there is no other party to be protected from unethical behavior and so review was not needed.

Informed Consent Statement: Informed consent has been obtained from the person who contributed the red blood cells.

Data Availability Statement: Data is contained within the article and Supplementary Materials.

Acknowledgments: We thank the BMSF and NMR facilities at UNSW Mark Wainwright Analytical Centre for the structural determination of the synthesised compounds. T.T.Y. is thankful to UNSW Sydney for the University International Postgraduate Award.

Conflicts of Interest: The authors declare no conflict of interest.

\section{References}

1. Prestinaci, F.; Pezzotti, P.; Pantosti, A. Antimicrobial resistance: A global multifaceted phenomenon. Pathog. Glob. Health 2015, 109, 309-318. [CrossRef]

2. Davies, J.; Davies, D. Origins and Evolution of Antibiotic Resistance. Microbiol. Mol. Biol. Rev. 2010, 74, 417. [CrossRef] [PubMed]

3. Munita, J.M.; Arias, C.A. Mechanisms of Antibiotic Resistance. Microbiol. Spectr. 2016, 4, 2. [CrossRef] [PubMed]

4. Nguyen, F.; Starosta, A.L.; Arenz, S.; Sohmen, D.; Donhofer, A.; Wilson, D.N. Tetracycline antibiotics and resistance mechanisms. Biol. Chem. 2014, 395, 559-575. [CrossRef] [PubMed]

5. Douafer, H.; Andrieu, V.; Phanstiel, O.; Brunel, J.M. Antibiotic Adjuvants: Make Antibiotics Great Again! J. Med. Chem. 2019, 62, 8665-8681. [CrossRef]

6. Verderosa, A.D.; Totsika, M.; Fairfull-Smith, K.E. Bacterial Biofilm Eradication Agents: A Current Review. Front. Chem. 2019, 7, 824. [CrossRef]

7. Flemming, H.-C.; Wingender, J. The biofilm matrix. Nat. Rev. Microbiol. 2010, 8, 623-633. [CrossRef]

8. Sharma, D.; Misba, L.; Khan, A.U. Antibiotics versus biofilm: An emerging battleground in microbial communities. Antimicrob. Resist. Infect. Control. 2019, 8, 76. [CrossRef]

9. Mah, T.F.C.; O'Toole, G.A. Mechanisms of biofilm resistance to antimicrobial agents. Trends Microbiol. 2001, 9, 34-39. [CrossRef] 
10. Davies, D. Understanding biofilm resistance to antibacterial agents. Nat. Rev. Drug Discov. 2003, 2, 114-122. [CrossRef]

11. Sadekuzzaman, M.; Yang, S.; Mizan, M.F.R.; Ha, S.D. Current and Recent Advanced Strategies for Combating Biofilms. Compr. Rev. Food Sci. Food Saf. 2015, 14, 491-509. [CrossRef]

12. Lamret, F.; Colin, M.; Mongaret, C.; Gangloff, S.C.; Reffuveille, F. Antibiotic Tolerance of Staphylococcus aureus Biofilm in Periprosthetic Joint Infections and Antibiofilm Strategies. Antibiotics 2020, 9, 547. [CrossRef] [PubMed]

13. Kang, H.-K.; Kim, C.; Seo, C.H.; Park, Y. The therapeutic applications of antimicrobial peptides (AMPs): A patent review. J. Microbiol. 2017, 55, 1-12. [CrossRef]

14. Mishra, B.; Reiling, S.; Zarena, D.; Wang, G. Host defense antimicrobial peptides as antibiotics: Design and application strategies. Curr. Opin. Chem. Biol. 2017, 38, 87-96. [CrossRef]

15. Magana, M.; Pushpanathan, M.; Santos, A.L.; Leanse, L.; Fernandez, M.; Ioannidis, A.; Giulianotti, M.A.; Apidianakis, Y.; Bradfute, S.; Ferguson, A.L.; et al. The value of antimicrobial peptides in the age of resistance. Lancet Infect. Dis. 2020, 20, e216-e230. [CrossRef]

16. Fox, J.L. Antimicrobial peptides stage a comeback. Nat. Biotechnol 2013, 31, 379-382. [CrossRef]

17. Mahlapuu, M.; Håkansson, J.; Ringstad, L.; Björn, C. Antimicrobial Peptides: An Emerging Category of Therapeutic Agents. Front. Cell. Infect. Microbiol. 2016, 6, 1-12. [CrossRef]

18. Bahar, A.A.; Ren, D. Antimicrobial Peptides. Pharmaceuticals 2013, 6, 1543-1575. [CrossRef]

19. Ostaff, M.J.; Stange, E.F.; Wehkamp, J. Antimicrobial peptides and gut microbiota in homeostasis and pathology. EMBO Mol. Med. 2013, 5, 1465-1483. [CrossRef]

20. Patel, S.; Akhtar, N. Antimicrobial peptides (AMPs): The quintessential 'offense and defense' molecules are more than antimicrobials. Biomed. Pharmacother 2017, 95, 1276-1283. [CrossRef]

21. Koo, H.B.; Seo, J. Antimicrobial peptides under clinical investigation. Pept. Sci. 2019, 111, e24122. [CrossRef]

22. Ghosh, C.; Sarkar, P.; Issa, R.; Haldar, J. Alternatives to Conventional Antibiotics in the Era of Antimicrobial Resistance. Trends Microbiol. 2019, 27, 323-338. [CrossRef]

23. Lei, J.; Sun, L.; Huang, S.; Zhu, C.; Li, P.; He, J.; Mackey, V.; Coy, D.H.; He, Q. The antimicrobial peptides and their potential clinical applications. Am. J. Transl. Res. 2019, 11, 3919-3931.

24. Hancock, R.E.W.; Sahl, H.-G. Antimicrobial and host-defense peptides as new anti-infective therapeutic strategies. Nat. Biotechnol. 2006, 24, 1551-1557. [CrossRef]

25. Ghosh, C.; Manjunath, G.B.; Akkapeddi, P.; Yarlagadda, V.; Hoque, J.; Uppu, D.S.S.M.; Konai, M.M.; Haldar, J. Small Molecular Antibacterial Peptoid Mimics: The Simpler the Better! J. Med. Chem. 2014, 57, 1428-1436. [CrossRef]

26. Engler, A.C.; Wiradharma, N.; Ong, Z.Y.; Coady, D.J.; Hedrick, J.L.; Yang, Y.-Y. Emerging trends in macromolecular antimicrobials to fight multi-drug-resistant infections. Nano Today 2012, 7, 201-222. [CrossRef]

27. Haug, B.E.; Stensen, W.; Kalaaji, M.; Rekdal, Ø.; Svendsen, J.S. Synthetic Antimicrobial Peptidomimetics with Therapeutic Potential. J. Med. Chem. 2008, 51, 4306-4314. [CrossRef]

28. Molchanova, N.; Wang, H.; Hansen, P.R.; Høiby, N.; Nielsen, H.M.; Franzyk, H. Antimicrobial Activity of $\alpha$-Peptide/ $\beta$-Peptoid Lysine-Based Peptidomimetics Against Colistin-Resistant Pseudomonas aeruginosa Isolated From Cystic Fibrosis Patients. Front. Microbiol. 2019, 10, 275. [CrossRef]

29. Karlsson, A.J.; Pomerantz, W.C.; Neilsen, K.J.; Gellman, S.H.; Palecek, S.P. Effect of Sequence and Structural Properties on 14-Helical $\beta$-Peptide Activity against Candida albicans Planktonic Cells and Biofilms. ACS Chem. Biol. 2009, 4, 567-579. [CrossRef]

30. Epand, R.F.; Raguse, L.; Gellman, S.H.; Epand, R.M. Antimicrobial 14-Helical $\beta$-Peptides: Potent Bilayer Disrupting Agents. Biochemistry 2004, 43, 9527-9535. [CrossRef]

31. Karlsson, A.J.; Flessner, R.M.; Gellman, S.H.; Lynn, D.M.; Palecek, S.P. Polyelectrolyte Multilayers Fabricated from Antifungal $\beta$-Peptides: Design of Surfaces that Exhibit Antifungal Activity Against Candida albicans. Biomacromolecules 2010, 11, 2321-2328. [CrossRef]

32. Chongsiriwatana, N.P.; Patch, J.A.; Czyzewski, A.M.; Dohm, M.T.; Ivankin, A.; Gidalevitz, D.; Zuckermann, R.N.; Barron, A.E. Peptoids that mimic the structure, function, and mechanism of helical antimicrobial peptides. Proc. Natl. Acad. Sci. USA 2008, 105, 2794. [CrossRef] [PubMed]

33. Chongsiriwatana, N.P.; Miller, T.M.; Wetzler, M.; Vakulenko, S.; Karlsson, A.J.; Palecek, S.P.; Mobashery, S.; Barron, A.E. Short Alkylated Peptoid Mimics of Antimicrobial Lipopeptides. Antimicrob. Agents Chemother. 2011, 55, 417. [CrossRef]

34. Patch, J.A.; Barron, A.E. Helical Peptoid Mimics of Magainin-2 Amide. J. Am. Chem. Soc. 2003, 125, 12092-12093. [CrossRef] [PubMed]

35. Li, Y.; Smith, C.; Wu, H.; Padhee, S.; Manoj, N.; Cardiello, J.; Qiao, Q.; Cao, C.; Yin, H.; Cai, J. Lipidated Cyclic $\gamma$-AApeptides Display Both Antimicrobial and Anti-inflammatory Activity. ACS Chem. Biol. 2014, 9, 211-217. [CrossRef] [PubMed]

36. Padhee, S.; Hu, Y.; Niu, Y.; Bai, G.; Wu, H.; Costanza, F.; West, L.; Harrington, L.; Shaw, L.N.; Cao, C.; et al. Non-hemolytic $\alpha$-AApeptides as antimicrobial peptidomimetics. Chem. Commun. 2011, 47, 9729-9731. [CrossRef] [PubMed]

37. Niu, Y.; Padhee, S.; Wu, H.; Bai, G.; Qiao, Q.; Hu, Y.; Harrington, L.; Burda, W.N.; Shaw, L.N.; Cao, C.; et al. Lipo- $\gamma$-AApeptides as a New Class of Potent and Broad-Spectrum Antimicrobial Agents. J. Med. Chem. 2012, 55, 4003-4009. [CrossRef]

38. Sarig, H.; Rotem, S.; Ziserman, L.; Danino, D.; Mor, A. Impact of Self-Assembly Properties on Antibacterial Activity of Short Acyl-Lysine Oligomers. Antimicrob. Agents Chemother. 2008, 52, 4308. [CrossRef] 
39. Zaknoon, F.; Goldberg, K.; Sarig, H.; Epand, R.F.; Epand, R.M.; Mor, A. Antibacterial Properties of an Oligo-Acyl-Lysyl Hexamer Targeting Gram-Negative Species. Antimicrob. Agents Chemother. 2012, 56, 4827. [CrossRef]

40. Choi, S.; Isaacs, A.; Clements, D.; Liu, D.; Kim, H.; Scott, R.W.; Winkler, J.D.; DeGrado, W.F. De novo design and in vivo activity of conformationally restrained antimicrobial arylamide foldamers. Proc. Natl. Acad. Sci. USA 2009, 106, 6968-6973. [CrossRef]

41. Tang, H.; Doerksen, R.J.; Jones, T.V.; Klein, M.L.; Tew, G.N. Biomimetic Facially Amphiphilic Antibacterial Oligomers with Conformationally Stiff Backbones. Chem. Biol. 2006, 13, 427-435. [CrossRef] [PubMed]

42. Liu, D.; Choi, S.; Chen, B.; Doerksen, R.J.; Clements, D.J.; Winkler, J.D.; Klein, M.L.; DeGrado, W.F. Nontoxic Membrane-Active Antimicrobial Arylamide Oligomers. Angew. Chem. Int. Ed. 2004, 43, 1158-1162. [CrossRef]

43. Ishitsuka, Y.; Arnt, L.; Majewski, J.; Frey, S.; Ratajczek, M.; Kjaer, K.; Tew, G.N.; Lee, K.Y.C. Amphiphilic Poly(phenyleneethynylene)s Can Mimic Antimicrobial Peptide Membrane Disordering Effect by Membrane Insertion. J. Am. Chem. Soc. 2006, 128, 13123-13129. [CrossRef] [PubMed]

44. Kuppusamy, R.; Yasir, M.; Yee, E.; Willcox, M.; Black, D.S.; Kumar, N. Guanidine functionalized anthranilamides as effective antibacterials with biofilm disruption activity. Org. Biomol. Chem. 2018, 16, 5871-5888. [PubMed]

45. Wales, S.M.; Hammer, K.A.; Somphol, K.; Kemker, I.; Schröder, D.C.; Tague, A.J.; Brkic, Z.; King, A.M.; Lyras, D.; Riley, T.V.; et al. Synthesis and antimicrobial activity of binaphthyl-based, functionalized oxazole and thiazole peptidomimetics. Org. Biomol. Chem. 2015, 13, 10813-10824. [CrossRef] [PubMed]

46. Lin, S.; Chen, Y.; Li, H.; Liu, J.; Liu, S. Design, synthesis, and evaluation of amphiphilic sofalcone derivatives as potent Gram-positive antibacterial agents. Eur. J. Med. Chem. 2020, 202, 112596. [CrossRef]

47. Thapa, R.K.; Diep, D.B.; Tønnesen, H.H. Topical antimicrobial peptide formulations for wound healing: Current developments and future prospects. Acta Biomater. 2020, 103, 52-67. [CrossRef] [PubMed]

48. Rios, A.C.; Moutinho, C.G.; Pinto, F.C.; Del Fiol, F.S.; Jozala, A.; Chaud, M.V.; Vila, M.M.D.C.; Teixeira, J.A.; Balcão, V.M Alternatives to overcoming bacterial resistances: State-of-the-art. Microbiol. Res. 2016, 191, 51-80. [CrossRef]

49. Patrulea, V.; Borchard, G.; Jordan, O. An Update on Antimicrobial Peptides (AMPs) and Their Delivery Strategies for Wound Infections. Pharmaceutics 2020, 12, 840. [CrossRef]

50. Yu, T.T.; Nizalapur, S.; Ho, K.K.K.; Yee, E.; Berry, T.; Cranfield, C.G.; Willcox, M.; Black, D.S.; Kumar, N. Design, Synthesis and Biological Evaluation of N-Sulfonylphenyl glyoxamide-Based Antimicrobial Peptide Mimics as Novel Antimicrobial Agents. ChemistrySelect 2017, 2, 3452-3461. [CrossRef]

51. Yu, T.T.; Kuppusamy, R.; Yasir, M.; Hassan, M.M.; Alghalayini, A.; Gadde, S.; Deplazes, E.; Cranfield, C.; Willcox, M.D.P.; Black, D.S.; et al. Design, Synthesis and Biological Evaluation of Biphenylglyoxamide-Based Small Molecular Antimicrobial Peptide Mimics as Antibacterial Agents. Int. J. Mol. Sci. 2020, 21, 6789. [CrossRef] [PubMed]

52. Tian, S.-Z.; Pu, X.; Luo, G.; Zhao, L.-X.; Xu, L.-H.; Li, W.-J.; Luo, Y. Isolation and Characterization of New p-Terphenyls with Antifungal, Antibacterial, and Antioxidant Activities from Halophilic Actinomycete Nocardiopsis gilva YIM 90087. J. Agric. Food Chem. 2013, 61, 3006-3012. [CrossRef] [PubMed]

53. Zhang, X.-Q.; Mou, X.-F.; Mao, N.; Hao, J.-J.; Liu, M.; Zheng, J.-Y.; Wang, C.-Y.; Gu, Y.-C.; Shao, C.-L. Design, semisynthesis, $\alpha$-glucosidase inhibitory, cytotoxic, and antibacterial activities of p-terphenyl derivatives. Eur. J. Med. Chem. 2018, 146, 232-244. [CrossRef]

54. Yan, W.; Li, S.-J.; Guo, Z.-K.; Zhang, W.-J.; Wei, W.; Tan, R.-X.; Jiao, R.-H. New p-terphenyls from the endophytic fungus Aspergillus sp. YXf3. Bioorg. Med. Chem. Lett. 2017, 27, 51-54. [CrossRef]

55. Samshuddin, S.; Narayana, B.; Sarojini, B.K.; Shetty, D.N.; Suchetha Kumari, N. Synthesis, Characterization, and Biological Evaluation of Some New Functionalized Terphenyl Derivatives. Int. J. Med. Chem. 2012, 2012, 530392. [CrossRef] [PubMed]

56. Yu, T.T.; Bhadbhade, M.; Kuppusamy, R.; Black, D.S.; Kumar, N. A facile synthesis of meta- and para-terphenylglyoxamide-based peptidomimetics. Tetrahedron. Lett. 2020, 61, 152560.

57. Nizalapur, S.; Kimyon, O.; Yee, E.; Ho, K.; Berry, T.; Manefield, M.; Cranfield, C.G.; Willcox, M.; Black, D.S.; Kumar, N. Amphipathic guanidine-embedded glyoxamide-based peptidomimetics as novel antibacterial agents and biofilm disruptors. Org. Biomol. Chem. 2017, 15, 2033-2051. [CrossRef]

58. Kundi, V.; Ho, J. Predicting Octanol-Water Partition Coefficients: Are Quantum Mechanical Implicit Solvent Models Better than Empirical Fragment-Based Methods? J. Phys. Chem. B 2019, 123, 6810-6822. [CrossRef]

59. Wu, Y.M.; Salas, Y.L.; Leung, Y.C.; Hunter, L.; Ho, J. Predicting Octanol-Water Partition Coefficients of Fluorinated Drug-Like Molecules: A Combined Experimental and Theoretical Study. Aust. J. Chem. 2020, 73, 677-685. [CrossRef]

60. Ghose, A.K.; Crippen, G.M. Atomic Physicochemical Parameters for Three-Dimensional Structure-Directed Quantitative StructureActivity Relationships I. Partition Coefficients as a Measure of Hydrophobicity. J. Comput. Chem. 1986, 7, 565-577.

61. Klopman, G.; Li, J.-Y.; Wang, S.; Dimayuga, M. Computer Automated log P Calculations Based on an Extended Group Contribution Approach. J. Chem. Inf. Comput. Sci. 1994, 34, 752-781. [CrossRef]

62. Viswanadhan, V.N.; Ghose, A.K.; Revankar, G.R.; Robins, R.K. Atomic physicochemical parameters for three dimensional structure directed quantitative structure-activity relationships. 4. Additional parameters for hydrophobic and dispersive interactions and their application for an automated superposition of certain naturally occurring nucleoside antibiotics. J. Chem. Inf. Comput. Sci. 1989, 29, 163-172.

63. MarvinSketch 19.25.0; ChemAxon: Boston, MA, USA, 2018. 
64. Mohamed, M.F.; Abdelkhalek, A.; Seleem, M.N. Evaluation of short synthetic antimicrobial peptides for treatment of drugresistant and intracellular Staphylococcus aureus. Sci. Rep. 2016, 6, 29707. [CrossRef]

65. Otto, M. Staphylococcal biofilms. Curr. Top. Microbiol. Immunol. 2008, 322, 207-228.

66. Boles, B.R.; Horswill, A.R. Staphylococcal biofilm disassembly. Trends Microbiol. 2011, 19, 449-455. [CrossRef] [PubMed]

67. Sharma, G.; Sharma, S.; Sharma, P.; Chandola, D.; Dang, S.; Gupta, S.; Gabrani, R. Escherichia coli biofilm: Development and therapeutic strategies. J. Appl. Microbiol. 2016, 121, 309-319. [CrossRef]

68. Le, C.-F.; Fang, C.-M.; Sekaran, S.D. Intracellular Targeting Mechanisms by Antimicrobial Peptides. Antimicrob. Agents Chemother. 2017, 61, e02340-16. [CrossRef] [PubMed]

69. Raheem, N.; Straus, S.K. Mechanisms of Action for Antimicrobial Peptides with Antibacterial and Antibiofilm Functions. Front. Microbiol. 2019, 10, 2866. [CrossRef]

70. Yasir, M.; Dutta, D.; Willcox, M.D.P. Comparative mode of action of the antimicrobial peptide melimine and its derivative Mel4 against Pseudomonas aeruginosa. Sci. Rep. 2019, 9, 7063. [CrossRef]

71. Yasir, M.; Dutta, D.; Willcox, M.D.P. Mode of action of the antimicrobial peptide Mel4 is independent of Staphylococcus aureus cell membrane permeability. PLoS ONE 2019, 14, e0215703. [CrossRef]

72. O'Toole, G.A. Microtiter Dish Biofilm Formation Assay. JoVE 2011, 47, e2437. [CrossRef] [PubMed]

73. Yasir, M.; Dutta, D.; Willcox, M.D.P. Activity of Antimicrobial Peptides and Ciprofloxacin against Pseudomonas aeruginosa Biofilms. Molecules 2020, 25, 3843. [CrossRef] [PubMed]

74. Wu, M.; Maier, E.; Benz, R.; Hancock, R.E.W. Mechanism of Interaction of Different Classes of Cationic Antimicrobial Peptides with Planar Bilayers and with the Cytoplasmic Membrane of Escherichia coli. Biochemistry 1999, 38, 7235-7242. [CrossRef] 